\title{
WestVirginiaUniversity
}

THE RESEARCH REPOSITORY @ WVU

Graduate Theses, Dissertations, and Problem Reports

2002

\section{GASMAK2 model for longwall gob gas emission}

Qinghua Jin

West Virginia University

Follow this and additional works at: https://researchrepository.wvu.edu/etd

\section{Recommended Citation}

Jin, Qinghua, "GASMAK2 model for longwall gob gas emission" (2002). Graduate Theses, Dissertations, and Problem Reports. 1281.

https://researchrepository.wvu.edu/etd/1281

This Thesis is protected by copyright and/or related rights. It has been brought to you by the The Research Repository @ WVU with permission from the rights-holder(s). You are free to use this Thesis in any way that is permitted by the copyright and related rights legislation that applies to your use. For other uses you must obtain permission from the rights-holder(s) directly, unless additional rights are indicated by a Creative Commons license in the record and/ or on the work itself. This Thesis has been accepted for inclusion in WVU Graduate Theses, Dissertations, and Problem Reports collection by an authorized administrator of The Research Repository @ WVU. For more information, please contact researchrepository@mail.wvu.edu. 


\title{
GASMAK2 Model for Longwall Gob Gas Emission
}

\author{
Qinghua Jin
}

\author{
Thesis submitted to the \\ College of Engineering and Mineral Resources \\ at West Virginia University \\ in partial fulfillment of the requirements \\ for the degree of \\ Master of Science \\ in \\ Mining Engineering
}

Lloyd M. English, Ph.D., P.E., Chair

Felicia F. Peng, Ph.D.

Yi Luo, Ph.D.

Department of Mining Engineering

Morgantown, West Virginia

2002

Keywords: GASMAK2, Model, Coal, Longwall, Methane, Gob well 


\section{Abstract \\ GASMAK2 Model for Longwall Gob Gas Emission \\ Qinghua Jin}

This thesis discusses the development and improvement of an empirical model, GASMAK2, that describes methane control requirements for the longwalling coal in gassy areas. This is not a theoretical model; it uses an empirically determined gas emission rate as an input. The computer program divides longwall panels into segments, keeps track of the face advance and generates emission rates and volumes for both the entire panel and for individual zones within the panel. This model is Windows-based, uses the full capabilities of the Windows environment to provide a user-friendly program, and can aid in the determination of the number, size and location of methane control techniques that are needed for gob gas control. It is an excellent approximation, and the use of this model in conjunction with a careful data collection program should clearly indicate what future methane controls are needed. 


\section{Acknowledgements}

I am grateful to express my sincere appreciation to my academic advisor, Dr. Lloyd M. English, for his persistent encouragement, support and guidance during the period of graduate study and thesis work. He is a wonderful person whom I respect, whether in the academic field, in work, or in life, I learned a lot from his hard working and great personality. I can say it is really my luck and great pleasure to have him as my mentor.

I wish to thank, also, the thesis committee members, Dr. Felicia F. Peng, Dr. Yi Luo, and Dr. Keith A. Heasley for their valuable and constructive suggestions, comments and advice.

Special gratitude is extended to my parents, my wife, Hongyan Sun, and my son, Dun Jin, for their constant encouragement, understanding, support and endurance during the course of this study. 


\section{Table of Contents}

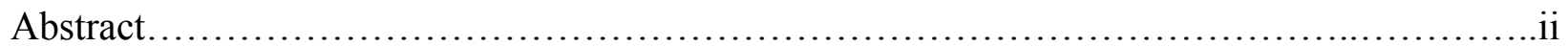

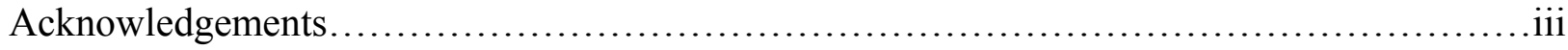

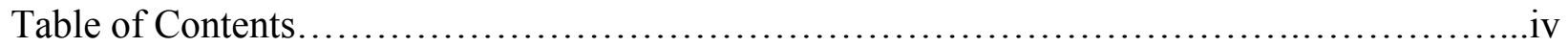

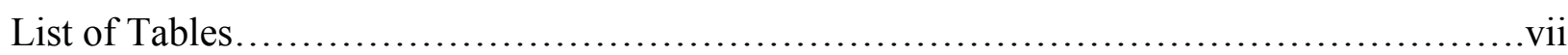

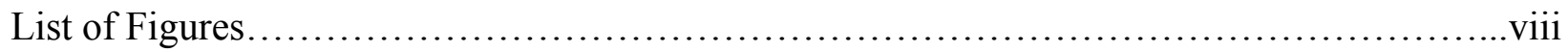

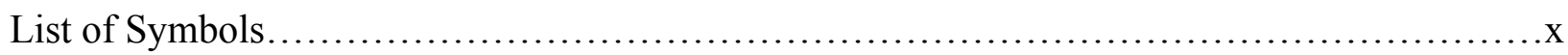

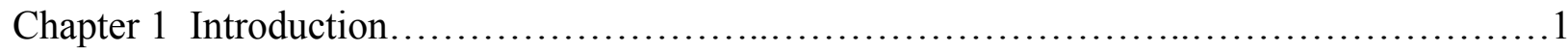

Chapter 2 Literature Overview....................................................

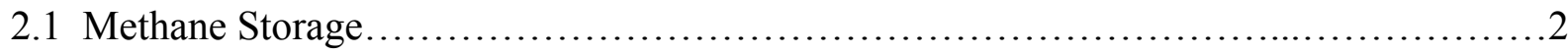

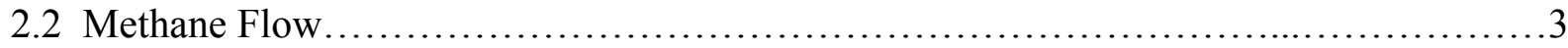

2.3 Methane Control Techniques...............................................

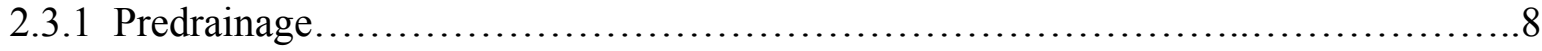

2.3.2 Active Drainage....................................................... 9

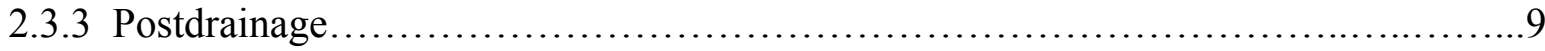

2.4 Previous Methane Prediction Models................................................11

2.4.1 Empirical Models........................................................ 12

2.4.2 Numerical Models.......................................................... 12

2.4.3 Statistical Model......................................................13

Chapter 3 The GASMAK Model: Original Program Overview..............................17

3.1 Overview of GASMAK Model.................................................... 17

3.1.1 Domain of GASMAK Model............................................ 17 


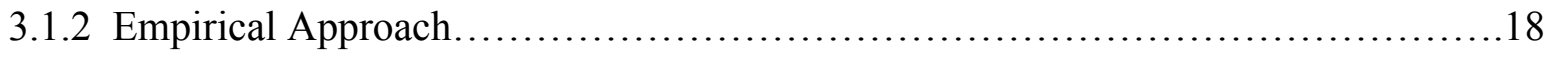

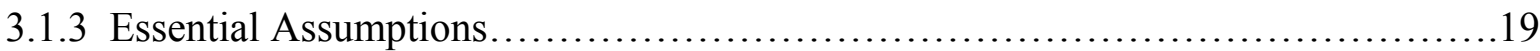

3.1.3.1 Uniformity of Increments of Advance......................................19

3.1.3.2 Consistence of Desorption Characteristic....................................20

3.1.4 GASMAK Model Operation..................................................22

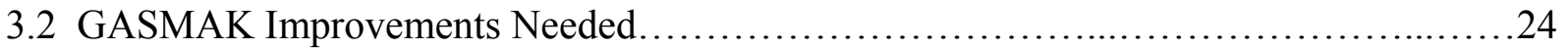

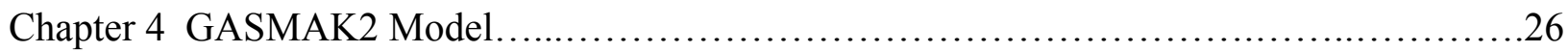

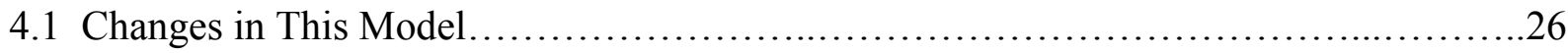

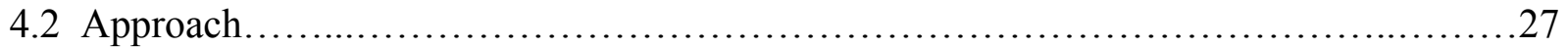

4.3 GASMAK2 Model Development................................................ 28

4.3.1 GASMAK2 Modeling Flow.......................................................

4.3.2 GASMAK2 Modeling Implementation and methods...............................29

4.3.2.1 GASMAK2 Model Input Database...........................................30

4.3.2.2 GASMAK2 Model Help System.............................................32

4.3.2.3 VBA Automation (Automated Output).....................................33

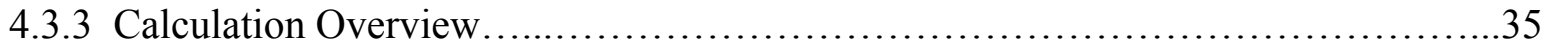

4.3.4 Components of the User Interface................................................38

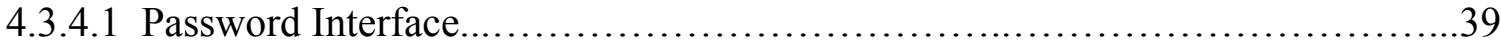

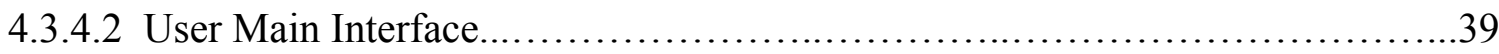

4.3.4.3 Open File Interface......................................................... 45

4.3.4.4 Save As File Interface...................................................... 46

4.3.4.5 Print File Interface........................................................ 47

4.3.4.6 Project and Panel Information Interface.......................................48 
4.3.4.7 Gob Well Calculation Information Interface...............................50

4.3.4.8 Help Interface....................................................52

4.3.4.9 Gob Well Interface........................................................

4.3.4.10 Data Points Being Input for Emission Curve Interface.....................55

4.3.4.11 Point Data Tabular View Interface.......................................56

4.3.4.12 Gob Well Information Interface........................................57

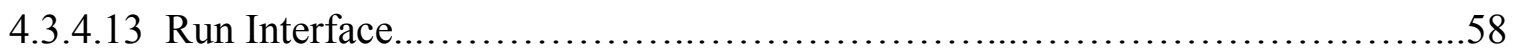

4.3.4.14 Feedback and Error interfaces......................................59

4.4 GASMAK2 Model Discussion................................................60

4.4.1 GASMAK2 Modeling Example Output Characteristic...........................60

4.3.2 Comparison With Other Models...............................................63

4.5 Hardware and Software Requirements......................................65

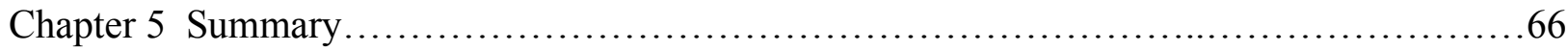

Chapter 6 Conclusions and Suggestions for Further Work .............................6 68

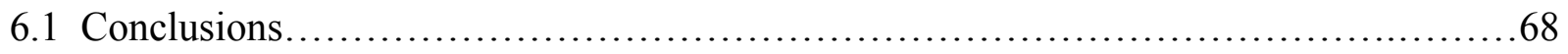

6.2 The Work Needed for Improving the Model..................................69

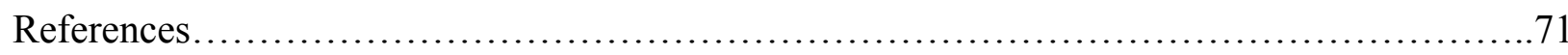

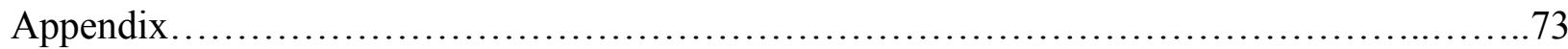

Appendix A Output Spreadsheet for GASMAK2 Model..........................74

Curriculum Vitae.............................................................99

Approval of Examining Committee..................................................94 


\section{List of Tables}

Table 1: $\quad$ Summary of Gas Drainage Methods in the United States......................18 


\section{List of Figures}

Figure 1: $\quad$ Illustration of the Coal Cleat System (ICF Resource, 1990)...................4

Figure 2: $\quad$ The Transport Methane Gas in Coal (ICF Resources, 1990)....................6

Figure 3: The General View of Coalbed Methane Drainage for Underground Coalmines....8

Figure 4: Gas in-Place forecast showing the probability of occurrence of each class of

occurrence...............................................................

Figure 5: $\quad$ Gas Emission Decline Curve (Gob Area) for "Floorgas and Roofgas

Geomechanical and Gas Release Model".................................15

Figure 6: Gas Emission Decline Curve (During and Post Extraction) for "Floorgas and

Roofgas Geomechanical and Gas Release Model"............................16

Figure 7: $\quad$ Segments Divided by GASMAK Model for a Long Wall Panel..................19

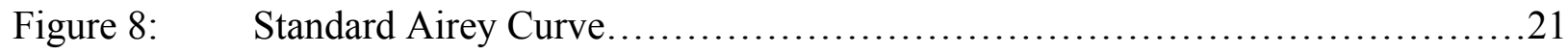

Figure 9: $\quad$ The Flow of GASMAK2 Empirical Modeling Development.....................29

Figure 10: Implementation Diagram of GASMAK2 Model Development...................30

Figure 11: Workflow Diagram for the Construction of Onboard Help System Contained

Within GASMAK2 Model....................................................33

Figure 12: Flow Sheet of GASMAK2 Model.......................................... 36

Figure 13: $\quad$ Password Interface of GASMAK2 Model..................................39

Figure 14: User Main Interface of GASMAK2 Model................................40

Figure 15: $\quad$ File Menu for GASMAK2 Model..........................................40

Figure 16: Run Menu for GASMAK2 Model......................................41

Figure 17: $\quad$ View Menu for GASMAK2 Model....................................41 


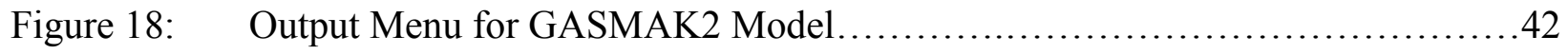

Figure 19: Help Menu for GASMAK2Model..............................................42

Figure 20: $\quad$ About GASMAK2 Model of Help File........................................43

Figure 21: Content of Individual Input Items of Help File...............................44

Figure 22: An Example of input description for Help File...................................45

Figure 23: $\quad$ Open File Interface for GASMAK2 Model....................................46

Figure 24: Save As File Interface for GASMAK2 Model..................................46

Figure 25: Print File Interface for GASMAK2 Model.......................................47

Figure 26: Input Interface of GASMAK2 Model — Project and Panel Information.............48

Figure 27: Input Interface of GASMAK2 Model — Gob Well Calculation Information......51

Figure 28: Help Interface of GASMAK2 Model........................................53

Figure 29: Input Interface of GASMAK2 Model — Gob Well...........................54

Figure 30: Input Interface of GASMAK2 Model — Data Points Being Input for Emission

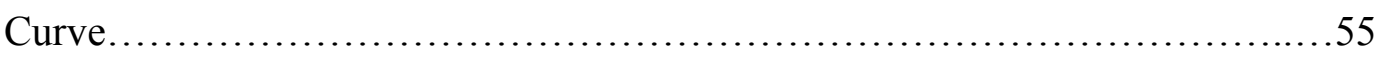

Figure 31: Point Data Tabular View Interface $\quad$.............................................5

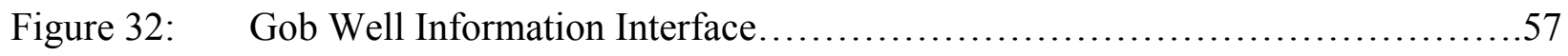

Figure 33: $\quad$ Running Interface of GASMAK2 Model...................................58

Figure 34: $\quad$ Error Message Box for GASMAK2 Model (1) ................................60

Figure 35: $\quad$ Error Message Box for GASMAK2 Model (2)...............................60

Figure 36: Gas Emission Rate Chart for GASMAK2 Model...............................61

Figure 37: Total Gas Emission Volumes Chart for GASMAK2 Model........................62

Figure 38: Total Methane Produced from 16 Gob Wells in 3 Panels.........................63

Figure 39: $\quad$ Predicted Gob Well Production Rates from CFD Model...........................64 


\section{List of Symbols}

A Gas content of coal sample dependent upon coal initial pressure

C Concentration of the specific gas

$D \quad$ Coefficient of diffusion

$k \quad$ Permeability

$t \quad$ Time after start of desorption

$t_{0} \quad$ Time constant depend upon coal lump size

$u \quad$ Gas velocity

$u_{x} \quad$ Velocity of diffusion in the $x$ direction

$V_{t} \quad$ Volume of methane released from a coal sample per mass of coal sample

$\mu \quad$ Dynamic viscosity

$\partial p / \partial x$ Pressure gradient 


\section{Chapter 1 Introduction}

With higher coal mining productivity and the trend towards mining deeper coal seams, emissions of methane from coal mines have increased significantly in modern coal mines. The ability to control methane in underground coal mines not only has a direct impact on mine safety and productivity, but it is also an economic issue. The mine operator needs to balance cost, efficiency, and safety at the same time. Coal mine gas has always been a major problem for miners. The gas emitted from coal seam and rock has always been regarded as a potential disaster for safe mine production ever since humans began to mine coal. Traditionally, methane control was performed using simply the ventilation system; however, this is more difficult or impossible to achieve nowadays. Additionally, methane released to the atmosphere is a major greenhouse gas contributing to global warming. In order to improve mine safety and to decrease downtime from methane in the mines, degasification systems to extract and/or capture much of the coalbed methane from coal seams before, during, or after mining are conducted. Methane drainage offers the added advantages of reducing ventilation costs, reducing development costs of the mine, reducing global warming threat, and allowing a waste product to be productively utilized. There are several kinds of gas drainage and capture technologies to control the gas in the working faces and roadways of mines. Gas recovery by gob wells is the most effective way to reduce gas emission and develop coalbed methane in longwall mines.

This thesis presents the characteristic of methane storage, flow, and control techniques. It also presents a Windows-based empirical model GASMAK2 for predicting longwall gob gas emissions. It can aid in the determination of methane control measures that needed for gob gas control. 


\section{Chapter 2 Literature Overview}

Methane is one of the most common strata gases. It is generated during the formation of coal and is subsequently stored in the coal seams and other rock strata by pressure. The amount of methane stored in coal is controlled by the pressure of the coal seam and other rock strata, and by the degree of coalification. When gas pressure decreases as a result of mining activities, methane flows out of the coal and into the atmosphere. Methane is not toxic but it is a safety hazard because it is highly explosive in atmospheric concentrations of 5 to 15 percent. Methane explosions have resulted in the deaths of many thousands of miners. As a result, degasification of the coal to acceptable levels is paramount to a safe and successful mining operation. Historically, the mine ventilation system has been a primary mechanism for controlling methane concentration to required safe levels. Underground mines are ventilated with large quantities of air to dilute methane to safe levels and vent it to the atmosphere. Today many countries use methane drainage techniques to reduce methane levels, and to reduce gas disasters. Methane gas control is a key element in mining operations and it has greatly enhanced safe production of coal mines. To date, a number of different gas drainage methods and technologies suitable for different geological and mining conditions in different mines have been developed. In these cases, the ventilation systems are supplemented with methane gas drainage systems.

\subsection{Methane Storage}

Methane is retained within fractures, voids and pores in the coal in two distinct forms, generally referred as compressed gas (free gas) and adsorbed gas (gas adsorbed onto the internal coal surfaces). The surfaces of coal are the discontinuities within matrix structure. The gases 
acting at the surfaces are unsaturated and mixed. When the coal is exposed to gases, the gas molecules will form bonds with the free surfaces. When the adsorptive bonding energy exceeds the short-distance repulsive force between gas molecules. The adsorbed molecules will become packed together as a monomolecular layer on the surface. In similar fashion, additional molecular layers may form at higher pressures. Different gases adsorb onto coal surface at different bonding strengths. Coal contains a very large number of small pores and a correspondingly high internal surface area. Significant quantities of methane may be adsorbed onto coal's surface, and typically accounts for $98 \%$ of the gas within a coal seam. The amount of gas in coalbed depends on temperature, pressure, degree of fracturing, rank, and permeability of the coal and surrounding strata. When the strata is pierced by boreholes or mined openings, the gas pressure gradient created induces migration of the methane towards those openings.

\subsection{Methane Flow}

Coal has an extensive natural fracture system called cleats (Kruger D., 1990,). There are two orthogonal sets of cleats, butt cleats and face cleats (shown as Figure 1). The distance and development between cleats can vary greatly between coal seams. This cleat system controls the permeable flow of methane once it has diffused through the coal. 


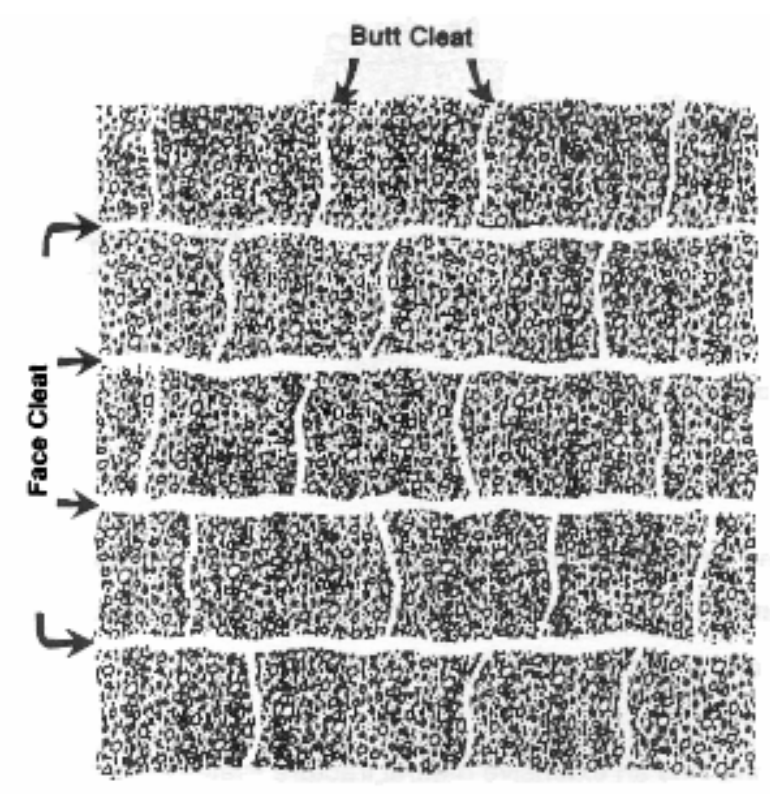

Figure 1: Illustration of the Coal Cleat System (ICF Resource, 1990)

Flow within the cleat system is described by Darcy's dynamic flow equations as free gas moving as a result of a pressure gradient. Darcy proposed this theory about gas flow in the fractures of permeable media as shown in Equation 2.1 in 1856 (McPherson, M. J., 1999).

$$
\begin{array}{ll}
u=\frac{k}{\mu} \frac{\partial p}{\partial x} & \mathrm{~m} / \mathrm{s} \\
\text { Where } u & =\operatorname{gas} \text { velocity }(\mathrm{m} / \mathrm{s}) \\
k & =\operatorname{permeability~}\left(\mathrm{m}^{2}\right) \\
\mu \quad & \text { dynamic viscosity }\left(\mathrm{Ns} / \mathrm{m}^{2}\right) \\
\partial p / \partial x & =\text { pressure gradient }(\mathrm{Pa} / \mathrm{m})
\end{array}
$$

Darcy's Law relates the flow rate in a reservoir to the pressure drop across the reservoir using a proportionally constant (i.e., permeability) and describes gas transport through the fracture system in the coal where the driving force is the pressure gradient. 
Diffusion flow occurs whenever a difference in concentration of molecules of a given gas occurs. The diffusivity property is represented by the coefficient of diffusion. The flux of gas transported in this mode follows the Fick's law of diffusion described by Equation 2.2 (McPherson, M. J., 1999):

$$
u_{x}=-D \frac{\partial c}{\partial x} \quad \mathrm{~m} / \mathrm{s}
$$

Where $u_{x} \quad=$ velocity of diffusion in the $x$ direction $(\mathrm{m} / \mathrm{s})$

$$
\begin{aligned}
& D \quad=\text { coefficient of diffusion }\left(\mathrm{m}^{2} / \mathrm{s} \text { but most often quoted in } \mathrm{cm}^{2} / \mathrm{s}\right) \\
& C \quad=\text { concentration of the specific gas }\left(\mathrm{m}^{3} / \mathrm{m}^{3} \text { of coal }\right)
\end{aligned}
$$

This law describes diffusion along the concentration gradient. The negative sign in the equation is necessary since movement occurs in the direction of decreasing concentration.

A high gas content coal does not necessarily imply a high gas flow. The ability of coal to transport the gas is measured by the properties of permeability and diffusivity. A number of references indicate that the movement of gas in coal is caused by Darcy (laminar) flow down a pressure gradient or diffusion along a concentration gradient. The literature provides no clear answers as to which type of behavior is taking place or which type of transport governs the rate of gas production. Controversy has existed and this might be because of the wide variation of properties that existed in coal structure. Current thinking is that within the coal matrix, diffusion and laminar flow occurs while, in the cleats and fractures, Darcy (laminar) flow dominates (Figure 2). Most investigations agree that diffusion flow is the controlling factor governs the rate of degassing coals of high permeability while Darcy flow in the fracture network is the dominant effect in high diffusivity coals. 


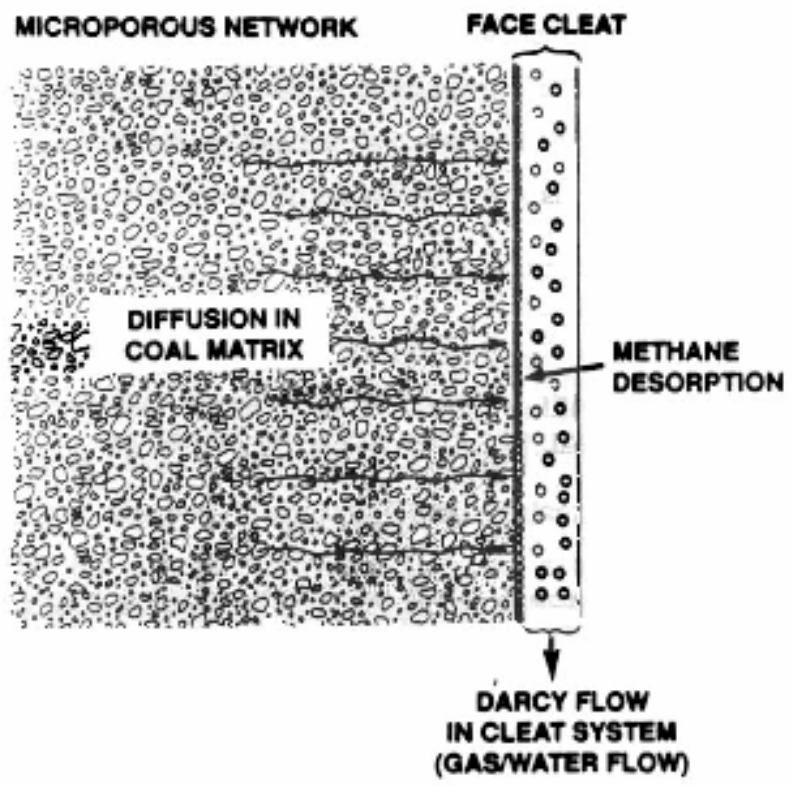

Figure 2: The Transport Methane Gas in Coal (ICF Resources, 1990)

In an undisturbed state, equilibrium exists between free gas and adsorbed gas in the pores and fracture networks of coal. If, however, the coal seam is intersected by a borehole, or disturbed by mining, then a gas pressure gradient that is created will result in flow through natural or stress-induced fractures. The reduced gas pressure in the pores will promote desorption.

Permeability is a measure of the ability of gases to flow through coal seams and surrounding rocks. Coal permeability depends upon the cleat structure, fractures, and the nature of their inter-connections. Strata movement, relaxation and compaction due to mining will change the permeability, which obviously means that disturbances by mining can decrease or increase the permeability. Because coal permeability is highly stress-dependent, it is a difficult parameter to numerically characterize in mines.

After desorbing from the coal surface, the movement of methane through the coal matrix is controlled by the concentration gradient of methane molecules (diffusion). In diffusions, 
molecules move from a zone of higher concentration to a zone of lower concentration. The movement of methane by diffusion occurs until the molecule intersects an open pathway or fracture in the coal, whereupon Darcy flow dominates.

\subsection{Methane Control Techniques}

With higher mining productivity and the trend towards mining deeper coal seams, emissions of methane from coal mines have increased significantly in modern coal mines. And, as previously mentioned, methane is a serious safety threat in coal mines.

Traditionally, the main technique used for controlling methane concentration has been ventilation. However, it is increasingly difficult to achieve economically today because it is not possible to move enough air to adequately dilute the increased methane emission. In order to improve mine safety and decrease downtime as a result of high concentration of methane in the mines, methane control systems to extract or capture much of the coalbed methane are needed. Particularly in gassy mines, the ventilation have to be supplemented with a drainage or capture system. Drainage systems reduce methane concentrations to acceptable levels in the working areas by draining the gas before, during, or after mining, depending on mining needs and mine design. There are three basic families of methane control techniques:

- Predrainage,

- Active Drainage, and

- Postdraiange.

In many cases, a combination of the above three drainage techniques are used.

Methane drainage methods used in the U.S. mainly include vertical wells, gob wells, horizontal boreholes, and cross-measure boreholes. No matter what methane control techniques 
the operator uses, the primary purpose is the same: remove enough gas from the mine, so that ventilation system can dilute the remaining gas that will be emitted into the mine to acceptable levels.

Figure 3 is from Guidebook on Coalbed Methane Drainage for Underground Coal Mines (Mutmansky, J. M., 1999), it gives us a general view of predrainage and postdrainage methane control techniques.

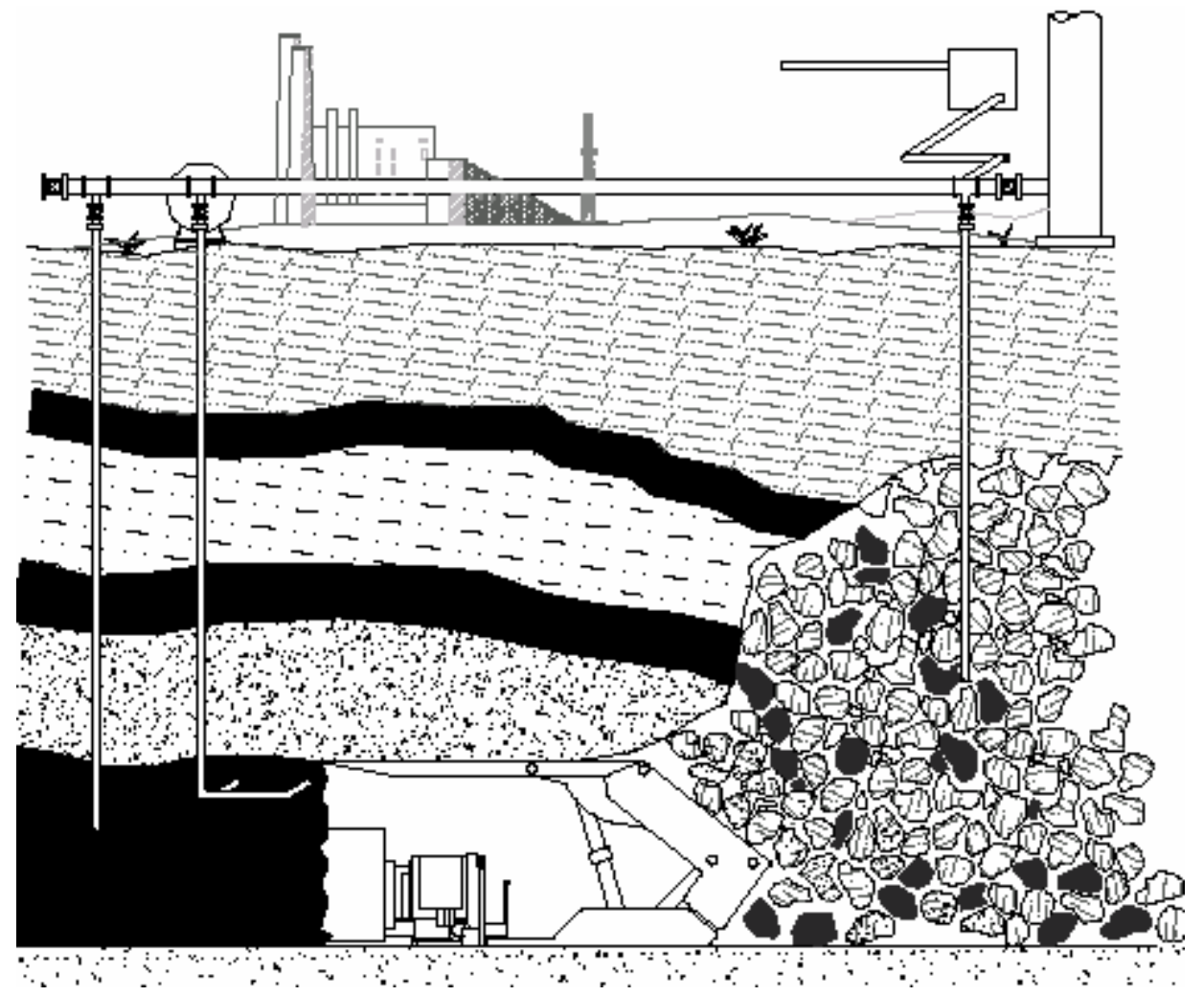

Figure 3: The General View of Coalbed Methane Drainage for Underground Coal Mines

\subsubsection{Predrainage}

Predrainage techniques are used for draining gas from the coal seam and the adjacent strata before mining operations begin. (Creedy, D. P. et al., 1997) 
Stimulated vertical wells are the optimal predrainage techniques used in the United States. Vertical wells are drilled through a coal seam or seams and used to predrain the methane several years in advance of mining. They typically require hydraulic stimulation to fracture the coal seam. They can remove from 50 to 90 percent of gas content from the coal seam,. This is high concentration gas that may be sold commercially. One advantage of this method over the other techniques is that they can be applied to multiple coal seams simultaneously.

\subsubsection{Active Drainage}

Active drainage techniques are employed for capturing gas from the coal seam being mined and the adjacent strata during the active mining operations.

Horizontal holes are the most common active drainage technique used in the United States. They are drilled from the mine workings into unmined areas of coal seam. They drain methane from the coal seam prior to mining so that the methane content may be reduced before mining and limit the flow of methane into the mining section. Because methane drainage occurs only from the mined coal seam and the period of drainage is relatively short, the recovery efficiency of this technique is low. In most cases, only $30 \%$ to $50 \%$ of the methane contained in the coal seam being mined may be drained using this technique.

\subsubsection{Postdrainage}

Postdrainage techniques are the most important method used in longwall coal mines today. The gas volume drained by this method accounts for 80 to 85 percent of the total volume produced at the mine. It is common knowledge in the mining industry that gas emitted from 
surrounding strata can release high volumes after mining activities pass through, far exceed the gas emitted from the actively mined coal seam itself.

Vertical gob wells are boreholes that extract methane from the gob areas of a mine. (A gob area is where all the coal has been removed; overlying strata has collapsed, fractured, and subsided.) Gob wells differ from pre-mining vertical wells is they are operated only after mining has been completed in the well location and fractures the strata around the well bore. The methane emitted from the fractured strata then flows into the well and up to the surface, frequently with the assistance of vacuum pumps. The number of gob wells on a longwall panel is controlled by mining rates and the gas content of the caved strata. When this technique is used with good controls, methane extracted from gob wells can be put in a pipeline. The principal disadvantage is the need of acquisition of surface rights and surface environmental planning restrictions.

Cross-measure boreholes, a technique common in European countries, are drilled at an angle above, and sometimes below the strata being mined from existing mine entries. The boreholes are strategically pre-placed in areas to be mined out with the goal of draining the overlying or underlying strata and exhausting gas from the gob area. The angle at which the holes are drilled is a function of the height and width of the geologic zone to be drained, the panel width, and the location of the entry from which the holes are to be drilled. Anywhere from $35 \%$ to $75 \%$ of the total gas released in an underground district can be captured at purities ranging from $35 \%$ to $70 \%$. Higher purity gas is generally not available. However, there are markets for low-quality gas in Europe.

The cross-measure system for coalbed methane drainage has been most successful in Eastern Europe and Asia, while the general ease of using vertical gob wells in the U.S. make the 
use of cross-measure boreholes uneconomic. Gob wells are the most effective method of reducing methane content in rapidly moving longwall faces. Cross-measure systems may become attractive in the U.S. only in areas where surface access is difficult.

Although coalbed methane may be controlled by the above three drainage techniques, the literature overview indicates the postdrainage approach is likely to be the most common technique all over the world because of the higher levels of emissions from surrounding strata. For this reason, this thesis focuses on gob wells.

\subsection{Previous Methane Prediction Models}

The development of coalbed methane drainage projects has fostered modeling efforts all over the world (Curl, S. J., 1978). A review of currently available models and related identified models and laboratory experiments used to predict methane emission in underground coal mines. There are different types of models, and adapting these models for all situations posed several problems. The worst problem is that site specific data would be needed for every region. The few global emissions models that exist are reasonable, but are hampered by lack of practical input information to use theoretical approaches accurately. Some data are not even available for some countries.

The methane prediction models can be subdivided into the categories of numerical, empirical, and statistical models depending on the methods used in their calculations. Of these models, the numerical models are the most popular. Numerical models are the most general, but they use sophisticated boundary conditions and theoretical inputs that are not well understood, and this leads to a wide range of methane production assessments. Methane emission models using statistical approach are rarely found in literature. The reason for this may be that most 
model developers have made their statistical approach fall within the category of an empirical approach.

\subsubsection{Empirical models}

The empirically based models are the simplest models among the three categories. Empirical models are based on simple mathematical descriptions of observable physical phenomena. They are very fast, only simple input is needed and the formulas are very easy to apply. Although the empirical models are relatively simple, requiring few input parameters, they lack the theoretical precision required for detailed predictions. The empirical models are limited by observations used in their development. Care must be taken to ensure that the assumptions and accuracy support the model development. Nearly all the empirical methane models are formed by fitting a simple function to a set of data, including this GASMAK2 model of my thesis work. These models are relatively easy to develop, but their predictive power is restricted by the limitations of the input data set.

\subsubsection{Numerical model}

Many researchers have developed numerical models for predicting methane production from coal seams in the past for two main purposes: to enhance understanding and to enhance prediction accuracy. The domain size of these numerical models range from laboratory scale to single-well, full-field models. Nearly each numerical model has its own specialized uses, but few are universally applicable. The numerical models are solved using numerical techniques such as finite element methods. The physical relationships in these numerical models are represented by functions, differential equations, and inequalities (King, G. R., \& Ertekin, T. M., 
1989). For a numerical model to be practically useful one, the user needs a high degree of knowledge about the domain of application. Current knowledge is not adequate for theoretical approaches or we do not understand how the basic parameters change with time, distance, or with the influence of mining. Also, numerical models are limited by coding difficulties because we can not describe the theory precisely in computer language. There can be a significant range of uncertainty in the value of the parameters input to the numerical model.

\subsubsection{Statistical model}

It is common to find statistical models for estimating methane resources in the petroleum industry; but it is rare in the mining industry. During the literature overview, only one statistical model for methane resource estimating was found from internet. It is reported (Coal mine methane resources estimation and reserve evaluation) that this model used frequency distributions of the parameters and quantifying the risk associated with the resource estimate and therefore increases the confidence level of the estimate. This type of analysis can be facilitated through random sampling of distributions, therefore, allowing the probability of occurrence of resource volumes to be determined. The investigator estimated coal mine methane resource based on single value or the average of measurements of important parameters, for example, gas content, coal density and coal thickness. Figure 4 shows a forecast distribution for the gas in place of a coal seam using the statistical model (Pilcher, R. C., Collings R. C., \& Marshall, J. S., 2000). 


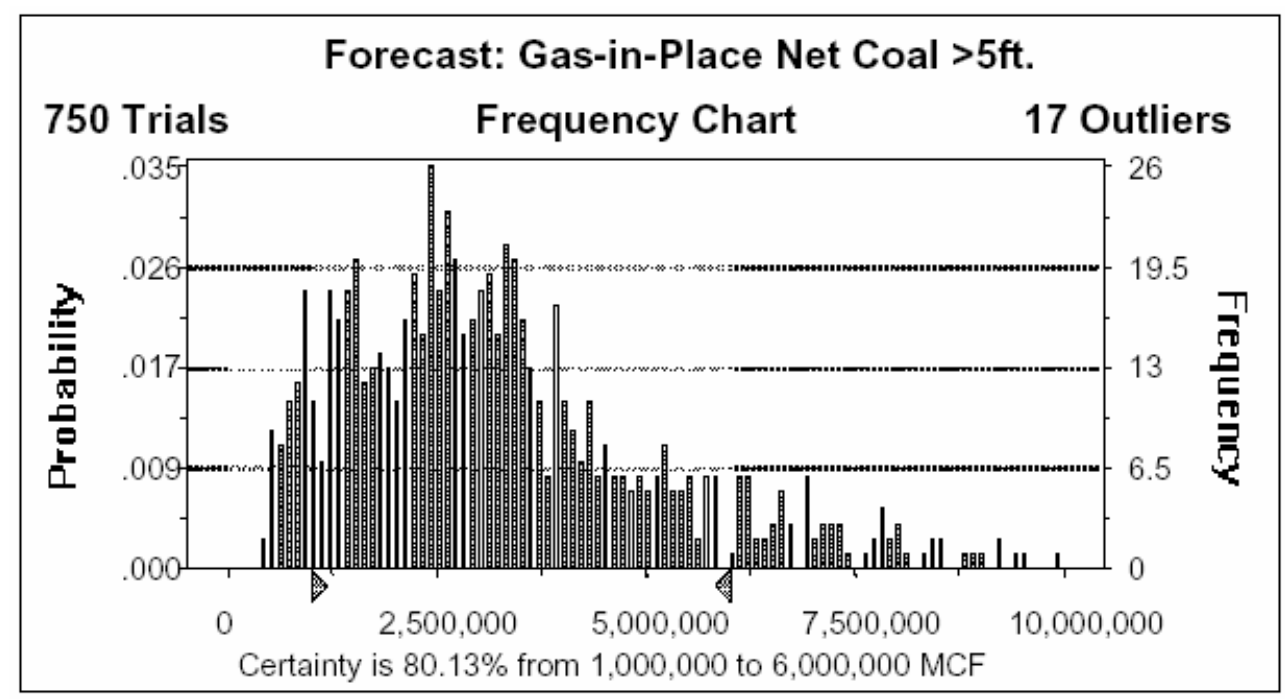

Figure 4: Gas in-place forecast showing the probability of occurrence of each class of occurrence

This figure shows that there is an $80.13 \%$ probability that a 160 -acre (64.75 hectares) tract will have between 1 and 6 million cubic feet. It seems there is not practical use for the statistical model because it just offer the user the probability.

It is worth mentioning a very sophisticated model-“Floorgas and Roofgas Geomechanical and Gas Release Model"-developed by Lunagas Pty Limited, Newcastle, Australia. It has been commercialized and operates on a PC Windows-based platform. This model relies heavily on geological factors, experience, and history matching. It might be the most sophisticated model in the world currently. Nevertheless, a substantial quantity of geomechanical and lithological input data are required to run this model. The reasonably accurate prediction results are sound, provided sufficient geological, mining, and gas data are made available. But in many situations, the user could not have all the information required about these input data, and it is difficult for us to use this model then. Although this model uses theory heavily, its reliance upon historical data still places it firmly in the empirical category. 
Figure 5 shows the development of a particular gas emission decline curve (gas emission decay with time) for a specific location (http://members.ozemail.com.au/ lunagas/).

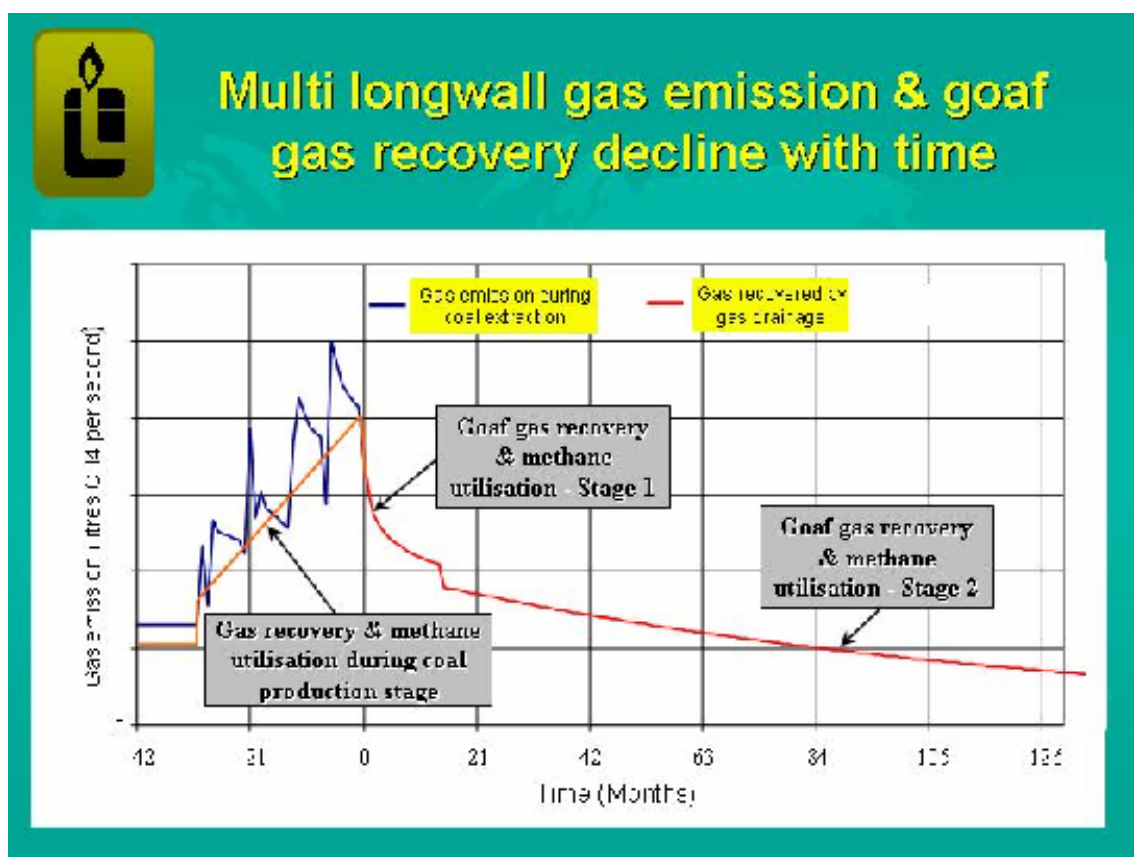

Figure 5: Gas Emission Decline Curve (Gob Area) for "Floorgas and Roofgas Geomechanical and Gas Release Model" 


\section{Gas Emission During \& Post Extraction}

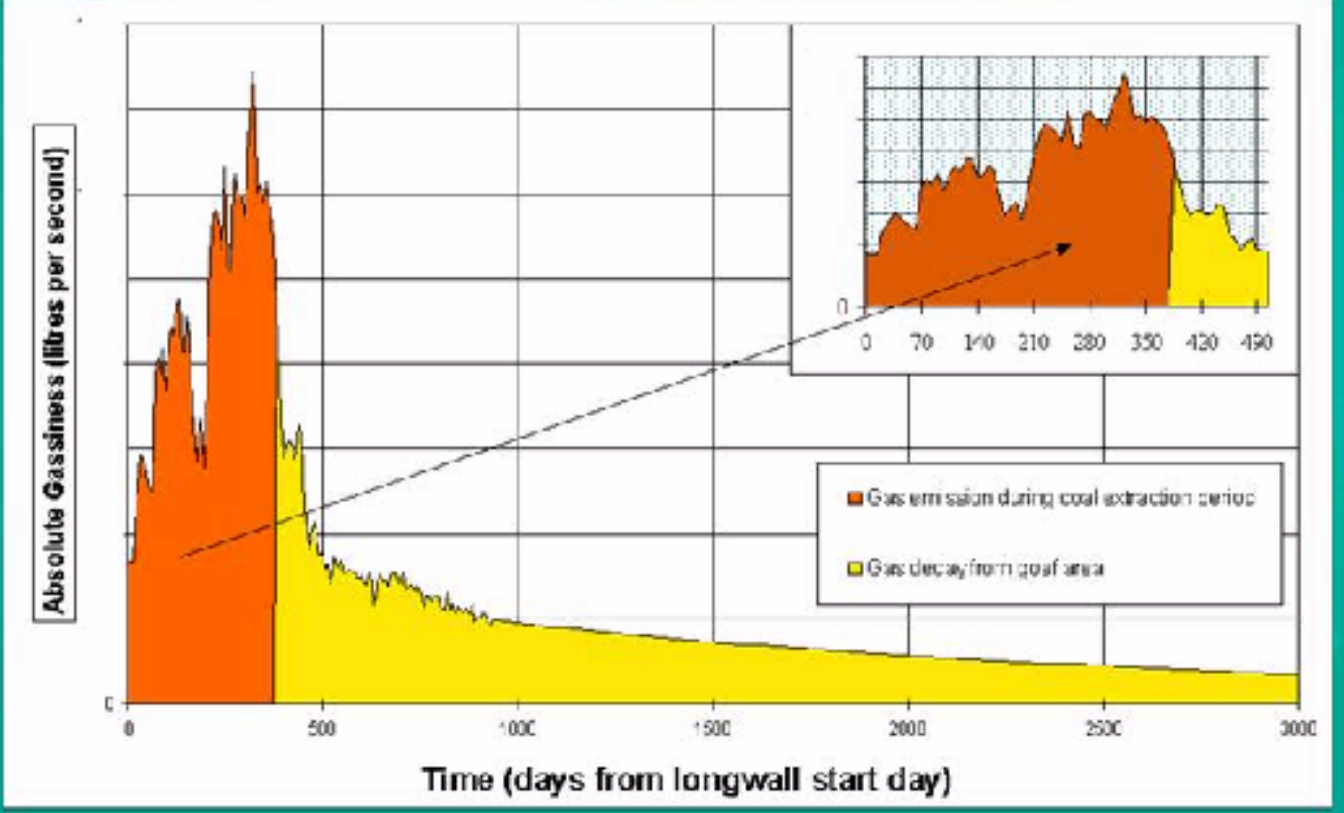

Figure 6: Gas Emission Decline Curve (During and Post Extraction) for "Floorgas and Roofgas Geomechanical and Gas Release Model"

Empirical models lack the theoretical base required for accurate prediction, but numerical models lack the availability of accurate input data. With current knowledge, an empirical approach is the most useful. The GASMAK2 model is empirical. 


\section{Chapter 3 The GASMAK Model: Original Program Overview}

For longwall coal mine operation, the first thing that must be determined is what gas volume and what emission rates longwall mining operation will produce. An empirical model, GASMAK, was developed by Lloyd M. English (English L.M., 1997) that could forecast gas inflow rates and volumes based upon basic local data and historical information from similar sites.

\subsection{Overview of the GASMAK Model}

GASMAK model was initially presented in the Ph.D. dissertation of English (1997).

\subsubsection{Domain of GASMAK2 Model}

GASMAK model is developed specially for gob gas control. Studies indicate that the methane produced by the gob areas can exceed $80 \%$ of the total methane produced in a mine. There are 84 mines (of more than 400 mines total at present) in the United States that are classified as gassy mines. Among the 84 gassy mines, only 33 have gas drainage systems and the others depend solely on ventilation systems to control methane. A summary of gas drainage methods used in the United States is shown in Table 1. According to this table, 31 of the 33 mines with gas drainage systems have adopted gob well drainage technology, accounting for nearly $94 \%$ of the total. Seventeen of these mines simultaneously use other methane control techniques as well. Gob well drainage technique is the most common method in the U.S. coal industry. Most mine operators that use gob wells can make reasonable estimates of the effectiveness of their gob wells. Gas recovery by gob wells may be the most promising way to 
reduce gas emissions and to develop coalbed methane as a commercial resource safety. This provides the impetus for using a model such as GASMAK.

Table 1 Summary of Gas Drainage Methods in the United States

\begin{tabular}{|c|l|}
\hline Number of mines & \multicolumn{1}{c|}{ Drainage methods } \\
\hline 1 & Underground gas drainage \\
\hline 1 & Underground gob gas drainage \\
\hline 14 & Gas drainage by surface gob wells \\
\hline 5 & Gob well drainage and underground gas drainage \\
\hline 12 & $\begin{array}{l}\text { Gob well, underground gas drainage, and pre-drainage } \\
\text { using surface vertical wells }\end{array}$ \\
\hline
\end{tabular}

\subsubsection{Empirical Approach}

Since the beginning of the coalbed methane industry, operators have relied greatly on technology from the petroleum industries to evaluate and develop coalbed methane properties. Much of this conventional oil and gas technology applies to coalbed methane operations, but often it must be modified. In some cases, coalbed methane operations require entirely different techniques. Currently, the knowledge is not detailed adequately for theoretical approaches.

The GASMAK model is empirical. In order to estimate methane generation in gob areas of the longwall panel, English identified the key variables that affect methane generation and developed an empirical model of methane generation based on these variables. The key parameters of this model are the methane emission rate as a function of time. The GASMAK model uses empirically determined gas emission rates as an input rather than depending on reservoir and rock mechanical theories to calculate emission rates. The model is coded in FORTRAN language. 


\subsubsection{Essential Assumptions}

Two following foundational assumptions are used in the development of his GASMAK model:

1. In specific, local geographic regions, uniform increments of gob produce methane in a relatively consistent manner.

2. Although carbonaceous materials will contain varying amounts of methane, they produce that methane by similar processes, yielding desorption curves that vary in magnitude but not in form. (English, L. M. 1997)

\subsubsection{Uniformity of Increments of Advance}

GASMAK model divides a longwall panel into equal length segments shown as Figure 7.

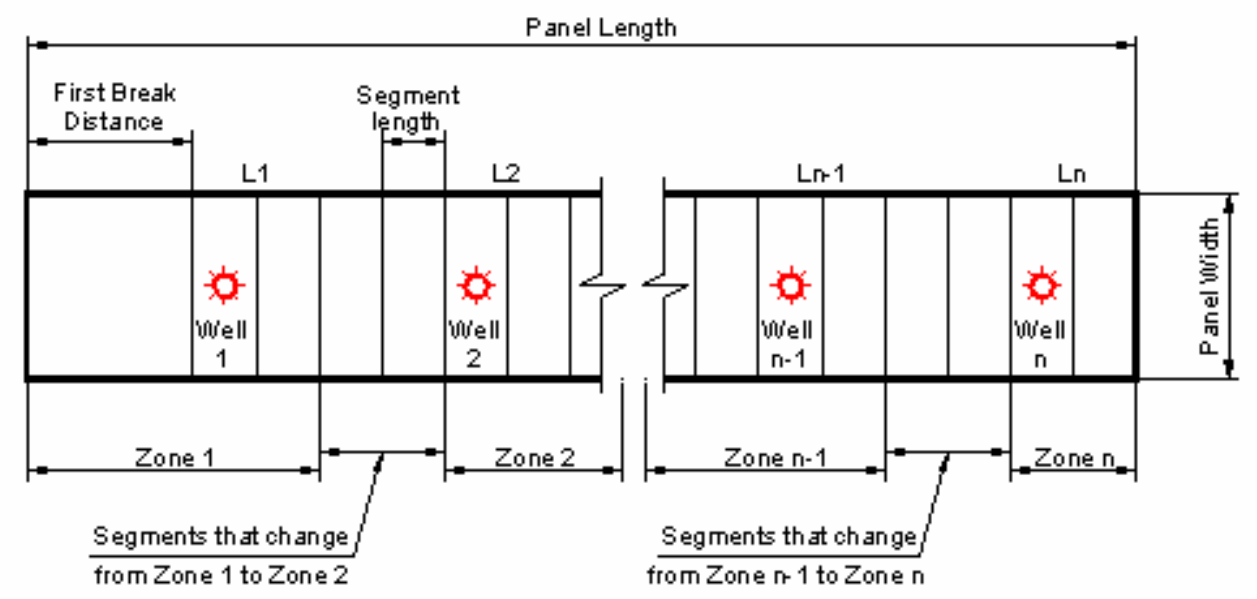

Figure 7: Segments Divided by GASMAK Model for a Long Wall Panel (English, 1999)

The first basic assumption is that, within a specific geographic region, each uniform increments of mining advance will create equal volume of gob, and for this volume of gob an 
equivalent quantity of methane will be produced. Many studies show that this assumption is reasonable, because coalbeds usually are fairly continuous and their gas contents are uniform and predictable. This uniformity of coal thickness and gas content makes coalbed methane prospects fairly easy to evaluate. The same logic applies to carbonaceous shales and reservoir rocks. Also, even though specific strata thicknesses and ratios may change between core holes, if the thickness is adequate, the relative mix will not change significantly.

\subsubsection{Consistency of Desorption Characteristic}

The surfaces in coal represent discontinuities in the matrix structure. The gases acting at the surface are unsaturated and mixed. When the coal is exposed to certain gases, the gas molecules will form bonds with it and become adsorbed onto these surfaces. Gases adsorbed to coal are released when pressure is reduced due to increasing kinetic energy; this is the process of desorption.

Current thinking for methane and other adsorbed gases is that for a local geographic region, the coal desorption characteristic is consistent. The difficulties encountered in the derivation and general applicability of analytical desorption equations led Airey (Airey, E. M., 1968) to propose an empirical relationship:

The rate of release of methane was measured, and the volume $V_{t}$ discharged in a time $t$ conformed to the empirical equation (Airey model):

$$
V_{t}=A\left(1-e^{-\left(t / t_{0}\right)^{1 / 3}}\right)
$$

Where:

$$
\begin{aligned}
& V_{t}=(\text { Volume of methane released from a coal sample }) /(\text { mass of coal sample }), \mathrm{ft}^{3} / \text { ton } \\
& A=\text { Gas content of coal sample dependent upon coal initial pressure, } \mathrm{ft}^{3} / \mathrm{ton}
\end{aligned}
$$


$t_{0}=$ Time constant depend upon coal lump size,$\quad \mathrm{hr}$

$t=$ Time after start of desorption. $\quad \mathrm{hr}$

Airey's theory is a development of earlier work in which an empirical equation was proposed to describe the emission of gas from broken coal. The concept of time in Airey's theory enables, for example, emissions to be expressed as a function of advance rate. This empirical relationship has been verified to be compatible with subsequent testing in many coals of different quality (Airey, E. M, 1968). The Airey curve is the foundation of the development of GASMAK model.

Figure 8 shows the adsorption curve for a specific coal with an assumed initial gas content of $150 \mathrm{cu} \mathrm{ft} / \mathrm{st}$ based on Airey model.

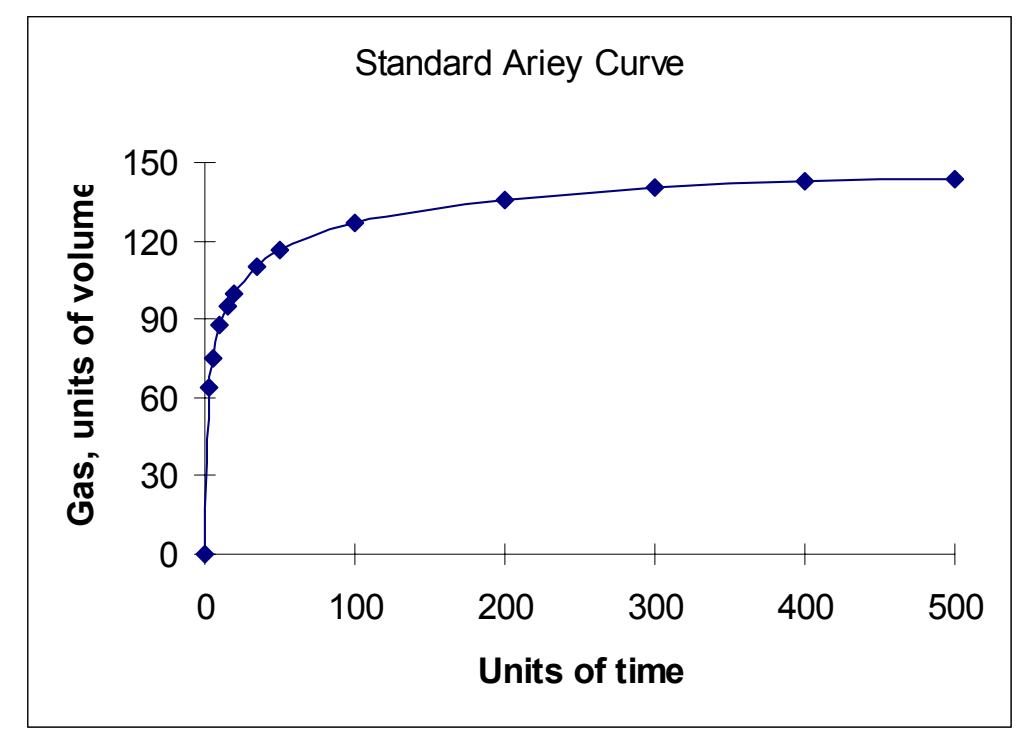

Figure 8: Standard Airey Curve

Often, researchers base models on fundamental principles. The fundamental principles must be well defined to be successful in model performance. In particular, we must ensure that the assumptions and the accuracy of available data support the calculations. A review of the published literature data strongly supports the reasonability of the basic assumptions that 
desorption characteristics of various carbonaceous materials behave in similar form (Curl, S. J. 1978).

The two assumptions (uniformity of increments of advance, and consistency of desorption characteristic) form a strong basis for the development of this model using empirical methods.

\subsubsection{GASMAK Model Operation}

The GASMAK model is written in Fortran and operated in a DOS environment. The input required include panel dimensions, mining rate, average depth of cover, the segment size to be used to divide the panel, and the size and location of the emission zones of interest. After preparing the text input file, the model can perform the following steps:

- Divide the panel into segments and different zones;

- $\quad$ Track the mine face advance;

- Determine the time each segment is undermined;

- Interpolate the empirical input curve, calculating the emission rate for each segment at each point in curve and each point in time;

- Calculate the current panel emission rate from the accumulated rates for all undermined segments at given time $i$ and,

- Report the panel gas emission rate and emitted gas volume for all undermined segments from time zero to project lifetime.

Based on the assumptions that uniform increments perform in a similar fashion while the gas desorbs from the gob, the total rate of methane emissions from a longwall panel at any time is the sum of the emission rates for all of the undermined increments belonging to that panel at 
that time; unmined segments are sent directly to the summation line with gas emission rates and emission volume values of zero. Since this model depends on an empirically obtained curve, necessary measurements need to be made at the mining operation of interest. The GASMAK model determines the emission rate using linear interpolation performed on data points input for the emission curve. Linear interpolation is used for predicting the emission rate changes over periods of time, assuming that the rate of change consistently follows the empirically determined Airey curve.

One advantage of the GASMAK model is that it not only forecasts the total emission rate from an individual panel, but it also divides a panel into separate zones (refer to Figure 7). Which can provide estimates of emissions that must be controlled by individual gob wells (or other methane control techniques such as cross measure systems). This model can be a substantial aid to designing efficient and economic methane control systems.

As it was expected, GASMAK model is sensitive to the input data. Gob gas emissions tend to be consistent in specific mining operations and regions, because of the site-specific characteristics (data points being input for emission curve) are required as model input. This methane inflow model can forecast methane flows in the gob area once the empirical data can be obtained in the field. It is an aid to the mine operator for ventilation and methane control planning.

\subsection{GASMAK Improvements Needed}

The GASMAK model was developed using Fortran. Fortran is one of the oldest programming languages in use. The Fortran language suffers from several disadvantages when compared to other computer languages. Despite its disadvantages, its large user base among 
scientists and engineers has maintained its popularity through the years. The most important disadvantages of Fortran language are:

- Memory can not be dynamically allocated; to run a larger problem one needs to recompile.

- There are no structures or linked lists (no pointers); one can implement them only in obscure ways.

- There is no low level access to $\mathrm{I} / \mathrm{O}$ primitives.

- String manipulation is not straightforward.

Because of these disadvantages, there are some restrictions when using GASMAK model. For example, Project ID has a maximum of 65 spaces; segment numbers can not exceed 600 , etc. The present GASMAK model can produce an output data table but it must be loaded into spreadsheet software for visualization. While operating this GASMAK model, the user must prepare an input table in the meticulous DOS format for the GASMAK model to read in advance. The most frustrating aspect of the GASMAK model is that, for a new GASMAK user, it is not modern standards of user-friendly uses.

The Windows-based GASMAK2 model was developed specifically to enhance user friendliness. Users can take the advantage of using an intuitive graphic user interface to increase their modeling efficiency. The interface has a consistent look and feel throughout the program, which enables users to navigate easily. 


\section{Chapter 4 GASMAK2 Model}

Consider the following situation: An experienced user sits in front of a computer, attempting to complete a familiar task using an unfamiliar application. For each step in the process, the user first reads some instructions from the manual open at his/her side and then turns to the computer to actually accomplish the actions about which they have just read. What are the cognitive processes involved in this situation? How should the interface be designed so as to minimize the difficulty of the task? The task is easier when the interface matches the familiar Microsoft Office graphical user interface (GUI). There is no correct "answer" to be sought on what each application interface should look like, and there is no one interface that will be ideal for everyone. This interface will help as many users as possible to get the most out of the program.

The GASMAK2 model is Windows-based and uses the full capabilities of the Windows environment to provide a user-friendly program to the users.

\subsection{Changes in This Model}

The Windows-based model is easier to use because of the graphical user interface. One of the objectives of the GASMAK2 model is to develop a Windows-based empirical model of methane emission rate as a function of time using new programming language. The intuitive design helps users to focus their attention on the results, not on how to get them, and gives users a positive work experience and enhances productivity.

The GASMAK2 was developed using Microsoft Visual Basic 6 (VB). There are a large number of reasons for the development of this GASMAK2 model using Visual Basic (refer to 
section 4.3). $\quad \mathrm{VB}$ is a productive tool for creating high performance applications, gives a complete windows application development system in one package, permits writing, editing, and testing Windows applications, and provides user-friendly interfaces for input and output. In addition, VB includes tools for writing and compiling help files (refer to help menu of GASMAK2 model).

\subsection{Approach}

The aim of developing an empirical model is to exhibit the same behavior as the system that is being modeled.

Examining the second word in "empirical model", what is a model? Neelamkavil states that " a model is a simplified representation of a system (or process or theory) intend to enhance our ability to understand, predict, and possibly control the behavior of the system." (Neelamkavil, 1987). Assume that someone wants to build something - it is useful to know whether the plans are realistic and will succeed before actually proceeding with construction. A road bridge, for example, is very expensive to build, and if it does not perform to specification, may even result in a disaster. What is needed is a simplified model that can be used to test for performance. The model of course is simpler than the actual bridge, as the real artifact is a very complex thing. If the bridge were truly, perfectly modeled, the model would have to account for its many molecules, or even atoms; the model complexity would become unmanageable.

Now examining the first word in "empirical model", the word empirical means "originating in or based on observation or experience" (WWWebster Dictionary). Empirical models are based on observation and experiment. If no relevant theory is available (or useable) to incorporate into the model, experiments and observations of the real world are made and 
incorporated into the model itself, along with a logical approach for usage. In practice, the modeler will usually have some preconceived ideas about the system which may be used as an initial basis for the model.

The choice of the descriptor "empirical" reflects the fact that GASMAK2 model is rooted in observation and experiment, and accordingly approaches system development from a very different perspective than that associated with traditional numerical or theoretical models. As with all reservoir simulations, certain data must be available and some assumptions must be made to generate a forecast. In this GASMAK2 model, data points that contribute to understanding the methane production rates are used for interpolating emission curves that define the methane emission functions of the gobs that need to be measured or estimated.

\subsection{GASMAK2 Model Development}

Empirical models are based on observation, and on the dependability of those observations. Empirical models have both practical and technical aspects. The practical aspects are concerned with the construction of models that closely correlate with one's experience and that are always open to interaction and revision. The technical aspects are concerned with the logical development of a method for using the data as a foundation for computing.

\subsubsection{GASMAK2 Modeling Flow}

A guiding principle for the GASMAK2 model development was Airey's equation and the original GASMAK empirical model. Figure 9 is the flow of GASMAK2 empirical modeling development. There are two foundational assumptions used in the development of the GASMAK model, i.e., uniformity of increments of advance, and consistency of desorption 
characteristic. (Refer to the chapter 3). From the flow of GASMAK2 empirical modeling development, one can see that the GASMAK2 model is based on a very simple and straightforward formula, the E. M. Airey equation. The advantage of this approach is that it is very fast, only simple input is needed, and the formula is very easy to apply.

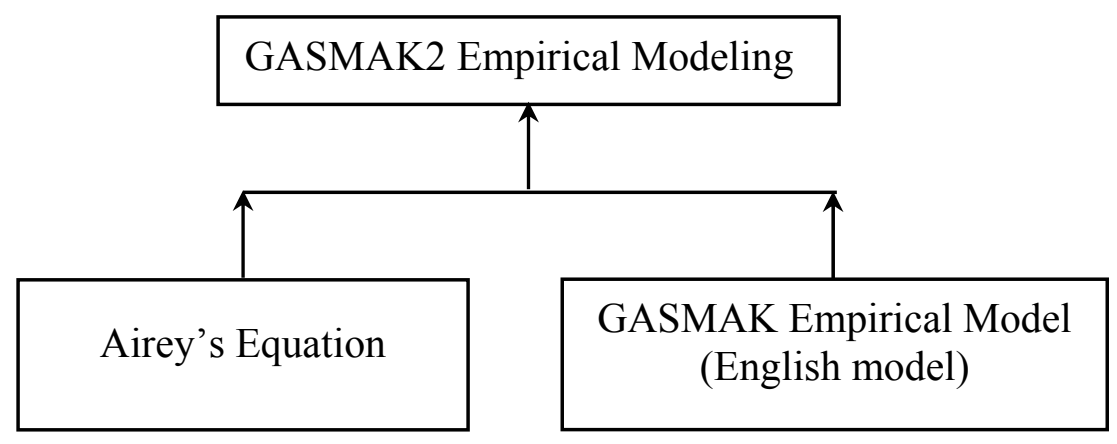

Figure 9: The Flow of GASMAK2 Empirical Modeling Development

\subsubsection{GASMAK2 Modeling Implementation and Methods}

The GASMAK2 model was written in Microsoft Visual Basic 6, a visual programming language which provided the user interface design component necessary for our approach. Visual Basic provides most of the flexibility and discipline of other structured languages, such as PASCAL, and C, but allows the rapid development and prototyping of visual control elements. It is these visual control elements which are essential to providing non-computer expert access to GASMAK2. Figure 10 is the implementation diagram of GASMAK2 Model development. The main features of GASMAK2 development are input database, help system, and automation. 


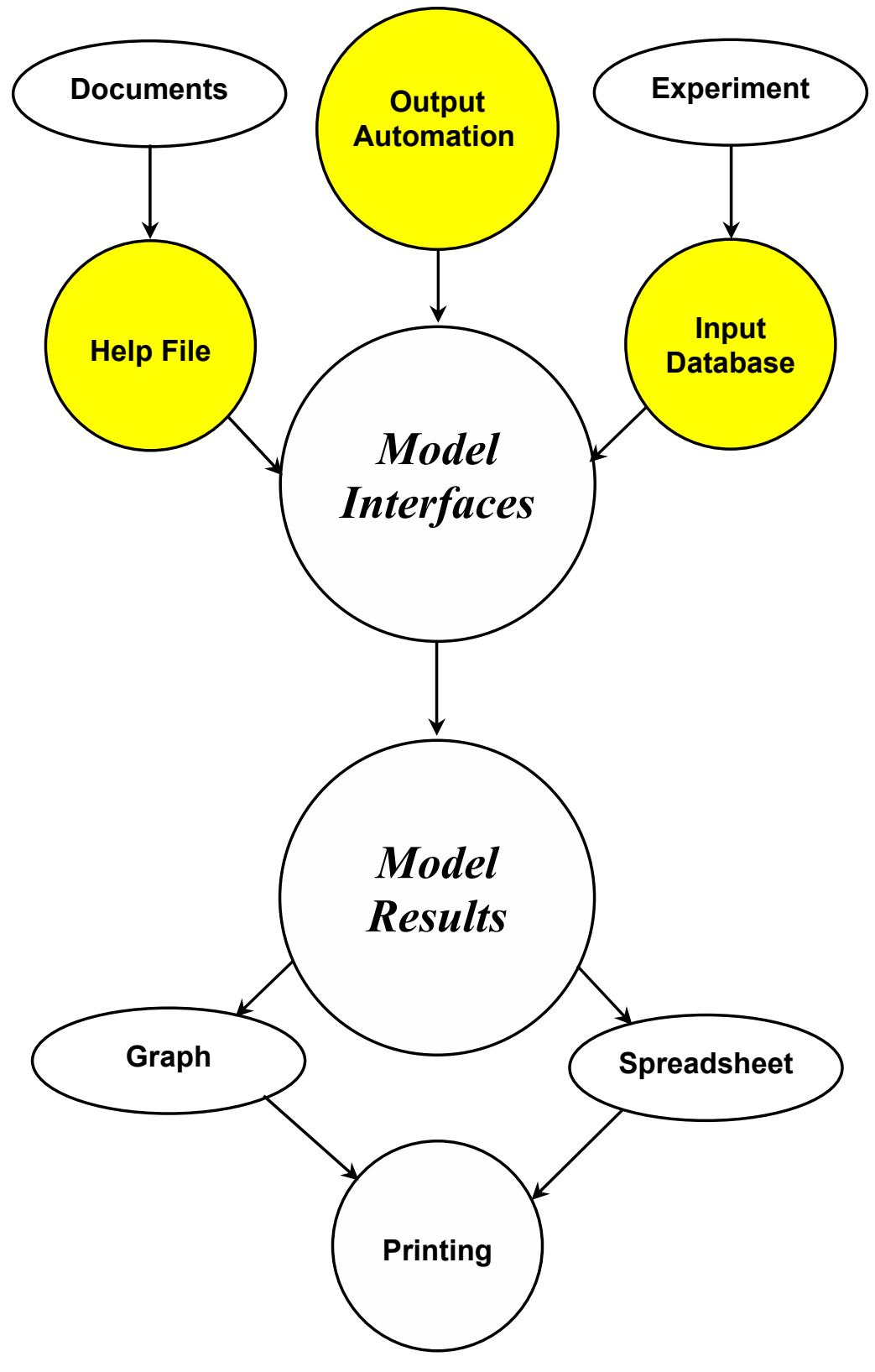

Figure 10: Implementation Diagram of GASMAK2 Model Development

\subsubsection{GASMAK2 Model Input Database}

The model input database is an extremely flexible and powerful tool for modifying model inputs. The GASMAK2 model can be run with the default settings by simply clicking the "OK" button on the appropriate dialog box. Alternatively, the properties of the model may be explored 
by varying model inputs. This is done in GASMAK2 by editing input values, and using action buttons on the model dialog form itself, or by modifying the model input database.

Because GASMAK2 includes many potential input values, it is most practical to have two levels of input entry. The most commonly modified inputs and initial conditions for a submodel are accessible on the model dialog itself. These inputs are commonly the driving variables of the model. All other inputs (data points being input for emission curve and gob well information, etc.) may also be accessed by entering the model input database. Changes made on the form are only active until the form is closed. Input changes must be made in the model input database, using the File-exit and save changes option, on completion to save the changes. In situations where an input occurs in both the model database and on a model dialog form, the value outlined on the form takes precedence when the model is run.

Traditionally model input files for GASMAK have been manipulated as complex ASCII files and required a separate ASCII file text editor. This is the technique used by the original GASMAK model. There are a number of problems with this approach. These include starting with a separate text editor program within the modeling environment, the discontinuity of user interface that this represents, and the complex formatting and abbreviations generally used in these files. To avoid these problems and to meet the specifications on ease of use, GASMAK2, employs an input database editor in a spreadsheet format which is consistent with the program, and a graph forms-based user interface for the rest of the model. This spreadsheet-like mode of operation will be familiar to anyone who has used a modern Excel such as Microsoft database program Access or Quattro Pro. The GASMAK2 input database editor is called from the model dialog menu and appears as an integral part of the modeling environment itself. The parameter database editor has facilities to cut, copy and paste information from other applications using the 
Windows clipboard, and to search for text entries and values within the parameter database. It is also possible to print out either selected areas of the database or the entire database to any printer supported by Windows.

Data Access Objects (DAO) is a mature technology, with the bugs worked out. DAO gives complete control over the entry of data. DAO can be used to make changes to the tables that are immediate and do not need to refresh access records. A new recordset object is automatically added to the recordsets collection when user opens the recordset, and it is automatically removed when user closes it.

\subsubsection{GASMAK2 Model Help System}

In order to meet the criteria of accessibility and open documentation, GASMAK2 uses the Microsoft Help Workshop to create a help file. This help file has been created using Microsoft Word which to create Rich Text Files (RTF) containing the textual information, inserting graphics and adding header/footer entries that allow hyper-help functionality. The help workshop then compiles this RTF into a help file format that is compatible with the help file manager (winhelp.exe) and display system built into Windows operation systems.

The advantage of using a word processor and secondary workshop combination in this manner is that other scientists may contribute to the content of the help file without the need for any specialist programming skills. Also the word-processed help file may be used with little or no modification to form the basis of a printed manual or hardcopy documentation of the modeling system.

The initial task in constructing the help file in GASMAK2 was to gather information for the help topics; the second task was to develop a plan for the help system, which included i) 
defining the likely audience of the material, ii) planning the content of the help system, iii) planning the structure of help topics, iv) determining the topic file structure, and v) designing the individual help topics. These processes are summarized diagrammatically in Figure 11.

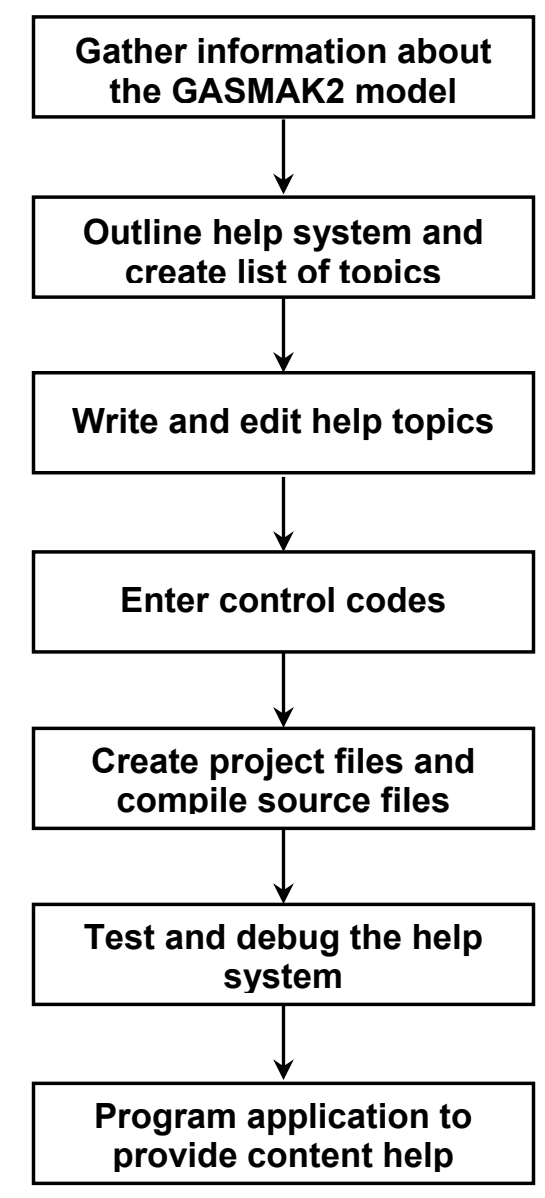

Figure 11: Workflow Diagram for the Construction of Onboard Help System Contained Within GASMAK2 Model

The help file is available in GASMAK2 at all times from the help menu on the main user interface window and it will be discussed in section 4.3.4.2 in more detail. 


\subsubsection{VBA Automation (Automated Output)}

Visual Basic for Application (VBA) in Microsoft Excel allows programming complex tasks within an application. It was first used to automate repetitive tasks and served to order the computer to do tasks that users usually did. Each iteration of Windows has contained a corresponding improvement in the techniques used for transferring data among its applications. Today's leading technique is called Automation (Jacobson, R., 1999). The GASMAK2 model can automatically generate the spreadsheet for output, but the resulting Excel output spreadsheet is very large (see Appendix A). Since most users will be analytical and visually inclined, charts and graphs can be used to explain complicated concepts, and to simplify the information conveyed. It is a great advantage to build in charts and graphs to visualize output information. Although most Excel users can create and format simple charts, personally figured charts and graphs ensure a level of conformity. Because VBA can do this more rapidly and more efficiently than the best user, the GASMAK2 contains workbooks to complete tasks that even well trained users could not perform within normal deadlines. Most of the functions needed to organize and analyze data are pre-programmed in Excel, so some common writing and spelling errors that occur during the programming are avoided.

To develop a good VBA program, the programmer must thoroughly master the functions and functionalities of Excel, understand the inner workings of Excel, work with the applications that support automation, listen to the user who has the knowledge of the data and understand what the user needs. At this point, the author is both the experienced user and the programmer. With the guidance of the creator of the original GASMAK model, normal programming never constitutes more than $25 \%$ of the work; the other $75 \%$ consists of understanding the needs of the user and designing the workbook within which the programming will be developed. 
Microsoft Access is the bestselling stand-alone relational database program for Windows offering both power and ease of use. The recordset object is the primary object used to manipulate data in Access databases.

\subsubsection{Calculation overview}

The following page outlines a basic calculating block diagram of GASMAK2 model for longwall gob gas emissions. The major elements of the calculation in this model are shown in Figure 12. The description of the elements in the model is provided below.

$\underline{\text { Model Element }} \quad \underline{\text { Comments }}$ first segment is larger than the rest because emissions do not start until the first major fall occurs. It also calculates the face location - the distance from panel start-up to the end of segment $i$ at which this segment starts emissions.

This section identifies those segments with emissions that go to a different zone when the face undercuts the next well, and computes the distance between start-up and well 1, the distance between wells, and the distance from the last well to the panel end.

Determines if the segment precedes the first well.

Determines if the segment is beyond the last well. are assigned to the last well. 


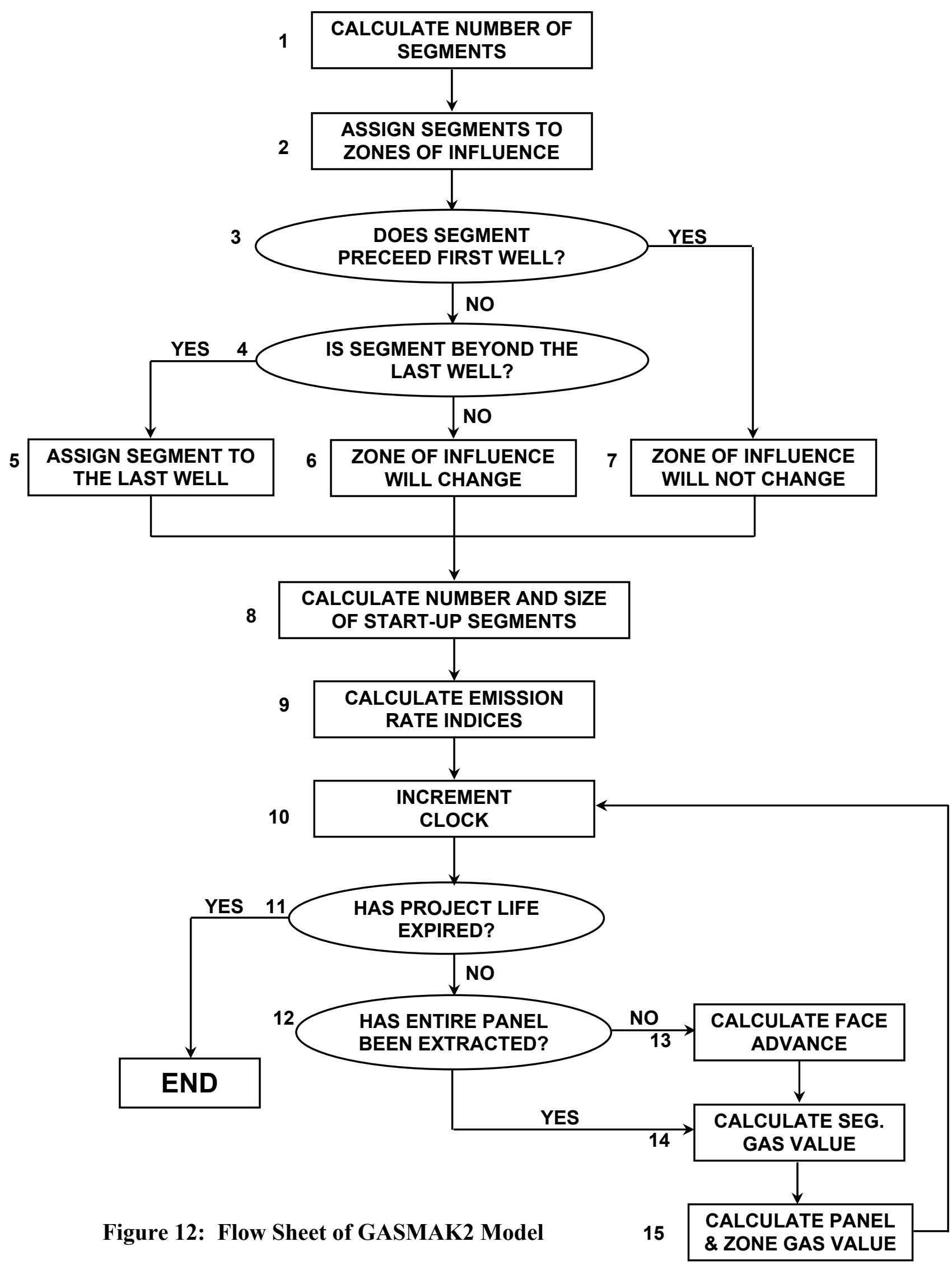


This section calculates the distance $W$ in advance of wells in which segments are influenced by the new well coming on line (i.e., the influence zone will change). $W$ is always 0 for well 1 . Assigns zones of influence for segments lying between wells 1 and $n$, some of the segments do not change zones, while the other segments change zones based on the data of segment "captured" by each well as it comes into production.

Identifies all of the segments up to and including the one that contains the first well, these will never change zones and permanently assigned to Zone 1 .

Identifies those segments at the start of the panel that do not disturb overlying material to the maximum height. Calculate the number of segments in start-up region (i.e., number of segments until the full height of Gob development is reached).

Calculates the desorption index for each segment by taking the ratio of each cross-sectional area to that of the cross-sectional area of a uniform segment of advance. All segments beyond the startup zone have an index of 1. The times and face location are initialized, and the gas emission portion of the program is started. All time and gas variables are set to zero to start calculations, as is the face location. This section starts the time-controlled part of the program. 

output.

Determines if the entire panel has been extracted. entire panel has been extracted. a large quantity of output in Microsoft Excel format.

\subsubsection{Components of the User Interface}

In recent years, the design of user interfaces has been one of the key element for the development of any software system. Frequently, software projects have been devoting more to the design of the interface than the underlying application code. This is not just a function of a competitive market, it indicates that users are demanding more sophisticated software interfaces and the ability to use complex software easily.

The work of interface development for this GASMAK2 model was more than 80 percent of the total work of software development. The key approach in the design of GASMAK2 model interface is to provide a visual communication tool for the user. The interfaces are arranged in consistent way, are comfortable to use, and also provide a beneficial (e.g., assisting in a user's task) environment. In keeping with the standard Windows environment it is possible to use the mouse to select model dialog controls or to use the tab key to move from control to control on the form and the space bar to toggle between values.

The user interfaces are described at the following sections. 


\subsubsection{Password Interface}

Password interface (shown as Figure 13) is for managing user access to this program. As a security precaution, a password is required to enter this GASMAK2 Model. If the password is unacceptable, the program exits. If the password is acceptable, the GASMAK2 model runs.

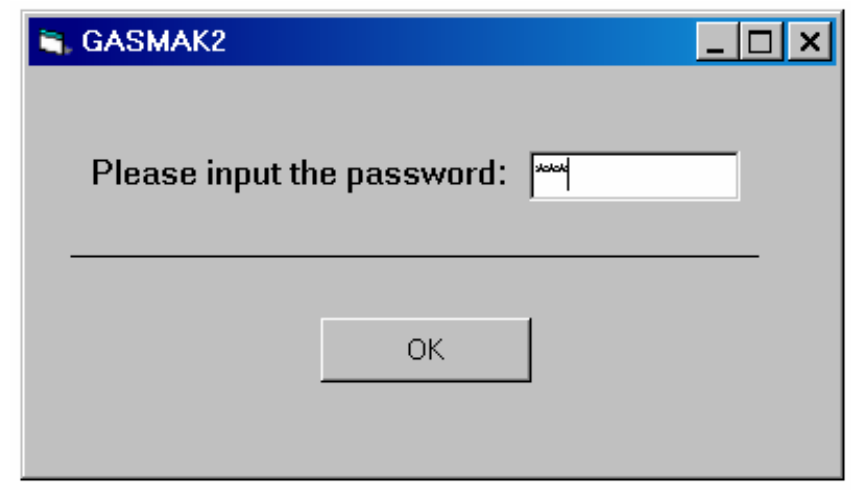

\section{Figure 13: Password Interface of GASMAK2 Model}

\subsubsection{User Main Interface}

Once started the GASMAK2 model automatically displays the user main interface as the first window (Figure14). This is the entry point for operating with GASMAK2 and provides access to all the other model input interfaces, which are opened as successive windows.

In most applications, menus are one of the main ways that users may issue commands. In this model we use dropdown menus which are visible on the top of the user main interface window. There are five menus in the user main interface: "File", "ㅁun", "ㅌiew", "ㅁutput", and "Help". Menu design involves the appropriate arrangement of functions into each menu list and similar options being grouped together so the user just needs to know that the function exists but does not necessarily need to know the names of the functions in the menus. The menus of this model is described as below: 


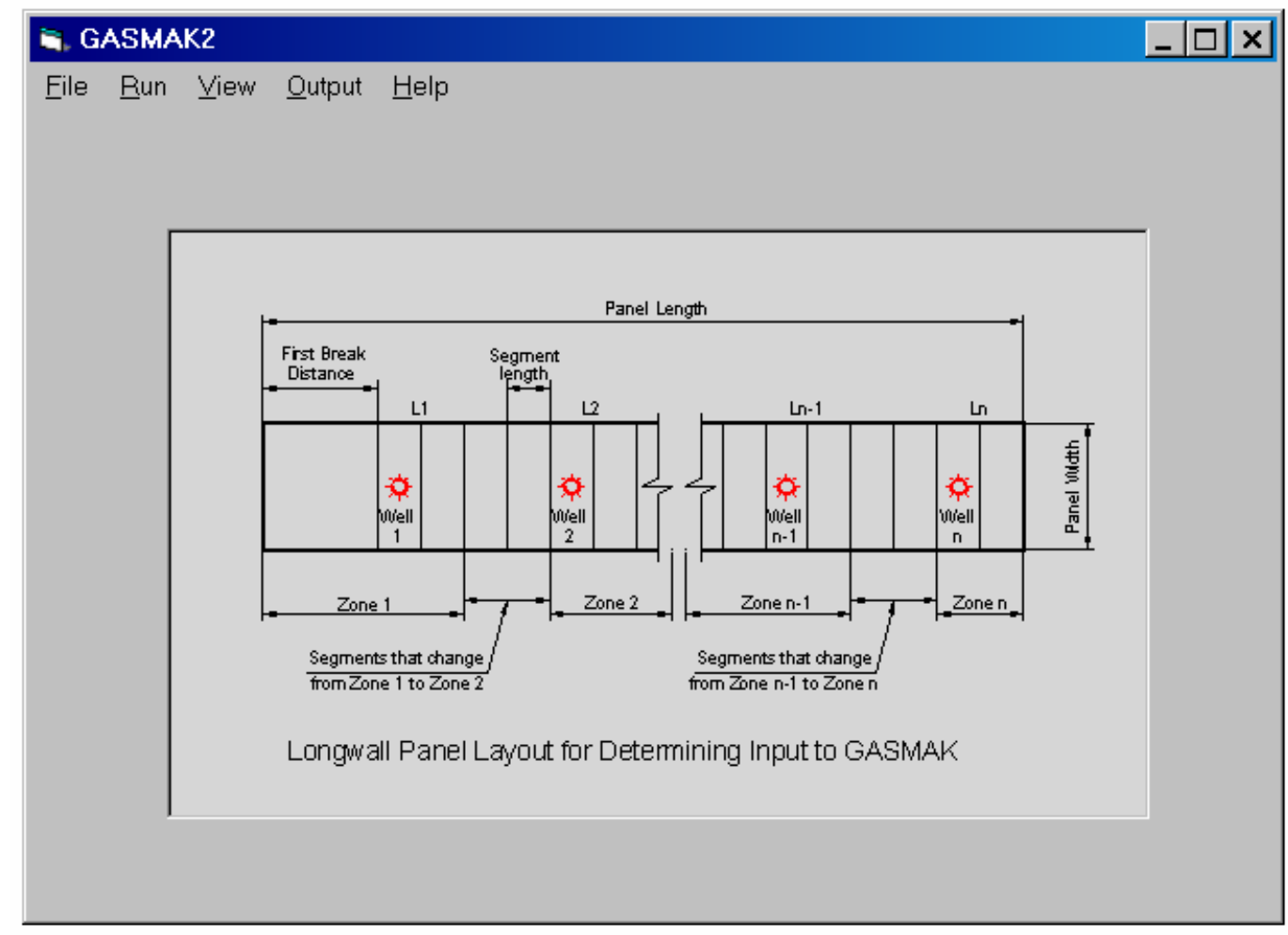

Figure 14: User Main Interface of GASMAK2 Model

\section{$\underline{\text { File Menu }}$}

It is common knowledge that the "File" menu is the beginning of operating a program. The "File" menu for GASMAK2 model is show in Figure 15.

\begin{tabular}{|c|c|}
\hline \multicolumn{2}{|l|}{ G. GASMAK2 } \\
\hline File $\underline{\text { Bun }}$ View & Qutput $\underline{\text { Help }}$ \\
\hline Input & $\mathrm{Ctrl+1}$ \\
\hline Open & $\mathrm{Ctrl}+\mathrm{O}$ \\
\hline Save As & $\mathrm{Ctrl}+\mathrm{A}$ \\
\hline Print & $\mathrm{Ctrl}+\mathrm{P}$ \\
\hline Exit & $\mathrm{Ctrl}+\mathrm{X}$ \\
\hline
\end{tabular}

Figure 15: File Menu for GASMAK2 Model 


\section{$\underline{\text { Run Menu }}$}

If the user is satisfied with the input data, using this Run menu shown as Figure 16 to generate the final output information.

\begin{tabular}{|c|c|c|c|c|}
\hline \multicolumn{5}{|c|}{ G. GASMAK2 } \\
\hline \multirow[t]{2}{*}{ File } & Bun & View & Qutput & Help \\
\hline & \multicolumn{2}{|c|}{ Start } & $\mathrm{Ctrl}+\mathrm{S}$ & \\
\hline
\end{tabular}

Figure 16: Run Menu for GASMAK2 Model

$\underline{\text { View Menu }}$

User can examine the original data (Point Data, and Well Information) with the "View" menu, shown in Figure 17. A tabular view provides a quick and easy way to display the records that user inputs.

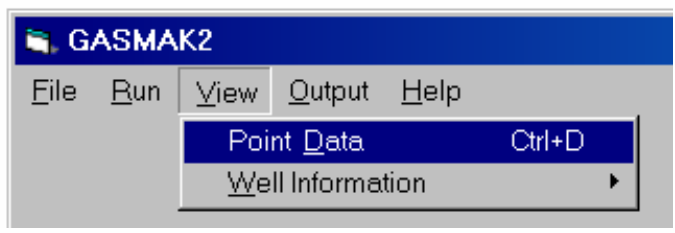

Figure 17: View Menu for GASMAK2 Model

\section{$\underline{\text { Output Menu }}$}

The results of model runs are automatically graphed or tabulated and may be printed out or copied to another application; to retrieve the final results charts using the "Output" menu, there are two commands within this menu (Figure 18). 


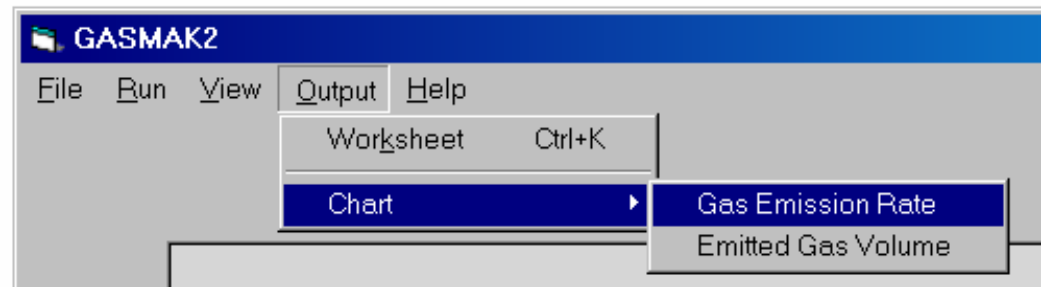

Figure 18: Output Menu for GASMAK2 Model

\section{$\underline{\text { Help Menu }}$}

A GASMAK2 model help menu is provided, one way to switch between help menu and the work environment. Figure 19 shows the user the help menu.

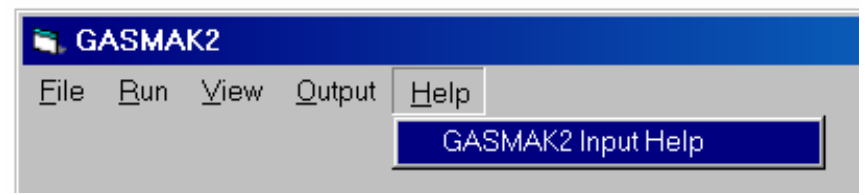

Figure 19: Help Menu for GASMAK2 Model

It is important to realize that an onboard help system is available for this GASMAK2 model. The help file contains information about GASMAK2 model and the individual input items descriptions. Click on the command of "GASMAK Input Help" from "Help" menu and the Windows Help will pop up (see Figure 20). The first page of this help file is a brief description of the GASMAK2 model.

A hierarchical structure of help topics was chosen for clarity, ease of navigation, and because it reflects the internal structure of GASMAK2. Help topics were designed with consideration for font size, color and layout to improve visual consistency and ease of navigation. 


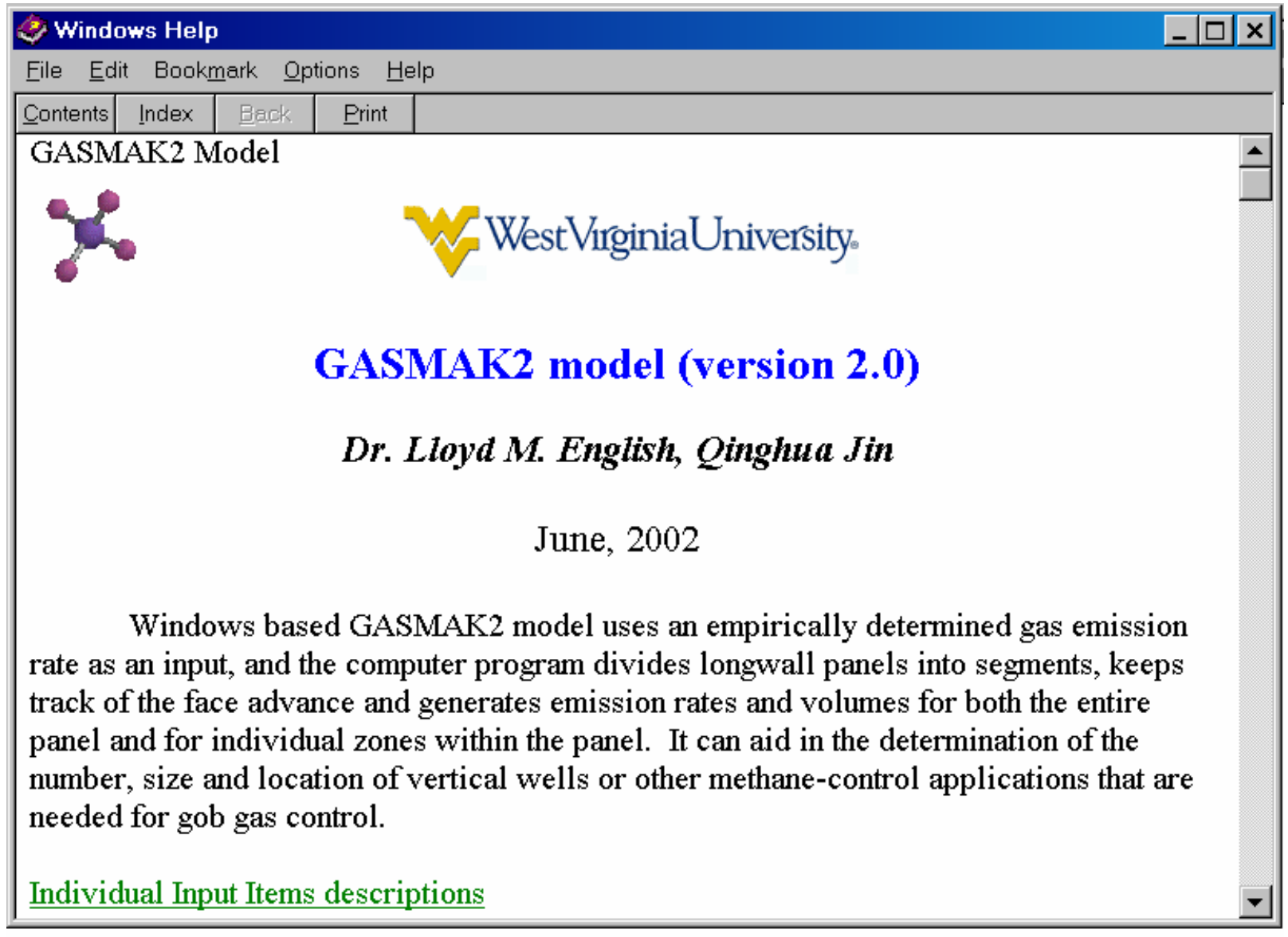

Figure 20: About GASMAK2 Model of Help File

The linkage of the "Individual Input Items descriptions" offer user a list of input parameters organized by input order. The content of individual input items is shown in Figure 21. 


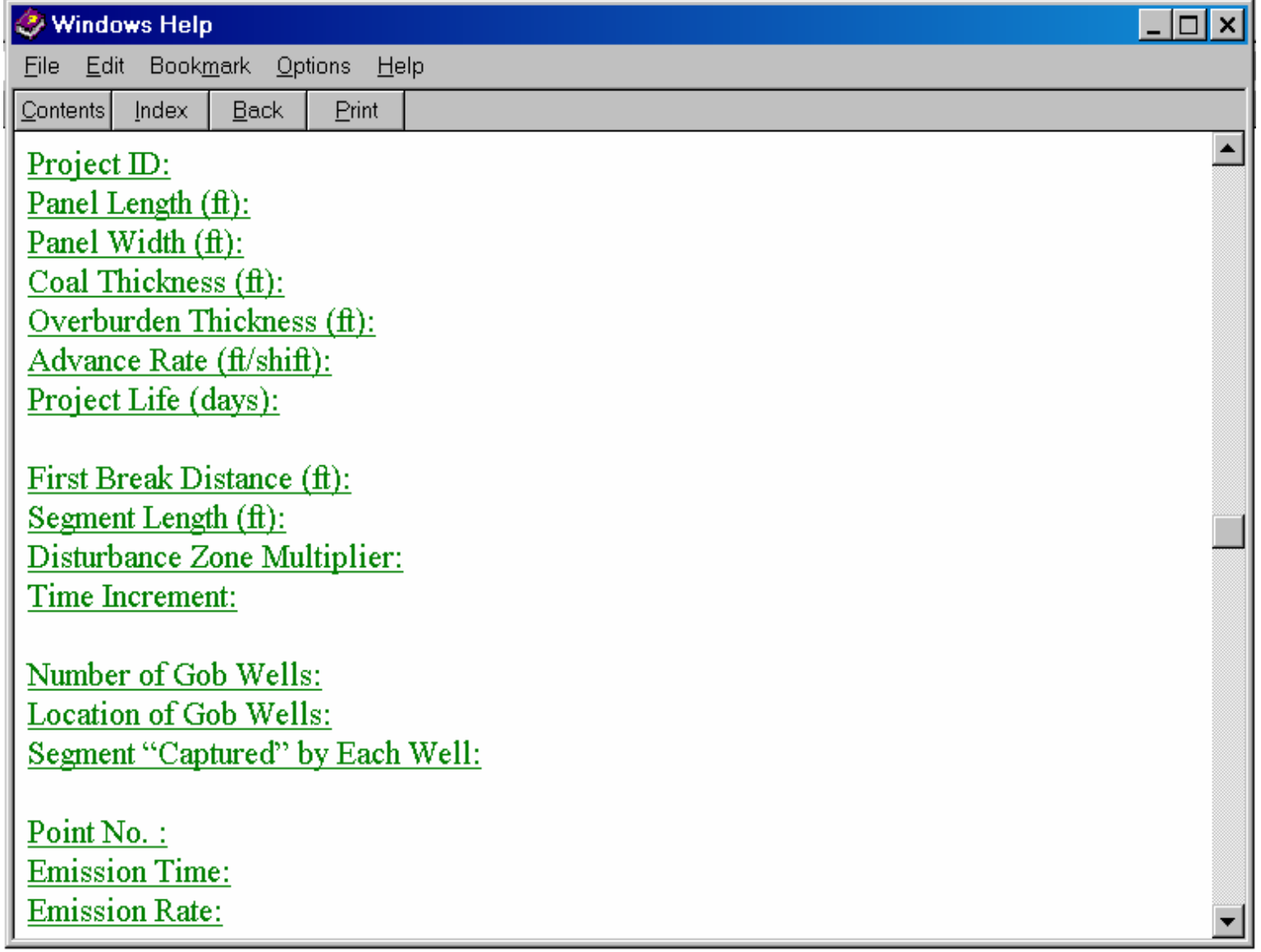

Figure 21: Content of Individual Input Items of Help File

With these links, the user can use as first stops in the search for information about each input parameter. An example of an input description for the GASMAK2 model is shown as Figure 22. 


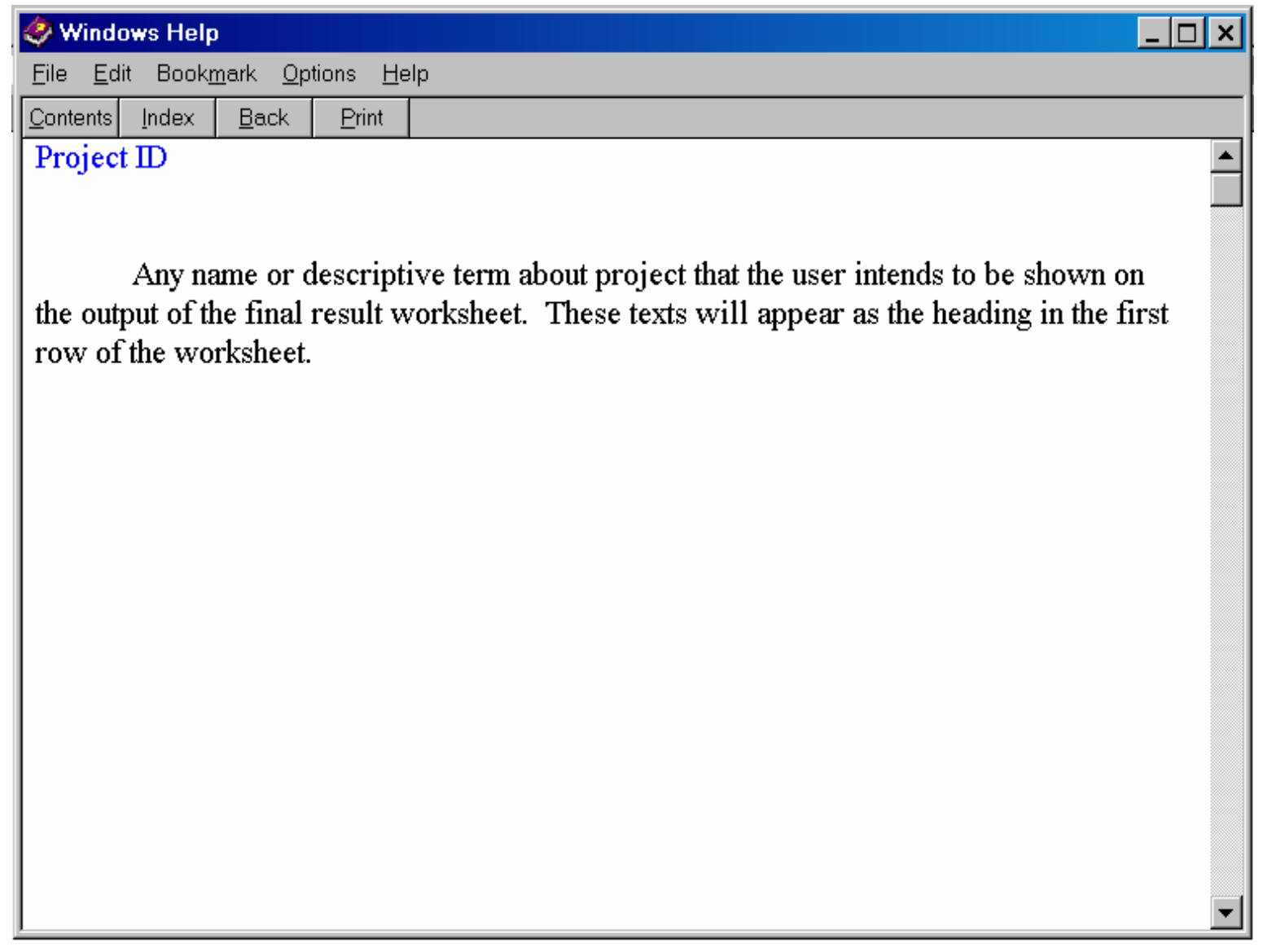

Figure 22: An Example of input description for Help File

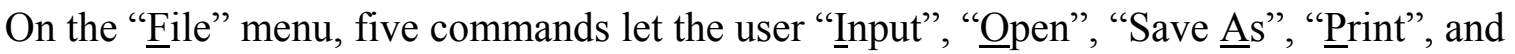
"Exit" (see figure 14). User can close down all GASMAK2 windows and exits the program using Exit command. Opening, saving, and printing files are basic file management tasks. The user can manage files through this "File" menu efficiently. Each underlined letter in a command is a shortcut to the same action as the corresponding menu item after the menu is open on the screen. 


\subsubsection{Open File Interface}

To retrieve a file from disk, choose the "Oppen" command from the "File" menu, the open dialog box appears, as shown in Figure 23.

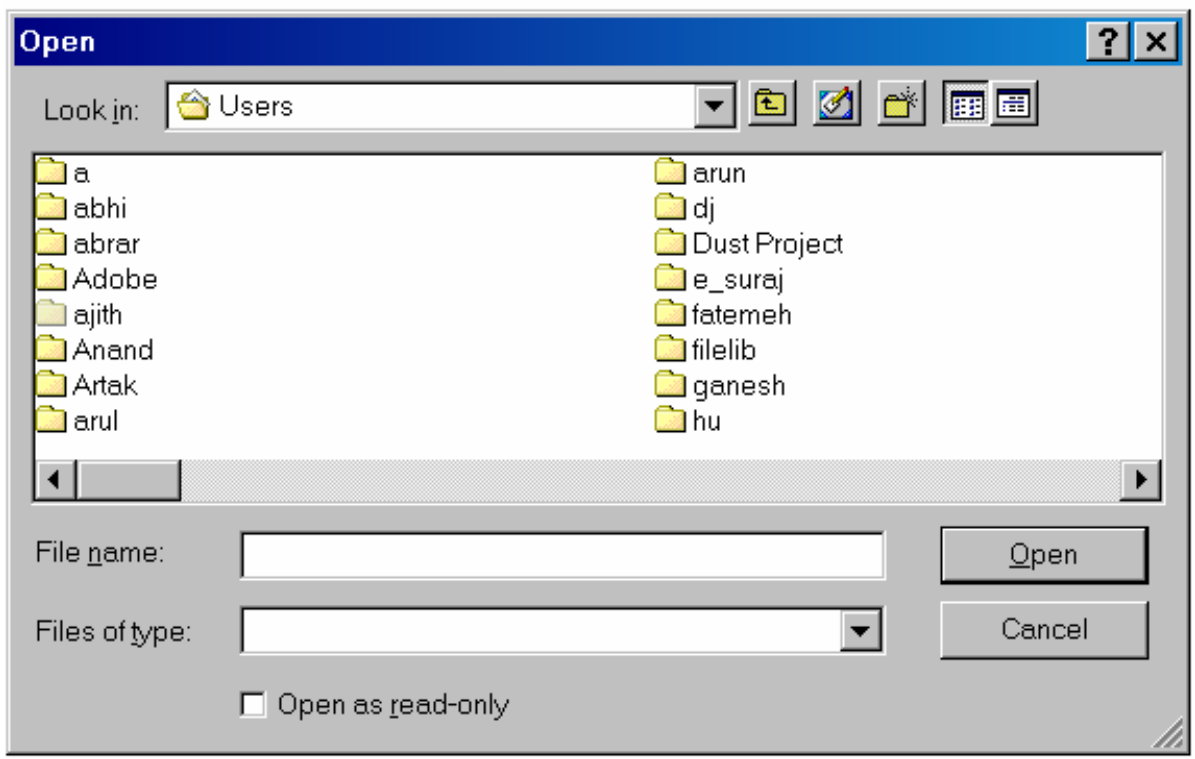

Figure 23: Open File Interface for GASMAK2 Model

\subsubsection{Save As File Interface}

Click on the "File" menu; select "Save Ass", a classic windows "Save As" dialog appears as Figure 24 to allow the user save files to disk. 


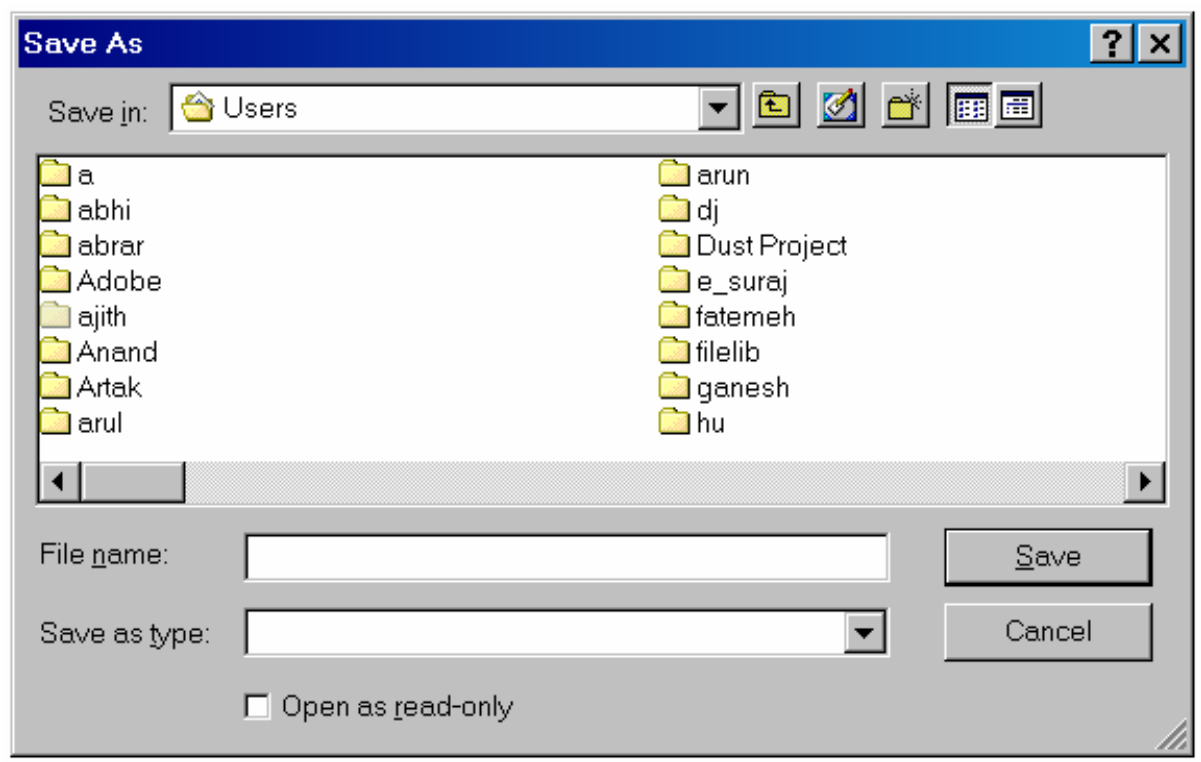

Figure 24: Save As File Interface for GASMAK2 Model

\subsubsection{Print File Interface}

Clicking on the "File" menu and selecting "Print" opens a dialog box (Figure 25) with options for printing an image.

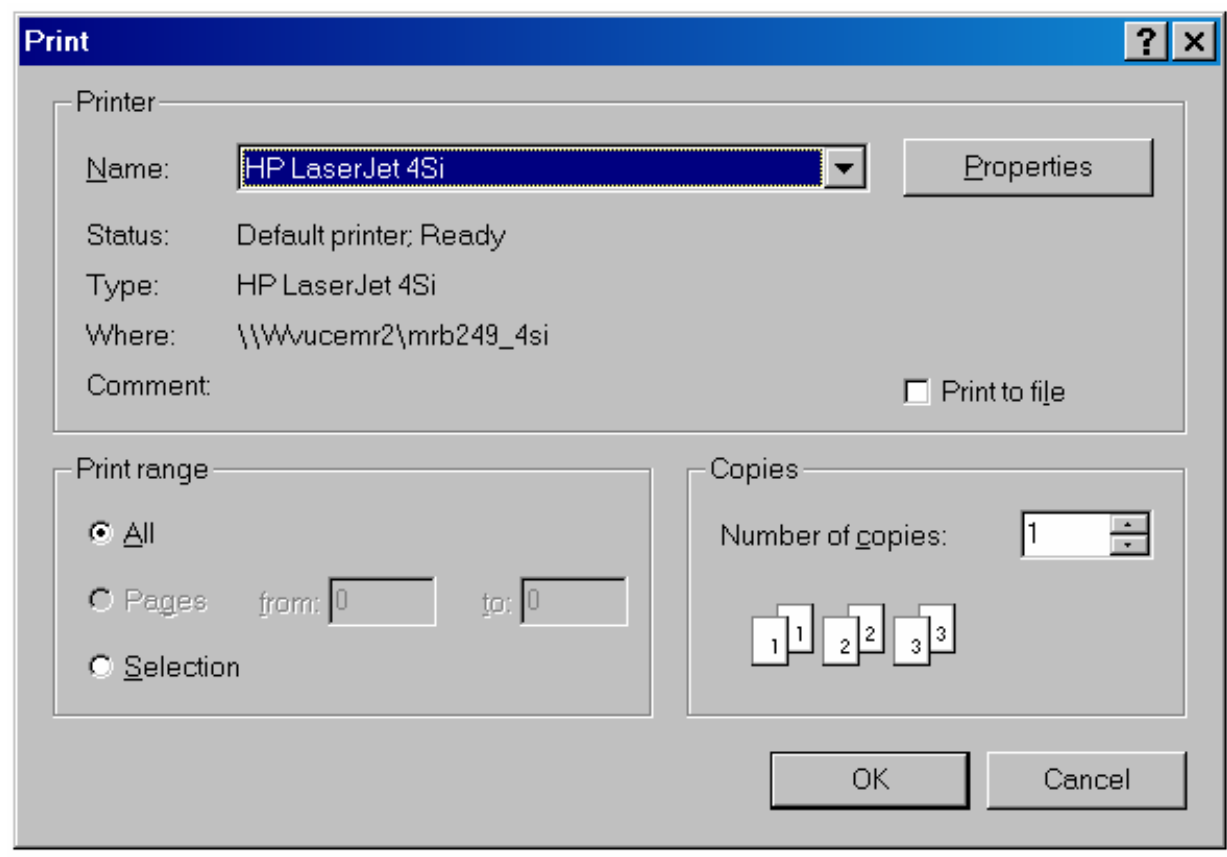

Figure 25: Print File Interface for GASMAK2 Model 
The establishment of a database is a very important step in the modeling process. The data that are collected must be used answer the questions: What do we have and how does it work? The input interfaces were developed to answer these questions.

To input the initial conditions calculated for GASMAK2 model, choose the "Input" command from the "File" menu, then display the next four interfaces one by one, shown respectively in Figure26, 27, 29, and 30.

The descriptions of inputs and required units for these Figures are described as below.

\subsubsection{Project and Panel Information Interface}

Model input interfaces are used to specify the main driving conditions for model runs and are supplemented by the model input database. Project information and panel information needed for the GASMAK2 model are shown as Figure 26.

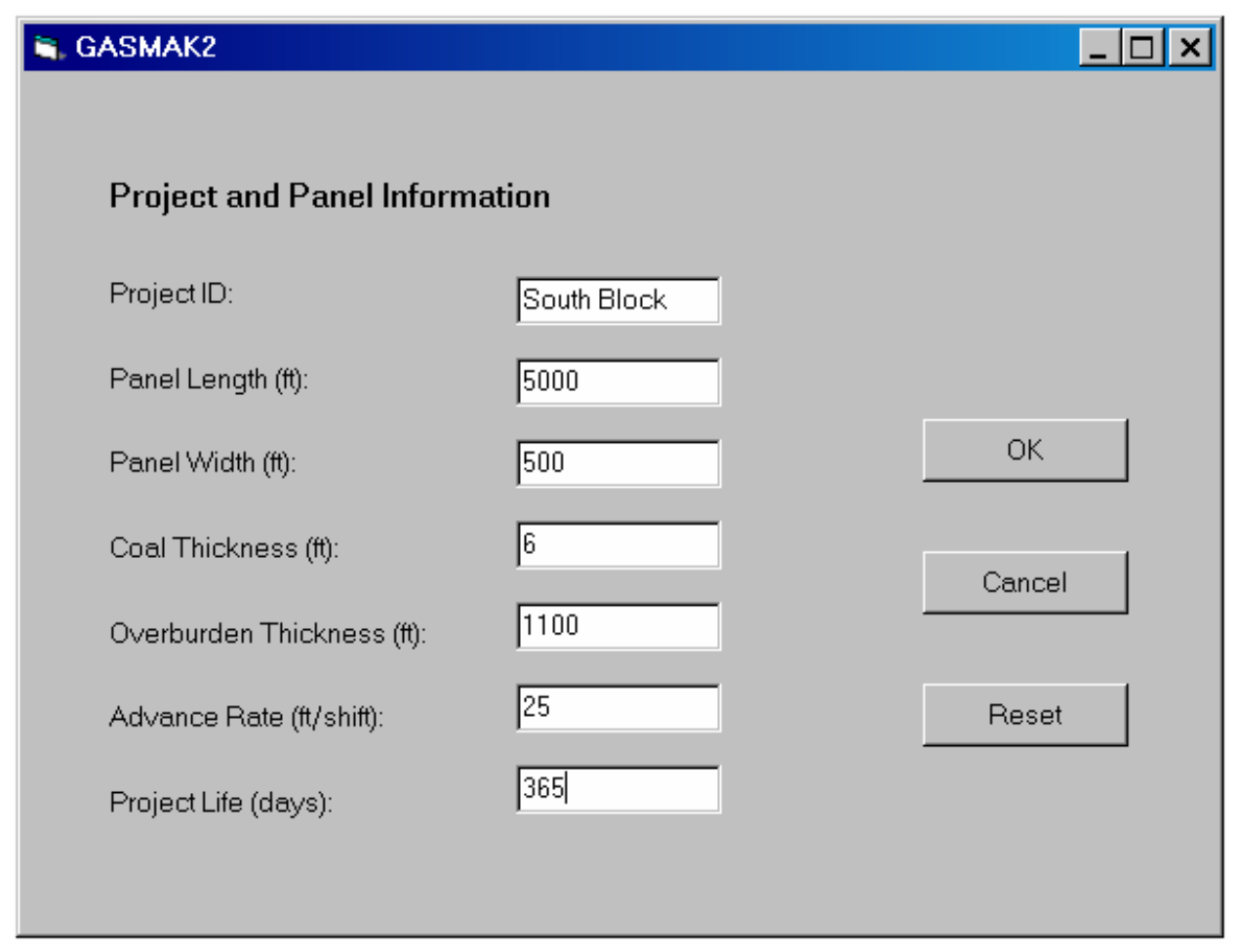

Figure 26: Input Interface of GASMAK2 Model — Project and Panel Information 


\section{- Project ID:}

Any name or descriptive term about project that the user intends to be shown on the output of the final result worksheet. These texts will appear as the heading in the first row of the worksheet.

\section{- Panel Length (ft):}

The total length of the longwall panel in feet. It is the distance between the out-by rib of the start-up entry and the face location at the recovery point excluding the barrier pillar remaining at the foot of the panel. Refer to the graph of longwall panel layout for determining input to GASMAK2 model shown on the user main interface (figure 14).

\section{- Panel Width (ft):}

The longwall panel width in feet. It is measured to the outside ribs.

\section{- Coal Thickness (ft):}

The average extraction thickness (not the coal seam thickness) over the entire longwall panel in feet. For example, if only 72 inches of an 8 feet seam are being extracted, then the input value for the coal thickness would be 6.0 feet.

\section{- Overburden Thickness (ft):}

The average depth of burial of the longwall panel in feet.

\section{- Advance Rate (ft/shift):}

The average advance of the longwall face in feet per shift. It is obtained by using an average for a one-week period, or by any reasonable method that the modeler may choose to use. Advance rate is the key parameter in this GASMAK2 model; the higher advance rate will result in more methane emission than lower advance rate, given that the other parameters stay the same. 


\section{- Project Life (days):}

The duration in days of the time period for which there is interest in the gas emissions. The longer project life will generate a greater quantity of output data in the final result worksheet than would extraction time only, and accordingly, the model run time will be greater. Appendix A is a output worksheet based on an input value for project life of 365 days, a panel length of $5000 \mathrm{ft}$, and an advance rate of $25 \mathrm{ft} / \mathrm{shift}$. At 66.7 elapsed days the mining operation reaches the panel end, but the gas emissions continue into the future. When using this GASMAK2 model for assessing ventilation needs, project life value should be twice of the time it takes to extract the total panel; for economic assessments, it should be extended beyond that.

Other components of this interface include formatted input boxes, and action buttons. Three selections in this interface for user operate this model conveniently:

○ "OK". If the users confirm all the input data are correct, and wish to continue to run this model, then click this button. This will initiate the model with values they have input and bring up the next input interface.

- "Cancel". This button is designed for the users to exit the input interface without performing any actions and closes this interface.

○ "Reset". If the users are not satisfied with the input data, using this button can set the status of all the input values to empty.

\subsubsection{Gob Well Calculation Information Interface}

This interface consists of gob well information needed for GASMAK2 model shown as Figure 27. 


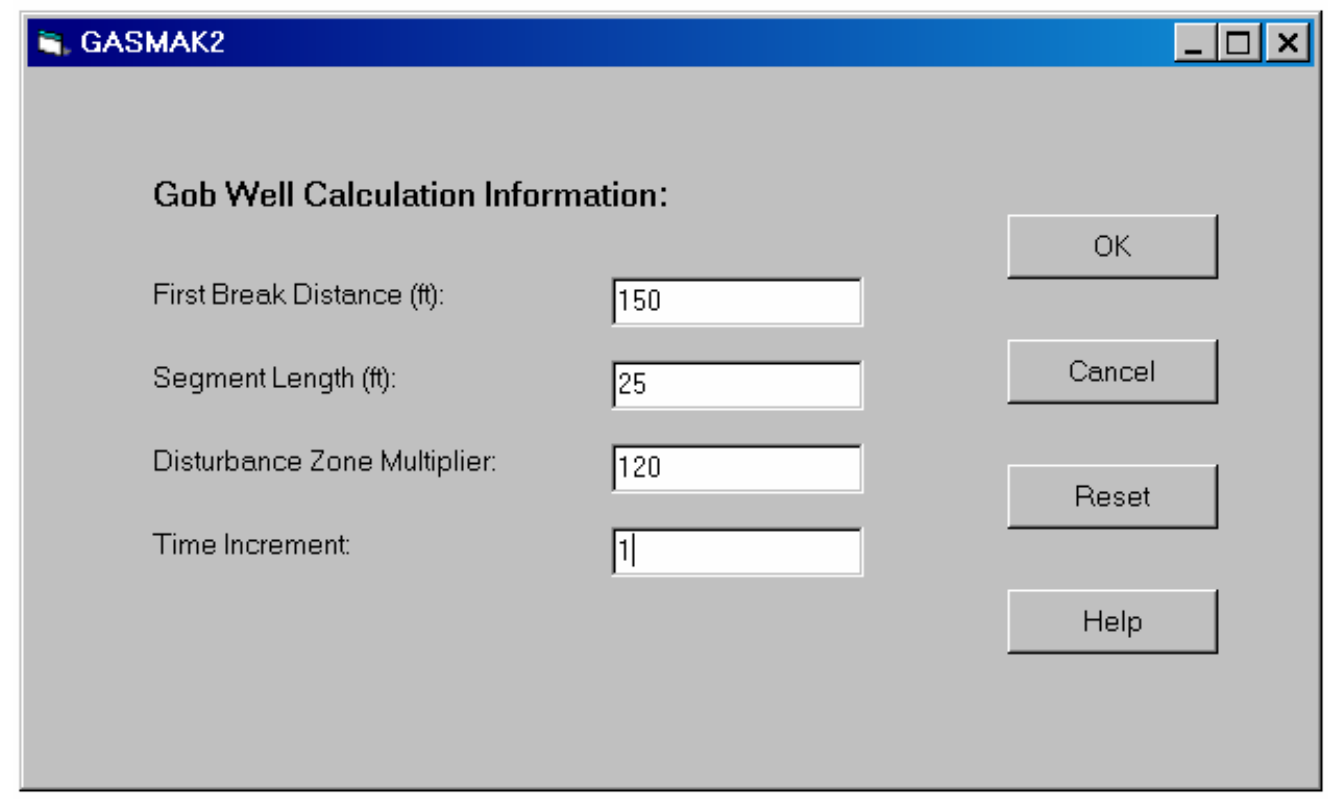

Figure 27: Input Interface of GASMAK2 Model — Gob Well Calculation Information

\section{- $\quad$ First Break Distance (ft):}

The distance in feet that the longwall face will advance before the first major break will occur in the overlying strata behind the longwall shields.

\section{- Segment Length (ft):}

The length in feet of the chosen uniform increment of advance. The GASMAK2 model can handle whatever number of segments may be desired, but the smaller each individual segment is, the greater the model run time will be.

\section{- Disturbance Zone Multiplier:}

This is a value obtained from experience, the number of seam thicknesses above extracted coal that will result in strata movement and stress reduction. It has an impact on the start-up segment emission because strata movement and stress reduction will change the permeability of the gas-bearing strata. The recommended disturbance zone multiplier value is 
50 120. For deeper mines, this value should be larger. One may run some parametric analyses to find values that match the history of emission data.

\section{- Time Increment:}

A value of 1 represents one eight-hour shift. In other words, if we want the contents of the output table shown by one-day increments, then input 3 . The larger the time increment is, the shorter the model run time and the less output worksheet will be.

There are four buttons in this interface for user operation, the same functions of "OK", "Cancel" and "Reset" as in the previous interface. The last button, "Help", can aid the user in opening the help interface (shown as Figure 28).

\subsubsection{Help Interface}

The longwall panel layout for determining input to GASMAK2 model is a valuable reference to the user for deciding gob well distribution. When inputting initial conditions in the gob well calculation information interface, the users do not need to return to the beginning of the

program to refer to this graph. The "OK" button was designed for closing this interface and continuing to input other information. 


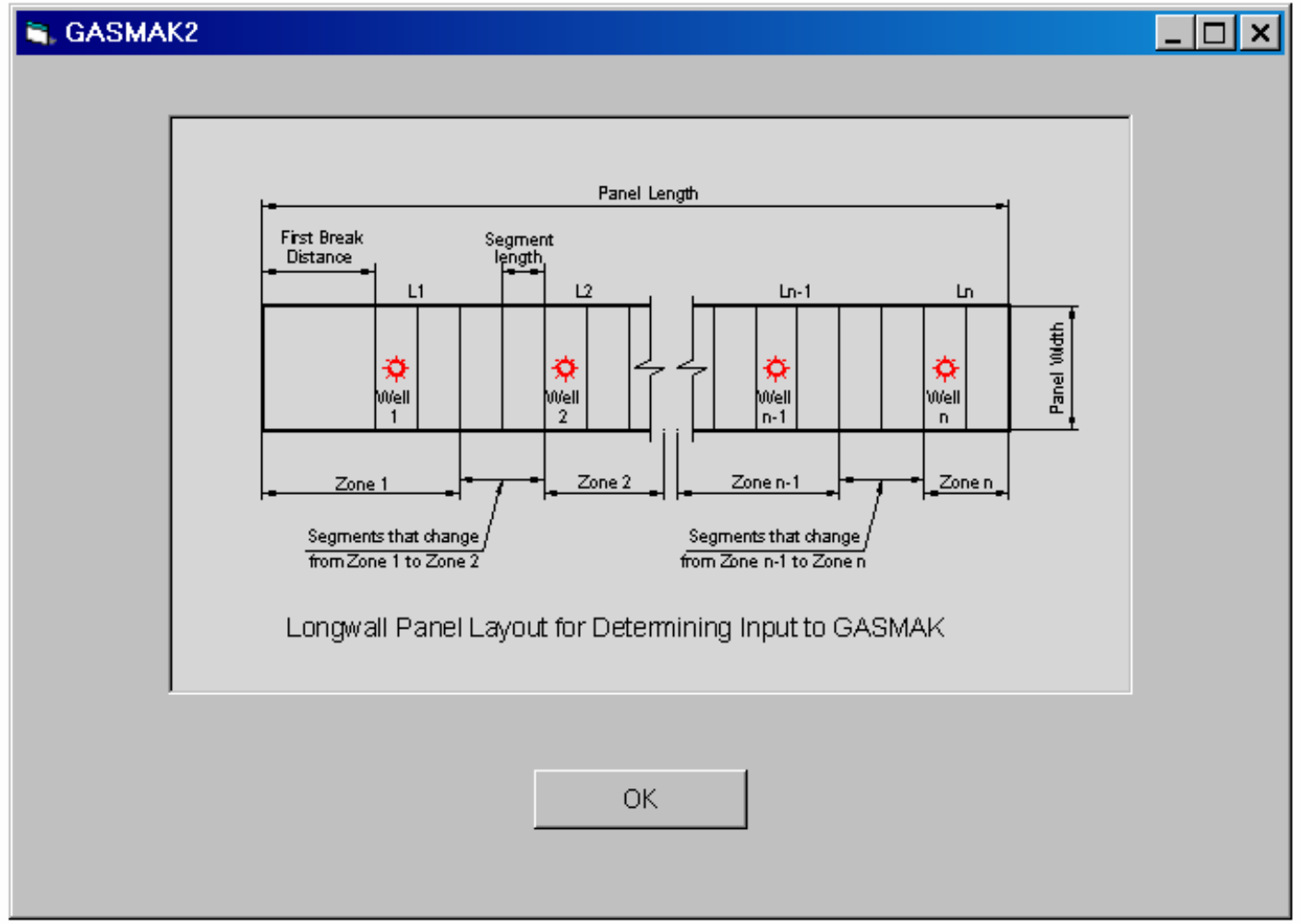

Figure 28: Help Interface of GASMAK2 Model

\subsubsection{Gob Well Interface}

Figure 29 shows the gob wells interface.

There are many different ways in which users can access the database. DAO (Data Access Objects) is one convention that may be used to access the gob wells database. When using DAO, a table is formed and is declared a 'recordset'. This recordset then makes possible several methods that can be used to manipulate a database. The Edit, AddNew and Delete methods are used in this interface for the main functions. Four command buttons - "Ádd", "Delete", "Get" and "Uppdate makes user access to the data for the gob wells easy. Users can import and export data with the gob well information databases using just these four buttons. 
The functions of another two buttons, "OK" and "Cancel", are the same as in the previous interface.

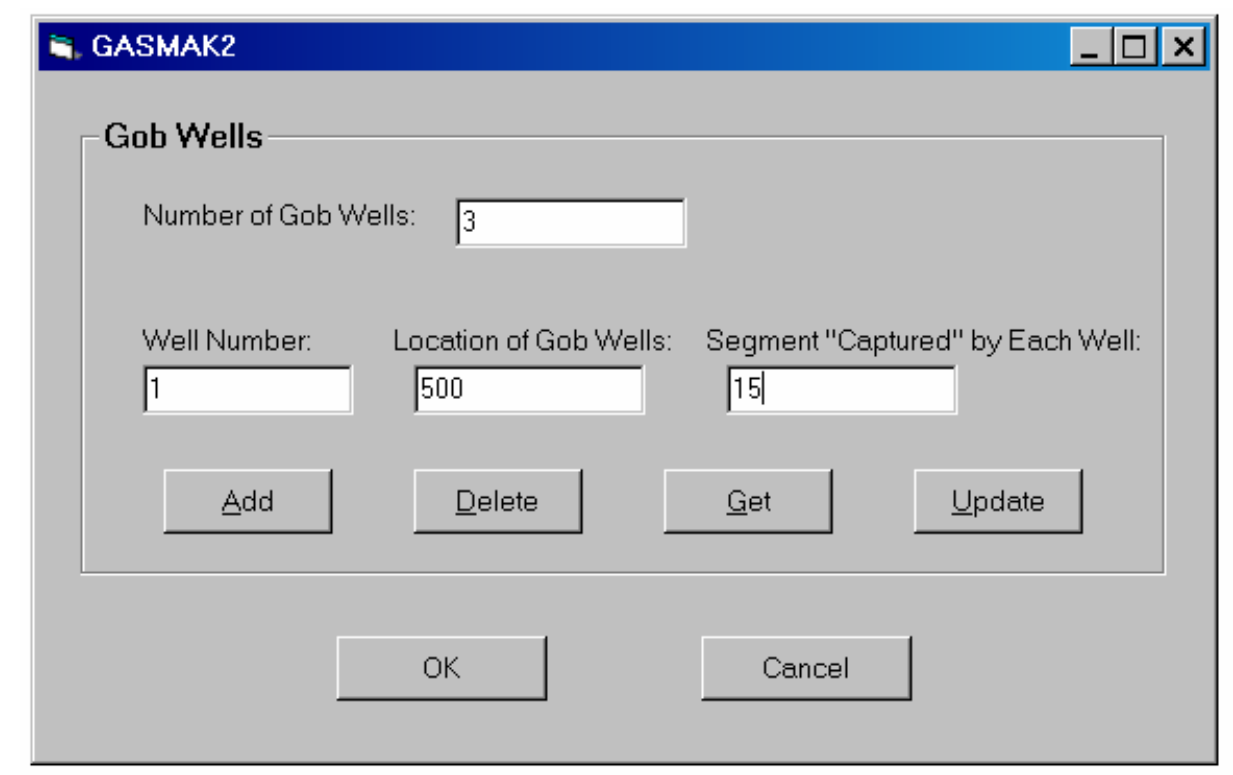

Figure 29: Input Interface of GASMAK2 Model — Gob Well

\section{- Number of Gob Wells:}

The number of gob degasification wells placed in the longwall panel. The number of gob wells depends on many factors such as the mining technology employed, the ventilation system, the characteristics of the coal seam and mine gas emission, and well size etc. In this model, the number of gob wells is also the number of zones of influence.

\section{- Location of Gob Wells:}

The distance in feet between panel start-up and each well. (Refer to the graph of the user main interface) In this model, the locations of the gob wells are also the zone change points.

\section{- Segment "Captured" by Each Well:}

The number of segments in front of each well that will be "captured" by succeeding the gob well. This value should always be less than half of the intervening segments. 


\subsubsection{Data Points Being Input for Emission Curve Interface}

The data points being input for the emission curve interface are shown in Figure 30. This interface is designed for using the empirically determined data points subsequently used for emission curve regression. Since the GASMAK2 model interpolates from these data it is best to use as many points as possible and to obtain those points closer together where the curve changes most rapidly.

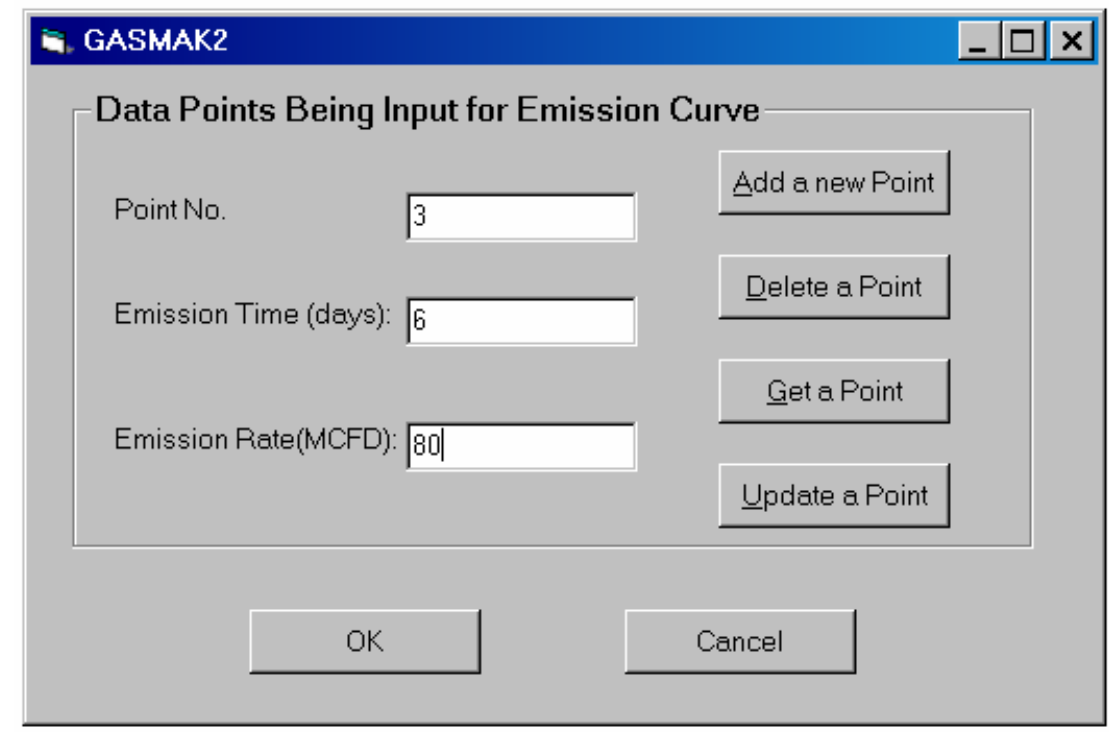

Figure 30: Input Interface of GASMAK2 Model — Data Points Being Input for Emission

\section{Curve}

\section{- Point No.:}

The order number of these input data.

\section{- Emission Time:}

The individual data point times for emission curve, in days. Users do not need to input these data consecutively, because the GASMAK2 model can sort these values automatically for user.

\section{- Emission Rate:}


The individual data point rates from the emission curve, in thousands of cubic feet daily (MCFD).

Since the GASMAK2 model interpolates the input data, the greater input data, the more accurate the result will be. This could be time-consuming if a lot of data is available. Because of this, the GASMAK2 interface was designed using a database. Microsoft Access is a relational database-management system. It enables one to store, organize, and manipulate collections of information in an electronic format, so that data can be manipulated and extracted with ease and flexibility. Users may not only input these data points from emission curves through Microsoft Access outside of the model, (it is the easier way to input data), but they also can use the four command buttons in this interface - "Ádd a new Point", "Delete a Point", "్et a Point", and "Update a Point". These buttons ease access to the data points for emission curves the users do not need to open Microsoft Access itself nor need to know how to run Access. The functions of the other two buttons, "OK" and "Cancel", are the same as in previous interfaces.

\subsubsection{Point Data Tabular View Interface}

The "Point Data" command from the "View" menu allows the user to read data points being input for emission curve from a table. Figure 31 is a tabular view of the data being input for the emission curve. This table helps user checking the data input.

This interface has the appearance of a spreadsheet, consisting of 3 columns and multiple rows. The first column contains the number of the point being input orderly; the second column contains the emission time value, and the third column contains the emission rate value. This interface is also an input database for the GASMAK2 model. 


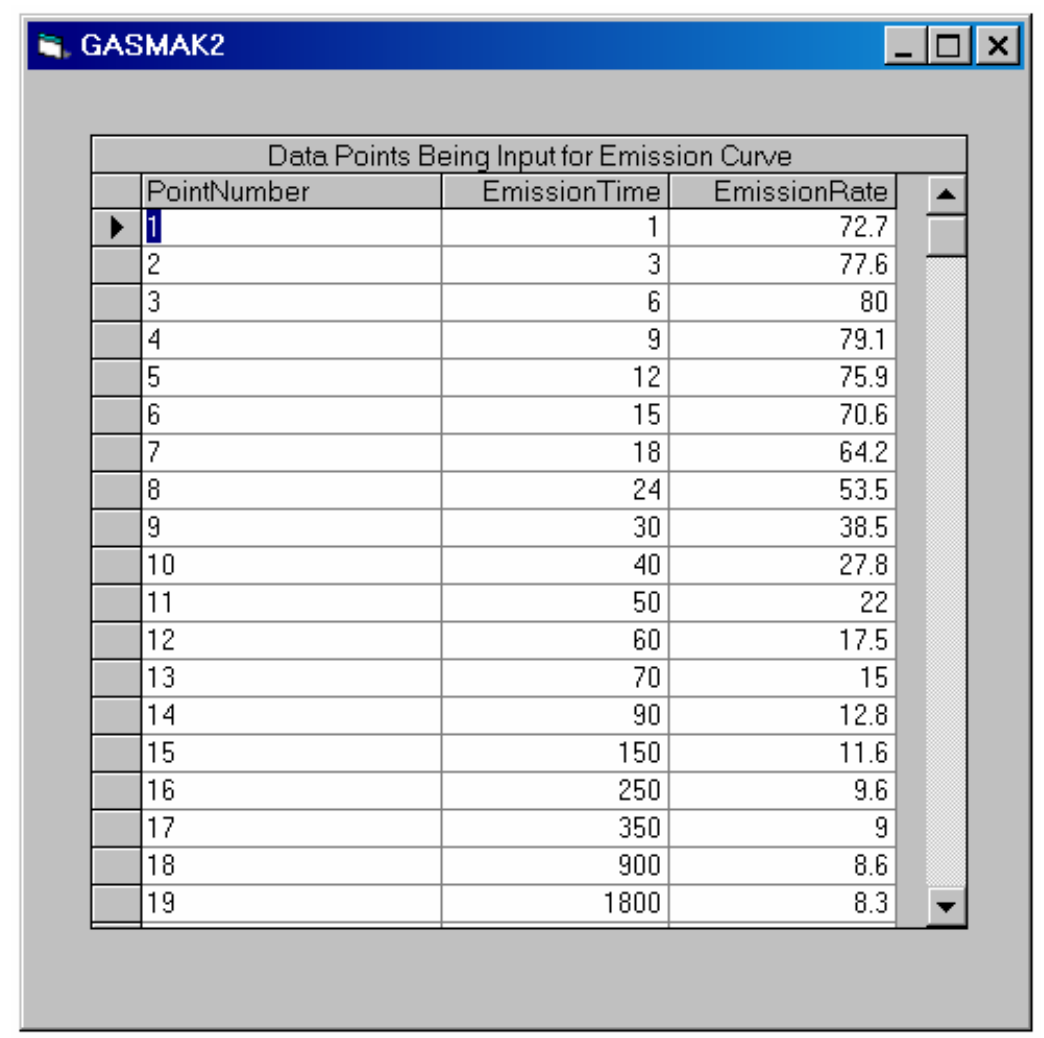

\section{Figure 31: Point Data Tabular View Interface}

\subsubsection{Gob Well Information Interface}

The "Well Information" command from the "View" menu offers the user a table for the gob well information. Figure 32 is an example of a tabular view of the gob well information.

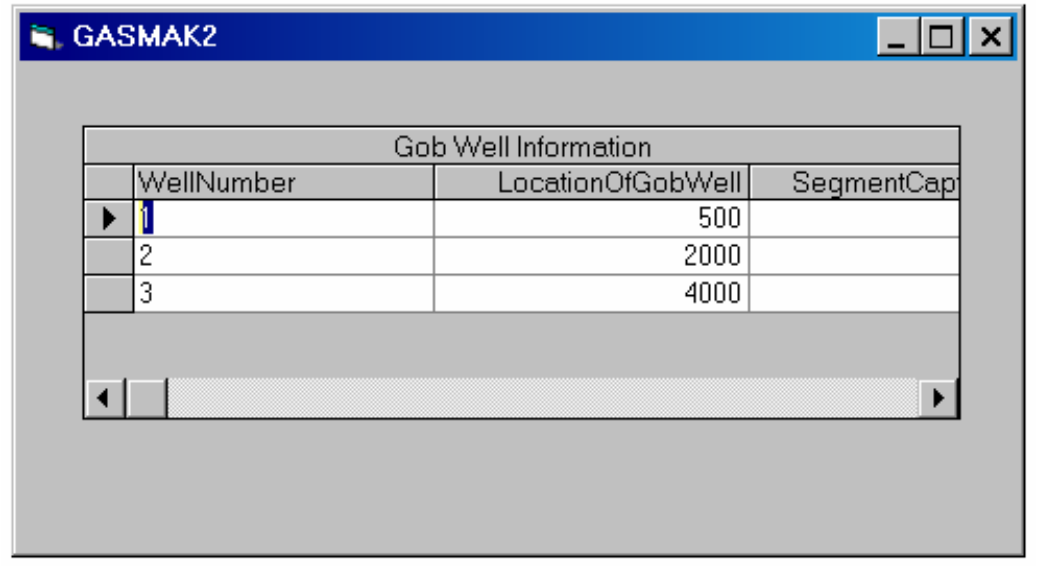

Figure 32: Gob Well Information Interface 
The each of the above two interfaces generate a datasheet which provides a tabular view of the input data. The way to determine which record is active is to examine the left side of the table. A dark triangle in this selection area points to the active record. When a table is larger than the screen, the user can use the vertical and horizontal scroll bars to view fields or records that appear beyond the current viewing area. However, when the user uses the scroll bar, the active record does not change.

\subsubsection{Run Interface}

When the "Start" command on the "R्un" menu is pressed where the user has finished inputting all the original data and the GASMAK2 model executes the program code. If the model code requires more than a few seconds to finish, a progress graph (Figure 33) is shown.

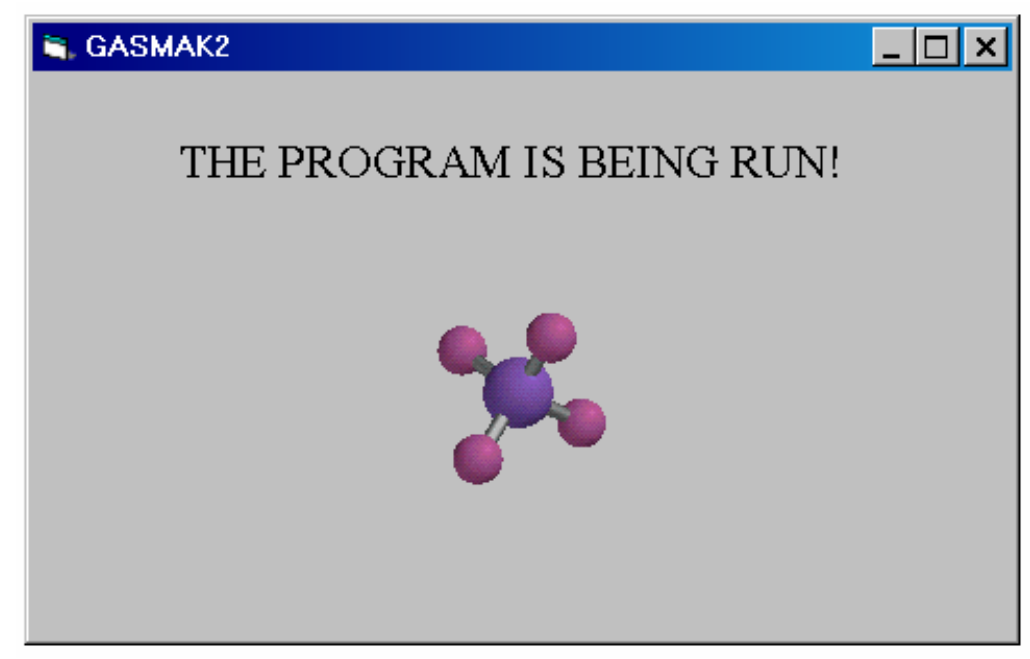

Figure 33: Running Interface of GASMAK2 Model

The time that this interface is shown on the screen depends on the project life, and time increment, and complexity of the input data. 
Upon completion of a modeling run, GASMAK2 generates outputs which include a worksheet and two charts with respect to the input values (project life, and time increment) in the worksheet. GASMAK2 provides automatically formatted graphs, with labeling and scaling performed from information gathered automatically from the worksheet.

An example of the actual output worksheet from a sample GASMAK2 run is presented in the Appendix A. The worksheet in Microsoft Excel format contains the following information:

- Project time, i.e. the elapsed days

- Longwall face location

- Emission rate for entire longwall panel

- Emission rates for zone 1 to $i$

- Cumulative gas production for longwall panel

- Cumulative gas production for zones 1 to $i$

\subsubsection{Feedback and Error interfaces}

One frustration for users of software is the lack of the feedback when the system is processing a long task. Unfortunately, users will always find situations where an error may occur. In the design stage of the GASMAK2 model, as many error situations as possible were anticipated and mechanisms were provided to prevent users from setting up these situations by displaying suitable warning messages. Error messages are, where possible, constructive and offer the user some constructive help in suggesting remedies for the situations. Many error message boxes were designed during the development of this GASMAK2 model. Figure 34 and 
35 show two examples. The popup message box warns the user and offers some information to run the program correctly.

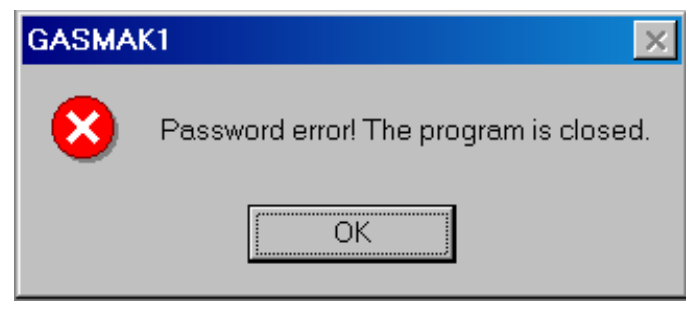

Figure 34: Error Message Box for GASMAK2 Model (1)

Numerical entries from the user are range and type checked for validity before acceptance for a model run.

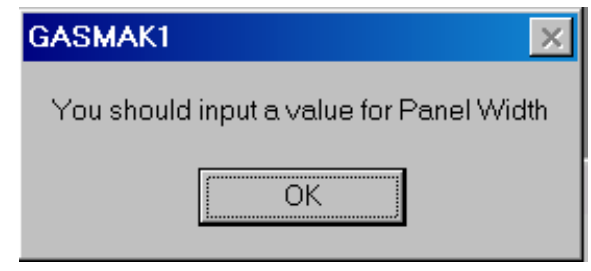

Figure 35: Error Message Box for GASMAK2 Model (2)

\subsection{GASMAK2 Model Discussion}

The GASMAK2 model gives a quick visual representations (Figure 36 and Figure 37) of model results, depicting the gas emission rate at various times of mining activities and the emitted gas volume as a function of project time.

\subsubsection{GASMAK2 Model Example Output Characteristic}

Figure 36 is an illustration of a GASMAK2 model output graph. From a profile of methane emission rate versus time one can see that there is a characteristic decline curve for gas 


\section{Gas Emission Rate}

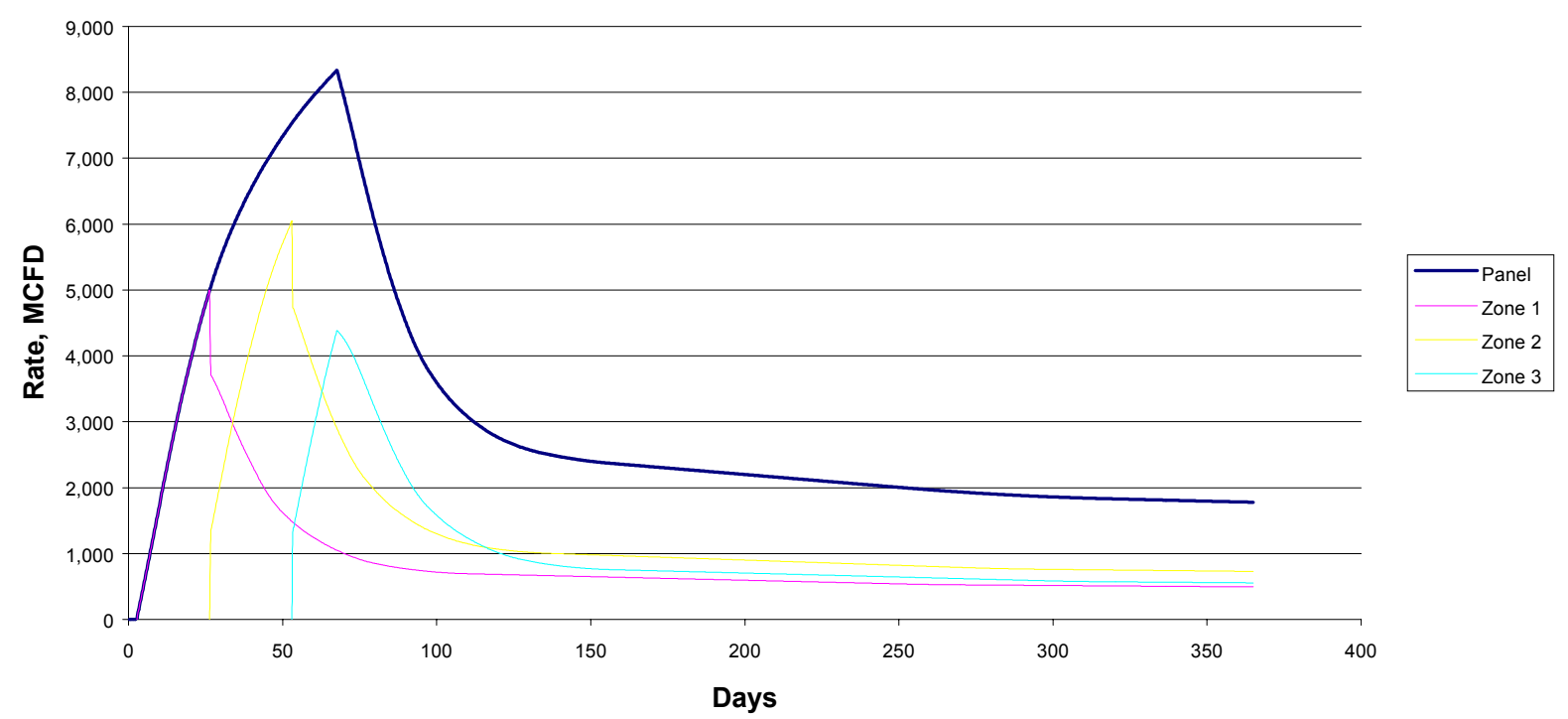

Figure 36: Gas Emission Rate Chart for GASMAK2 Model

emission rates follows the exponential pattern established by Airey. The reason for the early growth of the curve characteristic is that during the early stages of production, methane emission rates increase while strata subsides and fractures followed by a peak in methane emission rate when equilibrium is reached and then a long asymptotic decline. An adequate period of production is necessary in the beginning to establish the equilibrium decline pattern. As for the decline side of the curve, it may be disturbed somewhat if the production from the subject well is interfered with by adjacent wells. This curve can be used to fit the gas emission rate versus time data of production properties.

The rapid drop from the peak and the nonzero start of each zone is an artifact of the manner in which gob wells work and the mining process that creates the gas flow. Gob wells produce nothing until they are undermined and the strata that they penetrate are subsequently deformed. After mining, they start producing gas immediately, because their influence extends 
some distance into the previously created gob area. GASMAK2 accounts for this by assigning a portion of the previous well's zone of influence to the newly active zone as each gob well us undermined. The last zone, having no such gob area transfer, shows no such decline.

Each coal has a characteristic "desorption time" that includes the time required for methane molecules to desorb off the coal surface and diffuse through the coal into the cleat system. The coal's sorption time can vary from less than one to over 300 days depending on coal composition, cleat spacing, and reservoir pressure. The rate at which methane desorbs and diffuses determines the stage in the coal mining and utilization process at which the methane is emitted. A coal with a short sorption time of one or two days, for example, will emit most of its methane during mining operations, while a coal with a long sorption time of 100-200 days will emit much of its methane during post mining coal processing.

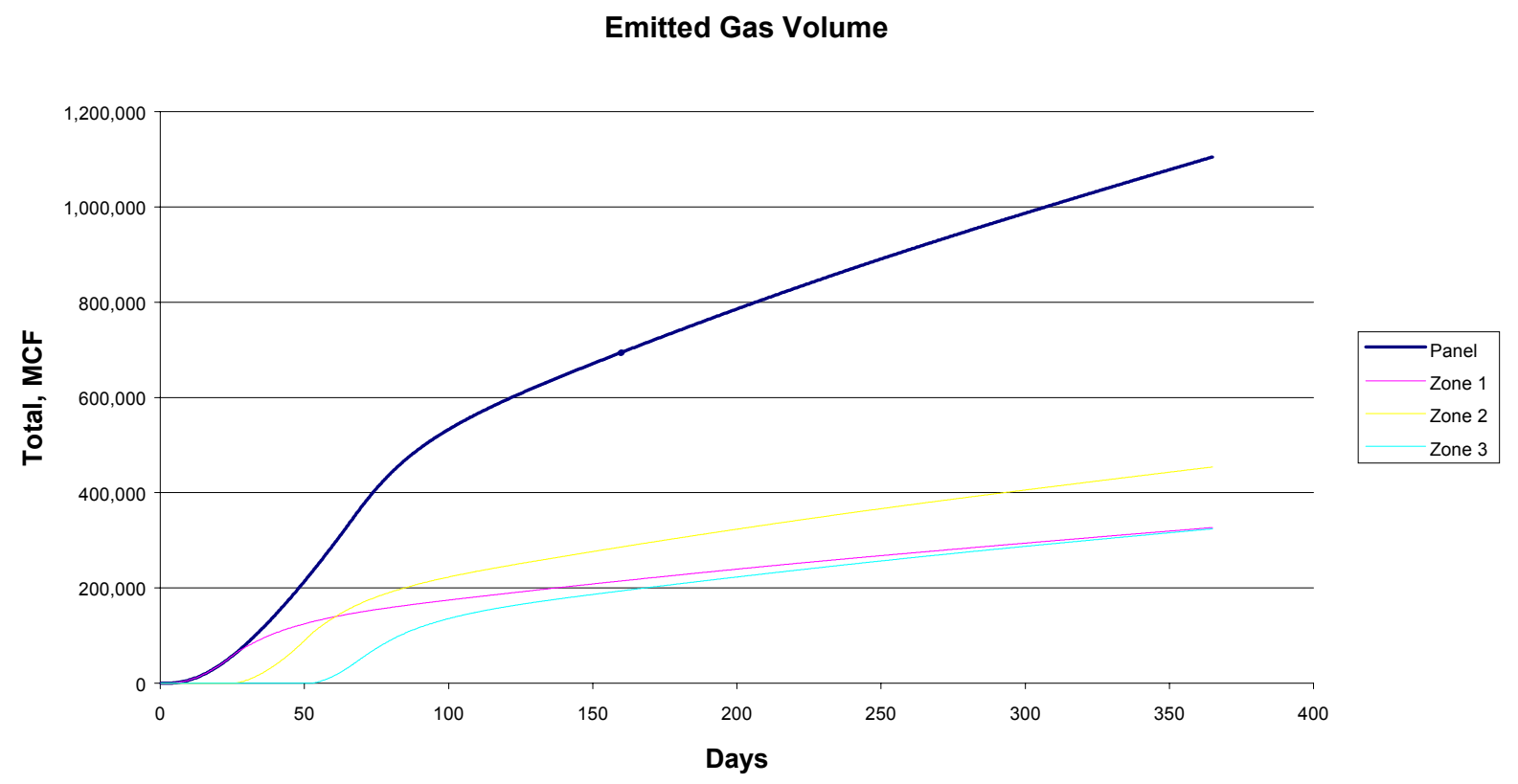

Figure 37: Total Gas Emission Volumes Chart for GASMAK2 Model 
Figure 37 is an example of GASMAK2 model output chart. The profile is same as the one from standard Airey curve (refer to Figure 7, chapter 3).

\subsubsection{Comparison With Other Models}

GASMAK2 model has been tested and validated against two other gas prediction models, they are the Australia Lunagas model (refer to chapter 2) and the CFD (Computational Fluid Dynamics) model. The output charts predicted by these two models are shown in Figure 38 and Figure 39. The knowledge and quantitative information about the two models are very limited. Further study is needed to improve the understanding of the difference between these models. However, the profile comparison at this stage is good.

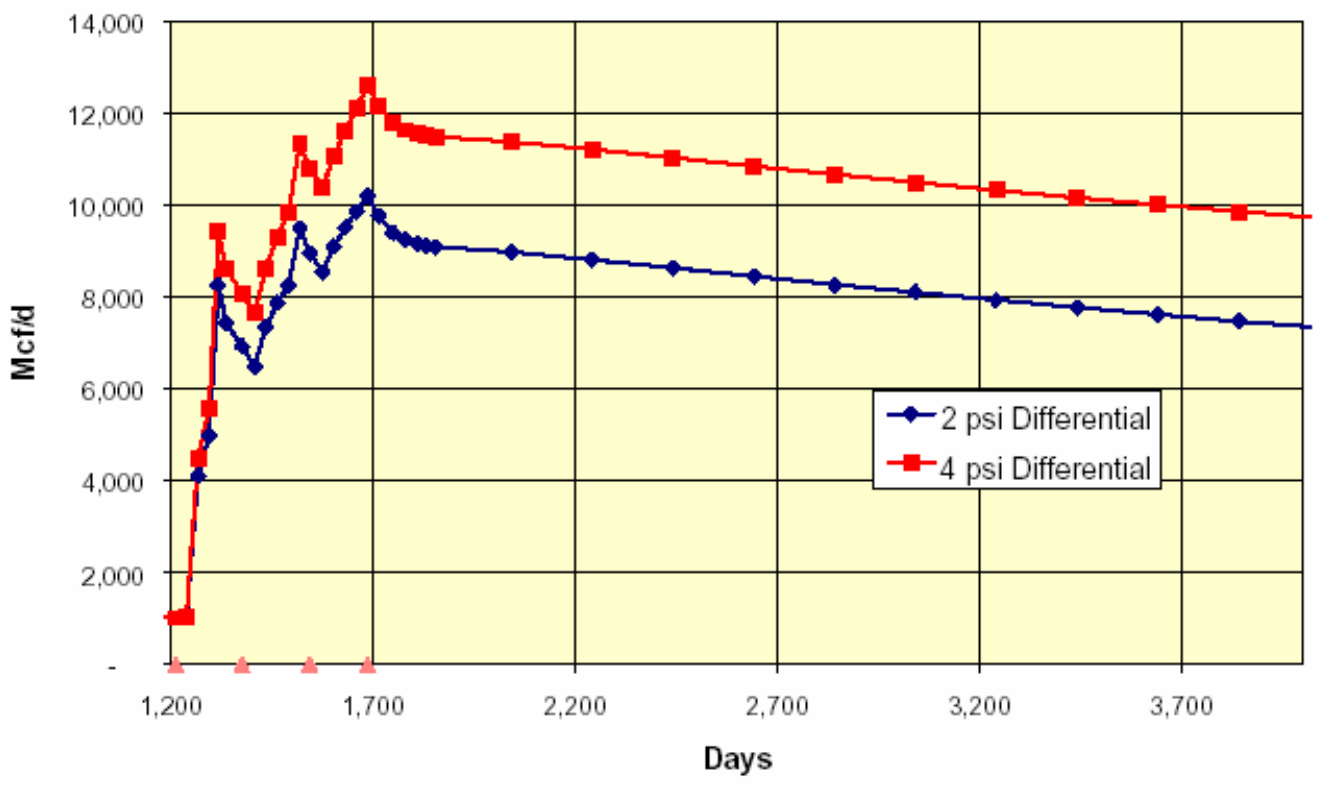

Figure 38: Total Methane Produced from 16 Gob Wells in 3 Panels (Australia Model) 


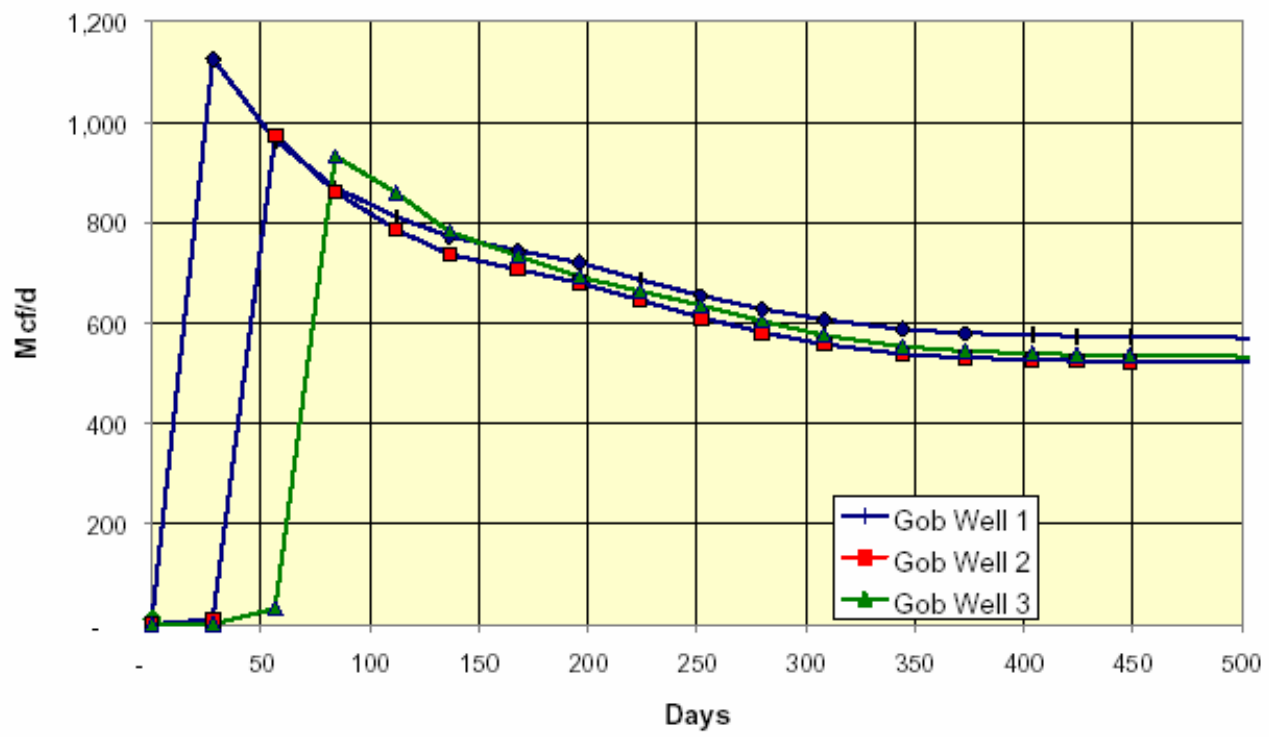

Figure 39: Predicted Gob Well Production Rates from CFD Model

(from Coal mine methane resources estimation and reserve evaluation)

The CFD model tracks material balances and uses the storage and flow characteristics of methane in coal, as well as other reservoir rocks, to provide a production forecast for a given recovery technique. This model uses numerical techniques to predict the gas emission rate into roadways or production into wellbores. Figure 39 shows the predicted production rates for three gob wells drilled into a longwall panel gob area.

When the GASMAK2 model was verified with the above two models, in the comparison with the output profiles, it can be seen that the predicted profiles by GASMAK2 model are in good agreement with the other models. The gas emission rate profiles predicted by GASMAK2 model were very close to those predicted by the numerical model and the statistical model. The curves have the same shape. The gas emission rates for these three model graphs are somewhat different. Several possible reasons for this difference include, geological conditions and mining technology. The geological conditions may include stratum, structure, thickness and structure 
characteristics of coal seams, gas content, gas pressure and drainage ability. Mining technology difference may include driving methods, working face size, and advance rate.

\subsection{Hardware and Software Requirements}

The computer program for the GASMAK2 model has been developed on a standard 586 computer. For general use, the recommended system configuration to use this program is Microsoft Windows 98 or later on a personal computer with a Pentium III processor, 128 megabytes (MB) of RAM, 10G Hard disk space and super VGA (800 x 600) or higher-resolution monitor with 256 colors. Also, Microsoft Visual Basic 6.0 compiler, Microsoft Excel 2000 and Microsoft Access 2000 are required to run the program. 


\section{Chapter 5 Summary}

The GASMAK2 model had the development of a Windows based empirical model of methane emissions for Gob well as its goal. It is 'empirical' because the methods and principles involved are based on observation and experiment. It was successful in the meeting its initial major goals, but much remains to be expanded and improved. The main objective - development of a Windows-based model for longwall gob gas emission - was achieved.

The GASMAK2 model is capable of quantifying the emission changes over time in longwall gob areas. The flow of methane gas from a coal bed that is being actively mined is very difficult to measure accurately; it must be predicted from the known properties of the bed. The GASMAK2 does not imulate the fundamental concepts governing the transport of gases through coal beds. However, it is an excellent approximation. Reasonable evaluation of the methane in a coal mine depends on a knowledge of production rate through time, and the use of this model in a good experimental program should clearly indicate what future developments are needed for methane control.

The strengths and successes of this GASMAK2 model in general include:

- The GASMAK2 model utilizes the convenience features of Windows such as a pointand-click Windows-based user interface, onboard help files, input database, and automatic final chart. This program is user friendly, intuitive, and easy to use;

- The GASMAK2 model is fast, and it requires simple input data; it represents a substantial increase in the efficiency of the original GASMAK model.

- The GASMAK2 model is simple to understand and may be easily adapted to existing gas emission estimates; 
- Comparison computations measurements with other models prove shows a good match, and it accurately reflects gob gas emission;

- This model can be used to predict future emission related to mine expansion.

The weaknesses of this approach are:

- Initial data is required to use the GASMAK2;

- Between adjacent sites variability may be high, and much of the variability cannot be accounted for in the GASMAK2 model.

- The model would benefit if mining rates could be made variable over a project life.

The GASMAK2 model provides user a useful tool for visualizing, assessing and designing methane control needs. Because the output is based on empirical input, it does not rely on reservoir properties. As with any computer model, the accuracy of the output will depend upon the care taken with obtaining the input data. The more reliable the input data, the better the quality of the resulting output. 


\section{Chapter 6 Conclusions and Suggestions for Further Work}

\subsection{Conclusions}

The GASMAK model was an empirical model that was initially reported in 1997 by Dr. Lloyd M. English. Here it is further developed as a Windows based program - GASMAK2 model by the author for his master thesis.

This thesis discusses the development of an empirical model that describes the generation of methane for longwall gob areas. The goal for the development of this model is to make it more useful as an aid in the determination of the number, size and location of vertical gob wells or other methane control application that are needed for gob gas control.

The research presented in this thesis addresses the problems of empirical model development for assessing gob gas control requirements. Several contributions toward the resolution of the problems have been made.

The design of a user interface is the crux of the development of any software system. In recent years, software projects have been devoting more to the design of the interface than the actual underlying application code. This may be a sign of a competitive market, where the users are demanding more sophisticated software interfaces, and frequently understand less about the problem itself.

The original GASMAK model is written in the Fortran Programming Language and it produced an output data table, but it must be loaded into a spreadsheet for visualization. The user must also prepare an input table in an appropriate DOS-based format for the GASMAK model to read in advance. The GASMAK2 model was developed specifically to make users this model for the convenience of the user. The GASMAK2 program offers a user-friendly interface, generates the spreadsheet, and creates the charts automatically. There are some new features in 
the GASMAK2 model for its input database, help file system and automation. It is a substantial enhancement to the original GASMAK model. A significant advantage of GASMAK2 model is that only one of the input data is needed to be measured, i.e. data points being input for emission curve, and which may be obtained from experiment. If there are no experiments for these data, the user can obtain historical data from same region or similar geological conditions. Comparisons of profiles have demonstrated that the profiles predicted by using GASMAK2 model are, in general, in good agreement with those predicted by other models. They have same shape profiles.

However, the GASMAK2 model is by no means completely developed. The remainder of this chapter presents some future directions for improving this GASMAK2 model.

\subsection{The Work Needed for Improving the Model}

Although the work carried out in this thesis has a substantial improvement to GASMAK model, it has revealed many promising areas of further work in GASMAK2 model development and some potential technical improvements would make this model even more useful. A few improvements worthy of further consideration can be briefly summarized as follows:

- Developing of nonlinear regression for determining the rate of methane emission. The GASMAK2 model is based on the Airey equation. Sometimes if a known geological anomaly were associated with a panel under construction, the mathematics theory of Newton or Conjugate method could be used to adjust the Airey equation accordingly.

- Modifying of GASMAK2 model for room-and-pillar operations. Currently, underground coal production in the U.S. is split almost 50-50 between large longwall 
mines and smaller room-and-pillar mines. Right now, the GASMAK2 model is designed for longwall mining operations. A modified model could be used to make emission estimates for full extraction room-and-pillar mining operations.

- Automatic drawing of panel layout graph using AutoCAD Development System (ADS) as an interactive graphical programming environment. ADS is a compiledlanguage program environment for developing AutoCAD applications, and an improved GASMAK2 model could offer the user a graphic map including gob well information, well number, size, location, and more, within panel.

- Developing of the "Query" tool for total methane volumes, peak emission rates value, time period captured by each well, and more. A typical search of the database is to help users find model results more easily. This modification can be made using SQL "Structured Query Language".

- Modeling a block of panels. GASMAK2 was developed for single longwall panel gas emissions. All the coal mines using longwall mining systems use blocks of panels. The model for a block of panels is even more practical.

- Enabling the use of varying coal production rates or the inclusion of down-time.

It should be noted that the above suggestions for further model development would be enhanced by user-input.

Outputs from this GASMAK2 model are used to design gas drainage technologies, and gas wells drilled from the surface. Because the volume of gas that is liberated during mining for a given period is also available, developers of coal mine can use this data to determine the specific emissions that must be controlled. They may also used for precise gas production 
predictions and the assessment of gas conditions necessary for planning commercial gas operations. 


\section{References}

Airey, E. M., 1968, Gas Emission from Broken Coal: An Experimental and Theoretical Investigation. International Journal of Rock mechanics and Mining Science, 5, pp. 475-494.

Boyer, C.M., [et al.], Kruger, D., 1990, Methane Emissions from Coal Mining: issues and opportunities for reduction, ICF Resources Incorporated; U.S. Environmental Protection Agency, pp.13-18.

Coal Mine and Coal Seam Gas Specialists, http://members.ozemail.com.au/ lunagas/

Creedy, D. P., Saghafi, A., \& Lama, R., 1997, Gas Control in Underground Coal Mining. London, IEA Coal Research, pp.3-34.

Curl, S. J., 1978, Methane Prediction in Coal Mines, London, IEA Coal Research, pp.6-41.

English, L. M., 1999, Empirical Model for Assessing Gob Gas Control Requirements, Society for Mining, Metallurgy, and Exploration, Inc., transactions 1999, Vol. 306, pp.5-10.

English, L. M., 1997, Gob Gas: A Synthesis of the Literature and an Empirical Model, Ph.D. Dissertation, West Virginia University.

Identifying Opportunities for Methane Recovery at U.S. Coal Mines: Draft Profiles of Selected Gassy Underground Coal Mines - U.S. EPA Office of Air and Radiation, September 1997.

Jacobson, R., 1999, Microsoft Excel 2000 VBA Foundation (Chinese Version).

King, G. R., \& Ertekin, T. M., 1989, A survey of Mathematical Models Related to Methane Production from Coal Seams, Part I: Empirical \& Equilibrium Sorption Models. In University of 
Alabama(Ed.), Proceeding of the 1989 Coalbed Methane Symposium, The University of Alabama/Tuscaloosa, April 17-20, pp125-138.

King, G. R., \& Ertekin, T. M., 1989, A survey of Mathematical Models Related to Methane Production from Coal Seams, Part II: Non-Equilibrium Sorption Models. In University of Alabama(Ed.), Proceeding of the 1989 Coalbed Methane Symposium, The University of Alabama/Tuscaloosa, April 17-20, pp139-155.

Kruger D., 1990, Methane Emissions From Coal Mining: Issues and Opportunities for Reduction, U.S. Environmental Protection Agency, p2.

McPherson, M. J., 1999, Mine Health and Safety, Virginia Tech. Section 12.2.2.1. Diffusion and Darcy flow.

Mutmansky, J. M., 1999, Guidebook on Coalbed Methane Drainage for Underground Coal Mines, U.S environmental Protection Agency (USEPA), Pennsylvania State University, pp2-8.

Neelamkavil 1987, Computer simulation and modeling, John Wiley \& Sons, pp30.

Pilcher, R. C., Collings R. C., \& Marshall, J. S., 2000, Overview of Practices and Models for Coal Mine Methane Resources Estimation and Reserve Evaluation. Second International Methane Mitigation Conference, Novosibirsk, Russia, June. 2000.

Rogers, R. E., 1994, Coalbed Methane: Principles and Practice. Mississippi State University, pp.148-195.

Saulsberry, J. L., Schafer, P. S., \& Schraufnagel R. A., 1996, A Guide to Coalbed Methane Reservoir Engineering, Gas Research Institute, Chicago, Illinois, U.S.A., pp4.26-4.28

WWWebster Dictionary: http://www.m-w.com/cgi-bin/dictionary. 
Appendix 
Appendix A Output Spreadsheet for GASMAK2 Model

\begin{tabular}{|c|c|c|c|c|c|c|c|c|c|}
\hline Days & Face & Panel Rate & Zone 1 Rate & Zone 2 Rate & Zone 3 Rate & Panel Cum. Gas & Zone 1 Gas & Zone 2 Gas & Zone 3 Gas \\
\hline 0.3 & 25 & 0 & 0 & 0 & 0 & 0 & 0 & 0 & 0 \\
\hline 0.7 & 50 & 0 & 0 & 0 & 0 & 0 & 0 & 0 & 0 \\
\hline 1.0 & 75 & 0 & 0 & 0 & 0 & 0 & 0 & 0 & 0 \\
\hline 1.3 & 100 & 0 & 0 & 0 & 0 & 0 & 0 & 0 & 0 \\
\hline 1.7 & 125 & 0 & 0 & 0 & 0 & 0 & 0 & 0 & 0 \\
\hline 2.0 & 150 & 0 & 0 & 0 & 0 & 0 & 0 & 0 & 0 \\
\hline 2.3 & 175 & 0 & 0 & 0 & 0 & 0 & 0 & 0 & 0 \\
\hline 2.7 & 200 & 0 & 0 & 0 & 0 & 0 & 0 & 0 & 0 \\
\hline 3.0 & 225 & 74 & 74 & 0 & 0 & 25 & 25 & 0 & 0 \\
\hline 3.3 & 250 & 148 & 148 & 0 & 0 & 74 & 74 & 0 & 0 \\
\hline 3.7 & 275 & 223 & 223 & 0 & 0 & 148 & 148 & 0 & 0 \\
\hline 4.0 & 300 & 299 & 299 & 0 & 0 & 248 & 248 & 0 & 0 \\
\hline 4.3 & 325 & 376 & 376 & 0 & 0 & 373 & 373 & 0 & 0 \\
\hline 4.7 & 350 & 453 & 453 & 0 & 0 & 524 & 524 & 0 & 0 \\
\hline 5.0 & 375 & 531 & 531 & 0 & 0 & 701 & 701 & 0 & 0 \\
\hline 5.3 & 400 & 609 & 609 & 0 & 0 & 904 & 904 & 0 & 0 \\
\hline 5.7 & 425 & 688 & 688 & 0 & 0 & 1134 & 1134 & 0 & 0 \\
\hline 6.0 & 450 & 766 & 766 & 0 & 0 & 1389 & 1389 & 0 & 0 \\
\hline 6.3 & 475 & 845 & 845 & 0 & 0 & 1671 & 1671 & 0 & 0 \\
\hline 6.7 & 500 & 925 & 925 & 0 & 0 & 1979 & 1979 & 0 & 0 \\
\hline 7.0 & 525 & 1004 & 1004 & 0 & 0 & 2314 & 2314 & 0 & 0 \\
\hline 7.3 & 550 & 1084 & 1084 & 0 & 0 & 2675 & 2675 & 0 & 0 \\
\hline 7.7 & 575 & 1164 & 1164 & 0 & 0 & 3063 & 3063 & 0 & 0 \\
\hline 8.0 & 600 & 1244 & 1244 & 0 & 0 & 3477 & 3477 & 0 & 0 \\
\hline 8.3 & 625 & 1323 & 1323 & 0 & 0 & 3919 & 3919 & 0 & 0 \\
\hline 8.7 & 650 & 1403 & 1403 & 0 & 0 & 4386 & 4386 & 0 & 0 \\
\hline 9.0 & 675 & 1483 & 1483 & 0 & 0 & 4881 & 4881 & 0 & 0 \\
\hline 9.3 & 700 & 1562 & 1562 & 0 & 0 & 5401 & 5401 & 0 & 0 \\
\hline 9.7 & 725 & 1642 & 1642 & 0 & 0 & 5948 & 5948 & 0 & 0 \\
\hline 10.0 & 750 & 1721 & 1721 & 0 & 0 & 6522 & 6522 & 0 & 0 \\
\hline \begin{tabular}{|l|}
10.3 \\
\end{tabular} & 775 & 1800 & 1800 & 0 & 0 & 7122 & 7122 & 0 & 0 \\
\hline \begin{tabular}{|l|}
10.7 \\
\end{tabular} & 800 & 1879 & 1879 & 0 & 0 & 7749 & 7749 & 0 & 0 \\
\hline 11.0 & 825 & 1958 & 1958 & 0 & 0 & 8401 & 8401 & 0 & 0 \\
\hline \begin{tabular}{|l|}
11.3 \\
\end{tabular} & 850 & 2036 & 2036 & 0 & 0 & 9080 & 9080 & 0 & 0 \\
\hline \begin{tabular}{|l|}
11.7 \\
\end{tabular} & 875 & 2114 & 2114 & 0 & 0 & 9785 & 9785 & 0 & 0 \\
\hline 12.0 & 900 & 2192 & 2192 & 0 & 0 & 10516 & 10516 & 0 & 0 \\
\hline \begin{tabular}{|l|}
12.3 \\
\end{tabular} & 925 & 2269 & 2269 & 0 & 0 & 11272 & 11272 & 0 & 0 \\
\hline \begin{tabular}{|l|}
12.7 \\
\end{tabular} & 950 & 2346 & 2346 & 0 & 0 & 12054 & 12054 & 0 & 0 \\
\hline 13.0 & 975 & 2423 & 2423 & 0 & 0 & 12862 & 12862 & 0 & 0 \\
\hline 13.3 & 1000 & 2499 & 2499 & 0 & 0 & 13695 & 13695 & 0 & 0 \\
\hline \begin{tabular}{|l|}
13.7 \\
\end{tabular} & 1025 & 2575 & 2575 & 0 & 0 & 14553 & 14553 & 0 & 0 \\
\hline 14.0 & 1050 & 2650 & 2650 & 0 & 0 & 15437 & 15437 & 0 & 0 \\
\hline 14.3 & 1075 & 2725 & 2725 & 0 & 0 & 16345 & 16345 & 0 & 0 \\
\hline \begin{tabular}{|l|}
14.7 \\
\end{tabular} & 1100 & 2799 & 2799 & 0 & 0 & 17278 & 17278 & 0 & 0 \\
\hline 15.0 & 1125 & 2873 & 2873 & 0 & 0 & 18236 & 18236 & 0 & 0 \\
\hline 15.3 & 1150 & 2946 & 2946 & 0 & 0 & 19218 & 19218 & 0 & 0 \\
\hline \begin{tabular}{|l|}
15.7 \\
\end{tabular} & 1175 & 3018 & 3018 & 0 & 0 & 20224 & 20224 & 0 & 0 \\
\hline 16.0 & 1200 & 3090 & 3090 & 0 & 0 & 21254 & 21254 & 0 & 0 \\
\hline 16.3 & 1225 & 3161 & 3161 & 0 & 0 & 22308 & 22308 & 0 & 0 \\
\hline \begin{tabular}{|l|}
16.7 \\
\end{tabular} & 1250 & 3232 & 3232 & 0 & 0 & 23385 & 23385 & 0 & 0 \\
\hline 17.0 & 1275 & 3302 & 3302 & 0 & 0 & 24485 & 24485 & 0 & 0 \\
\hline 17.3 & 1300 & 3371 & 3371 & 0 & 0 & 25609 & 25609 & 0 & 0 \\
\hline \begin{tabular}{|l|}
17.7 \\
\end{tabular} & 1325 & 3439 & 3439 & 0 & 0 & 26755 & 26755 & 0 & 0 \\
\hline 18.0 & 1350 & 3507 & 3507 & 0 & 0 & 27924 & 27924 & 0 & 0 \\
\hline \begin{tabular}{|l|}
18.3 \\
\end{tabular} & 1375 & 3574 & 3574 & 0 & 0 & 29116 & 29116 & 0 & 0 \\
\hline \begin{tabular}{|l|}
18.7 \\
\end{tabular} & 1400 & 3640 & 3640 & 0 & 0 & 30329 & 30329 & 0 & 0 \\
\hline 19.0 & 1425 & 3706 & 3706 & 0 & 0 & 31565 & 31565 & 0 & 0 \\
\hline
\end{tabular}




\begin{tabular}{|c|c|c|c|c|c|c|c|c|c|}
\hline 19.3 & 1450 & 3771 & 3771 & 0 & 0 & 32822 & 32822 & 0 & 0 \\
\hline 19.7 & 1475 & 3835 & 3835 & 0 & 0 & 34100 & 34100 & 0 & 0 \\
\hline 20.0 & 1500 & 3899 & 3899 & 0 & 0 & 35400 & 35400 & 0 & 0 \\
\hline 20.3 & 1525 & 3962 & 3962 & 0 & 0 & 36720 & 36720 & 0 & 0 \\
\hline 20.7 & 1550 & 4024 & 4024 & 0 & 0 & 38062 & 38062 & 0 & 0 \\
\hline 21.0 & 1575 & 4086 & 4086 & 0 & 0 & 39424 & 39424 & 0 & 0 \\
\hline 21.3 & 1600 & 4147 & 4147 & 0 & 0 & 40806 & 40806 & 0 & 0 \\
\hline 21.7 & 1625 & 4208 & 4208 & 0 & 0 & 42209 & 42209 & 0 & 0 \\
\hline 22.0 & 1650 & 4268 & 4268 & 0 & 0 & 43631 & 43631 & 0 & 0 \\
\hline 22.3 & 1675 & 4327 & 4327 & 0 & 0 & 45074 & 45074 & 0 & 0 \\
\hline 22.7 & 1700 & 4386 & 4386 & 0 & 0 & 46536 & 46536 & 0 & 0 \\
\hline 23.0 & 1725 & 4444 & 4444 & 0 & 0 & 48017 & 48017 & 0 & 0 \\
\hline 23.3 & 1750 & 4502 & 4502 & 0 & 0 & 49518 & 49518 & 0 & 0 \\
\hline 23.7 & 1775 & 4559 & 4559 & 0 & 0 & 51038 & 51038 & 0 & 0 \\
\hline 24.0 & 1800 & 4616 & 4616 & 0 & 0 & 52576 & 52576 & 0 & 0 \\
\hline 24.3 & 1825 & 4672 & 4672 & 0 & 0 & 54133 & 54133 & 0 & 0 \\
\hline 24.7 & 1850 & 4727 & 4727 & 0 & 0 & 55709 & 55709 & 0 & 0 \\
\hline 25.0 & 1875 & 4782 & 4782 & 0 & 0 & 57303 & 57303 & 0 & 0 \\
\hline 25.3 & 1900 & 4836 & 4836 & 0 & 0 & 58915 & 58915 & 0 & 0 \\
\hline 25.7 & 1925 & 4889 & 4889 & 0 & 0 & 60544 & 60544 & 0 & 0 \\
\hline 26.0 & 1950 & 4942 & 4942 & 0 & 0 & 62192 & 62192 & 0 & 0 \\
\hline 26.3 & 1975 & 4994 & 4994 & 0 & 0 & 63856 & 63856 & 0 & 0 \\
\hline 26.7 & 2000 & 5045 & 3721 & 1323 & 0 & 65538 & 65097 & 441 & 0 \\
\hline 27.0 & 2025 & 5095 & 3692 & 1403 & 0 & 67236 & 66327 & 909 & 0 \\
\hline 27.3 & 2050 & 5144 & 3661 & 1483 & 0 & 68951 & 67548 & 1403 & 0 \\
\hline 27.7 & 2075 & 5193 & 3630 & 1562 & 0 & 70682 & 68758 & 1924 & 0 \\
\hline 28.0 & 2100 & 5240 & 3599 & 1642 & 0 & 72428 & 69957 & 2471 & 0 \\
\hline 28.3 & 2125 & 5287 & 3566 & 1721 & 0 & 74191 & 71146 & 3045 & 0 \\
\hline 28.7 & 2150 & 5333 & 3533 & 1800 & 0 & 75968 & 72324 & 3645 & 0 \\
\hline 29.0 & 2175 & 5378 & 3499 & 1879 & 0 & 77761 & 73490 & 4271 & 0 \\
\hline 29.3 & 2200 & 5423 & 3465 & 1958 & 0 & 79569 & 74645 & 4924 & 0 \\
\hline 29.7 & 2225 & 5466 & 3430 & 2036 & 0 & 81391 & 75788 & 5603 & 0 \\
\hline 30.0 & 2250 & 5509 & 3394 & 2114 & 0 & 83227 & 76920 & 6307 & 0 \\
\hline 30.3 & 2275 & 5551 & 3359 & 2192 & 0 & 85077 & 78039 & 7038 & 0 \\
\hline 30.7 & 2300 & 5592 & 3322 & 2269 & 0 & 86941 & 79146 & 7795 & 0 \\
\hline 31.0 & 2325 & 5632 & 3285 & 2346 & 0 & 88818 & 80242 & 8577 & 0 \\
\hline 31.3 & 2350 & 5671 & 3248 & 2423 & 0 & 90709 & 81324 & 9384 & 0 \\
\hline 31.7 & 2375 & 5710 & 3210 & 2499 & 0 & 92612 & 82394 & 10218 & 0 \\
\hline 32.0 & 2400 & 5748 & 3173 & 2575 & 0 & 94528 & 83452 & 11076 & 0 \\
\hline 32.3 & 2425 & 5786 & 3135 & 2650 & 0 & 96456 & 84497 & 11959 & 0 \\
\hline 32.7 & 2450 & 5823 & 3098 & 2725 & 0 & 98397 & 85530 & 12868 & 0 \\
\hline 33.0 & 2475 & 5860 & 3061 & 2799 & 0 & 100351 & 86550 & 13801 & 0 \\
\hline 33.3 & 2500 & 5897 & 3024 & 2873 & 0 & 102316 & 87558 & 14759 & 0 \\
\hline 33.7 & 2525 & 5933 & 2987 & 2946 & 0 & 104294 & 88554 & 15740 & 0 \\
\hline 34.0 & 2550 & 5969 & 2951 & 3018 & 0 & 106284 & 89537 & 16747 & 0 \\
\hline 34.3 & 2575 & 6005 & 2915 & 3090 & 0 & 108285 & 90509 & 17777 & 0 \\
\hline 34.7 & 2600 & 6040 & 2879 & 3161 & 0 & 110299 & 91468 & 18830 & 0 \\
\hline 35.0 & 2625 & 6075 & 2843 & 3232 & 0 & 112324 & 92416 & 19907 & 0 \\
\hline 35.3 & 2650 & 6110 & 2808 & 3302 & 0 & 114360 & 93352 & 21008 & 0 \\
\hline 35.7 & 2675 & 6144 & 2773 & 3371 & 0 & 116408 & 94276 & 22132 & 0 \\
\hline 36.0 & 2700 & 6178 & 2738 & 3439 & 0 & 118467 & 95189 & 23278 & 0 \\
\hline 36.3 & 2725 & 6211 & 2704 & 3507 & 0 & 120538 & 96091 & 24447 & 0 \\
\hline 36.7 & 2750 & 6244 & 2670 & 3574 & 0 & 122619 & 96981 & 25638 & 0 \\
\hline 37.0 & 2775 & 6277 & 2637 & 3640 & 0 & 124711 & 97860 & 26852 & 0 \\
\hline 37.3 & 2800 & 6310 & 2603 & 3706 & 0 & 126815 & 98727 & 28087 & 0 \\
\hline 37.7 & 2825 & 6342 & 2571 & 3771 & 0 & 128928 & 99584 & 29344 & 0 \\
\hline 38.0 & 2850 & 6373 & 2538 & 3835 & 0 & 131053 & 100430 & 30623 & 0 \\
\hline 38.3 & 2875 & 6405 & 2506 & 3899 & 0 & 133188 & 101266 & 31922 & 0 \\
\hline 38.7 & 2900 & 6436 & 2474 & 3962 & 0 & 135333 & 102090 & 33243 & 0 \\
\hline
\end{tabular}




\begin{tabular}{|c|c|c|c|c|c|c|c|c|c|}
\hline 39.0 & 2925 & 6466 & 2442 & 4024 & 0 & 137489 & 102904 & 34584 & 0 \\
\hline 39.3 & 2950 & 6497 & 2411 & 4086 & 0 & 139654 & 103708 & 35946 & 0 \\
\hline 39.7 & 2975 & 6527 & 2379 & 4147 & 0 & 141830 & 104501 & 37329 & 0 \\
\hline 40.0 & 3000 & 6556 & 2348 & 4208 & 0 & 144015 & 105284 & 38731 & 0 \\
\hline 40.3 & 3025 & 6585 & 2318 & 4268 & 0 & 146210 & 106056 & 40154 & 0 \\
\hline 40.7 & 3050 & 6614 & 2287 & 4327 & 0 & 148415 & 106819 & 41596 & 0 \\
\hline 41.0 & 3075 & 6643 & 2257 & 4386 & 0 & 150629 & 107571 & 43058 & 0 \\
\hline 41.3 & 3100 & 6671 & 2226 & 4444 & 0 & 152853 & 108313 & 44540 & 0 \\
\hline 41.7 & 3125 & 6699 & 2197 & 4502 & 0 & 155086 & 109045 & 46041 & 0 \\
\hline 42.0 & 3150 & 6726 & 2167 & 4559 & 0 & 157328 & 109767 & 47560 & 0 \\
\hline 42.3 & 3175 & 6754 & 2138 & 4616 & 0 & 159579 & 110480 & 49099 & 0 \\
\hline 42.7 & 3200 & 6781 & 2109 & 4672 & 0 & 161840 & 111183 & 50656 & 0 \\
\hline 43.0 & 3225 & 6808 & 2081 & 4727 & 0 & 164109 & 111877 & 52232 & 0 \\
\hline 43.3 & 3250 & 6835 & 2053 & 4782 & 0 & 166388 & 112561 & 53825 & 0 \\
\hline 43.7 & 3275 & 6861 & 2026 & 4836 & 0 & 168675 & 113237 & 55437 & 0 \\
\hline 44.0 & 3300 & 6888 & 1999 & 4889 & 0 & 170971 & 113903 & 57067 & 0 \\
\hline 44.3 & 3325 & 6914 & 1972 & 4942 & 0 & 173276 & 114561 & 58714 & 0 \\
\hline 44.7 & 3350 & 6940 & 1947 & 4994 & 0 & 175589 & 115209 & 60379 & 0 \\
\hline 45.0 & 3375 & 6966 & 1922 & 5045 & 0 & 177911 & 115850 & 62060 & 0 \\
\hline 45.3 & 3400 & 6992 & 1897 & 5095 & 0 & 180242 & 116482 & 63759 & 0 \\
\hline 45.7 & 3425 & 7017 & 1873 & 5144 & 0 & 182581 & 117107 & 65473 & 0 \\
\hline 46.0 & 3450 & 7043 & 1850 & 5193 & 0 & 184928 & 117723 & 67204 & 0 \\
\hline 46.3 & 3475 & 7068 & 1827 & 5240 & 0 & 187284 & 118332 & 68951 & 0 \\
\hline 46.7 & 3500 & 7093 & 1805 & 5287 & 0 & 189649 & 118934 & 70713 & 0 \\
\hline 47.0 & 3525 & 7117 & 1784 & 5333 & 0 & 192021 & 119529 & 72491 & 0 \\
\hline 47.3 & 3550 & 7142 & 1764 & 5378 & 0 & 194402 & 120117 & 74284 & 0 \\
\hline 47.7 & 3575 & 7166 & 1743 & 5423 & 0 & 196790 & 120698 & 76091 & 0 \\
\hline 48.0 & 3600 & 7190 & 1724 & 5466 & 0 & 199187 & 121273 & 77913 & 0 \\
\hline 48.3 & 3625 & 7214 & 1705 & 5509 & 0 & 201592 & 121841 & 79750 & 0 \\
\hline 48.7 & 3650 & 7238 & 1687 & 5551 & 0 & 204005 & 122403 & 81600 & 0 \\
\hline 49.0 & 3675 & 7261 & 1670 & 5592 & 0 & 206425 & 122960 & 83464 & 0 \\
\hline 49.3 & 3700 & 7285 & 1653 & 5632 & 0 & 208853 & 123511 & 85341 & 0 \\
\hline 49.7 & 3725 & 7308 & 1637 & 5671 & 0 & 211289 & 124057 & 87231 & 0 \\
\hline 50.0 & 3750 & 7331 & 1621 & 5710 & 0 & 213733 & 124597 & 89135 & 0 \\
\hline 50.3 & 3775 & 7354 & 1606 & 5748 & 0 & 216184 & 125132 & 91050 & 0 \\
\hline 50.7 & 3800 & 7376 & 1591 & 5786 & 0 & 218643 & 125663 & 92979 & 0 \\
\hline 51.0 & 3825 & 7399 & 1576 & 5823 & 0 & 221109 & 126188 & 94920 & 0 \\
\hline 51.3 & 3850 & 7421 & 1561 & 5860 & 0 & 223583 & 126708 & 96873 & 0 \\
\hline 51.7 & 3875 & 7443 & 1546 & 5897 & 0 & 226064 & 127224 & 98839 & 0 \\
\hline 52.0 & 3900 & 7465 & 1532 & 5933 & 0 & 228552 & 127734 & 100817 & 0 \\
\hline 52.3 & 3925 & 7486 & 1517 & 5969 & 0 & 231048 & 128240 & 102806 & 0 \\
\hline 52.7 & 3950 & 7508 & 1503 & 6005 & 0 & 233551 & 128741 & 104808 & 0 \\
\hline 53.0 & 3975 & 7529 & 1489 & 6040 & 0 & 236060 & 129237 & 106821 & 0 \\
\hline 53.3 & 4000 & 7551 & 1476 & 4752 & 1323 & 238577 & 129729 & 108405 & 441 \\
\hline 53.7 & 4025 & 7572 & 1462 & 4706 & 1403 & 241101 & 130217 & 109974 & 909 \\
\hline 54.0 & 4050 & 7593 & 1449 & 4661 & 1483 & 243632 & 130699 & 111527 & 1403 \\
\hline 54.3 & 4075 & 7613 & 1436 & 4615 & 1562 & 246170 & 131178 & 113066 & 1924 \\
\hline 54.7 & 4100 & 7634 & 1423 & 4570 & 1642 & 248715 & 131652 & 114589 & 2471 \\
\hline 55.0 & 4125 & 7655 & 1410 & 4523 & 1721 & 251266 & 132123 & 116097 & 3045 \\
\hline 55.3 & 4150 & 7675 & 1398 & 4477 & 1800 & 253825 & 132588 & 117589 & 3645 \\
\hline 55.7 & 4175 & 7695 & 1386 & 4430 & 1879 & 256390 & 133050 & 119066 & 4271 \\
\hline 56.0 & 4200 & 7715 & 1374 & 4384 & 1958 & 258962 & 133508 & 120527 & 4924 \\
\hline 56.3 & 4225 & 7735 & 1362 & 4337 & 2036 & 261540 & 133962 & 121973 & 5603 \\
\hline 56.7 & 4250 & 7755 & 1350 & 4290 & 2114 & 264125 & 134412 & 123403 & 6307 \\
\hline 57.0 & 4275 & 7774 & 1339 & 4244 & 2192 & 266716 & 134859 & 124817 & 7038 \\
\hline 57.3 & 4300 & 7794 & 1328 & 4197 & 2269 & 269314 & 135301 & 126216 & 7795 \\
\hline 57.7 & 4325 & 7813 & 1317 & 4150 & 2346 & 271918 & 135740 & 127600 & 8577 \\
\hline 58.0 & 4350 & 7832 & 1306 & 4104 & 2423 & 274529 & 136175 & 128968 & 9384 \\
\hline 58.3 & 4375 & 7851 & 1295 & 4057 & 2499 & 277146 & 136607 & 130320 & 10218 \\
\hline
\end{tabular}




\begin{tabular}{|c|c|c|c|c|c|c|c|c|c|}
\hline 58.7 & 4400 & 7870 & 1285 & 4010 & 2575 & 279769 & 137035 & 131657 & 11076 \\
\hline 59.0 & 4425 & 7889 & 1275 & 3964 & 2650 & 282399 & 137460 & 132978 & 11959 \\
\hline 59.3 & 4450 & 7907 & 1265 & 3918 & 2725 & 285034 & 137882 & 134284 & 12868 \\
\hline 59.7 & 4475 & 7926 & 1255 & 3872 & 2799 & 287676 & 138300 & 135575 & 13801 \\
\hline 60.0 & 4500 & 7944 & 1245 & 3826 & 2873 & 290324 & 138715 & 136850 & 14759 \\
\hline 60.3 & 4525 & 7962 & 1236 & 3781 & 2946 & 292978 & 139127 & 138110 & 15740 \\
\hline 60.7 & 4550 & 7980 & 1226 & 3736 & 3018 & 295638 & 139536 & 139355 & 16747 \\
\hline 61.0 & 4575 & 7998 & 1217 & 3691 & 3090 & 298304 & 139942 & 140586 & 17777 \\
\hline 61.3 & 4600 & 8016 & 1208 & 3647 & 3161 & 300975 & 140344 & 141801 & 18830 \\
\hline 61.7 & 4625 & 8033 & 1198 & 3603 & 3232 & 303653 & 140744 & 143002 & 19907 \\
\hline 62.0 & 4650 & 8051 & 1189 & 3560 & 3302 & 306336 & 141140 & 144189 & 21008 \\
\hline 62.3 & 4675 & 8068 & 1180 & 3517 & 3371 & 309025 & 141533 & 145361 & 22132 \\
\hline 62.7 & 4700 & 8085 & 1171 & 3475 & 3439 & 311720 & 141924 & 146520 & 23278 \\
\hline 63.0 & 4725 & 8102 & 1162 & 3433 & 3507 & 314421 & 142311 & 147664 & 24447 \\
\hline 63.3 & 4750 & 8119 & 1153 & 3392 & 3574 & 317127 & 142696 & 148795 & 25638 \\
\hline 63.7 & 4775 & 8136 & 1145 & 3351 & 3640 & 319839 & 143077 & 149912 & 26852 \\
\hline 64.0 & 4800 & 8153 & 1136 & 3311 & 3706 & 322556 & 143456 & 151016 & 28087 \\
\hline 64.3 & 4825 & 8170 & 1128 & 3272 & 3771 & 325280 & 143832 & 152106 & 29344 \\
\hline 64.7 & 4850 & 8187 & 1119 & 3233 & 3835 & 328008 & 144205 & 153184 & 30623 \\
\hline 65.0 & 4875 & 8204 & 1111 & 3194 & 3899 & 330743 & 144575 & 154248 & 31922 \\
\hline 65.3 & 4900 & 8220 & 1103 & 3155 & 3962 & 333483 & 144943 & 155300 & 33243 \\
\hline 65.7 & 4925 & 8237 & 1095 & 3118 & 4024 & 336228 & 145308 & 156340 & 34584 \\
\hline 66.0 & 4950 & 8253 & 1087 & 3080 & 4086 & 338979 & 145670 & 157366 & 35946 \\
\hline 66.3 & 4975 & 8269 & 1079 & 3043 & 4147 & 341735 & 146030 & 158381 & 37329 \\
\hline 66.7 & 5000 & 8286 & 1071 & 3006 & 4208 & 344497 & 146387 & 159383 & 38731 \\
\hline 67.0 & 5000 & 8302 & 1064 & 2970 & 4268 & 347264 & 146742 & 160373 & 40154 \\
\hline 67.3 & 5000 & 8318 & 1056 & 2934 & 4327 & 350036 & 147094 & 161351 & 41596 \\
\hline 67.7 & 5000 & 8334 & 1049 & 2899 & 4386 & 352814 & 147444 & 162317 & 43058 \\
\hline 68.0 & 5000 & 8276 & 1042 & 2863 & 4371 & 355573 & 147791 & 163271 & 44515 \\
\hline 68.3 & 5000 & 8218 & 1035 & 2829 & 4354 & 358312 & 148136 & 164214 & 45967 \\
\hline 68.7 & 5000 & 8158 & 1028 & 2795 & 4336 & 361031 & 148478 & 165146 & 47412 \\
\hline 69.0 & 5000 & 8098 & 1021 & 2761 & 4317 & 363730 & 148819 & 166066 & 48851 \\
\hline 69.3 & 5000 & 8037 & 1014 & 2727 & 4296 & 366409 & 149157 & 166975 & 50283 \\
\hline 69.7 & 5000 & 7975 & 1007 & 2694 & 4273 & 369067 & 149492 & 167873 & 51708 \\
\hline 70.0 & 5000 & 7912 & 1001 & 2661 & 4250 & 371704 & 149826 & 168760 & 53124 \\
\hline 70.3 & 5000 & 7849 & 994 & 2629 & 4226 & 374321 & 150157 & 169637 & 54533 \\
\hline 70.7 & 5000 & 7786 & 988 & 2597 & 4201 & 376916 & 150487 & 170502 & 55933 \\
\hline 71.0 & 5000 & 7723 & 981 & 2566 & 4175 & 379490 & 150814 & 171358 & 57325 \\
\hline 71.3 & 5000 & 7659 & 975 & 2536 & 4148 & 382043 & 151139 & 172203 & 58708 \\
\hline 71.7 & 5000 & 7595 & 969 & 2506 & 4120 & 384574 & 151462 & 173038 & 60081 \\
\hline 72.0 & 5000 & 7530 & 963 & 2477 & 4091 & 387084 & 151783 & 173864 & 61445 \\
\hline 72.3 & 5000 & 7465 & 957 & 2449 & 4060 & 389573 & 152102 & 174680 & 62798 \\
\hline 72.7 & 5000 & 7400 & 951 & 2421 & 4029 & 392039 & 152419 & 175487 & 64141 \\
\hline 73.0 & 5000 & 7335 & 945 & 2394 & 3997 & 394484 & 152734 & 176285 & 65474 \\
\hline 73.3 & 5000 & 7270 & 939 & 2368 & 3964 & 396908 & 153047 & 177074 & 66795 \\
\hline 73.7 & 5000 & 7205 & 934 & 2342 & 3930 & 399309 & 153358 & 177855 & 68105 \\
\hline 74.0 & 5000 & 7141 & 928 & 2317 & 3896 & 401689 & 153667 & 178627 & 69403 \\
\hline 74.3 & 5000 & 7076 & 923 & 2293 & 3860 & 404048 & 153975 & 179392 & 70690 \\
\hline 74.7 & 5000 & 7011 & 918 & 2269 & 3824 & 406385 & 154281 & 180148 & 71965 \\
\hline 75.0 & 5000 & 6946 & 912 & 2246 & 3788 & 408700 & 154585 & 180897 & 73228 \\
\hline 75.3 & 5000 & 6882 & 907 & 2224 & 3750 & 410994 & 154888 & 181638 & 74478 \\
\hline 75.7 & 5000 & 6817 & 903 & 2202 & 3712 & 413266 & 155188 & 182372 & 75715 \\
\hline 76.0 & 5000 & 6753 & 898 & 2181 & 3674 & 415517 & 155488 & 183099 & 76940 \\
\hline 76.3 & 5000 & 6689 & 893 & 2161 & 3635 & 417746 & 155785 & 183820 & 78151 \\
\hline 76.7 & 5000 & 6626 & 889 & 2142 & 3595 & 419955 & 156082 & 184534 & 79350 \\
\hline 77.0 & 5000 & 6562 & 884 & 2122 & 3556 & 422142 & 156376 & 185241 & 80535 \\
\hline 77.3 & 5000 & 6499 & 880 & 2103 & 3516 & 424308 & 156670 & 185942 & 81707 \\
\hline 77.7 & 5000 & 6437 & 876 & 2084 & 3477 & 426454 & 156962 & 186637 & 82866 \\
\hline 78.0 & 5000 & 6374 & 872 & 2066 & 3437 & 428578 & 157252 & 187326 & 84011 \\
\hline
\end{tabular}




\begin{tabular}{|c|c|c|c|c|c|c|c|c|c|}
\hline 78.3 & 5000 & 6312 & 868 & 2047 & 3398 & 430682 & 157541 & 188008 & 85144 \\
\hline 78.7 & 5000 & 6251 & 864 & 2029 & 3358 & 432766 & 157829 & 188685 & 86263 \\
\hline 79.0 & 5000 & 6190 & 860 & 2011 & 3319 & 434829 & 158116 & 189355 & 87370 \\
\hline 79.3 & 5000 & 6129 & 856 & 1993 & 3280 & 436872 & 158401 & 190020 & 88463 \\
\hline 79.7 & 5000 & 6069 & 853 & 1976 & 3241 & 438895 & 158686 & 190678 & 89543 \\
\hline 80.0 & 5000 & 6010 & 849 & 1958 & 3202 & 440898 & 158969 & 191331 & 90610 \\
\hline 80.3 & 5000 & 5951 & 846 & 1941 & 3164 & 442881 & 159251 & 191978 & 91665 \\
\hline 80.7 & 5000 & 5892 & 843 & 1924 & 3126 & 444845 & 159532 & 192619 & 92707 \\
\hline 81.0 & 5000 & 5835 & 839 & 1907 & 3088 & 446790 & 159811 & 193255 & 93736 \\
\hline 81.3 & 5000 & 5777 & 836 & 1891 & 3050 & 448715 & 160090 & 193886 & 94753 \\
\hline 81.7 & 5000 & 5721 & 833 & 1875 & 3013 & 450622 & 160368 & 194511 & 95757 \\
\hline 82.0 & 5000 & 5665 & 830 & 1859 & 2975 & 452510 & 160644 & 195131 & 96749 \\
\hline 82.3 & 5000 & 5609 & 827 & 1844 & 2939 & 454380 & 160920 & 195745 & 97728 \\
\hline 82.7 & 5000 & 5554 & 824 & 1828 & 2902 & 456231 & 161194 & 196355 & 98696 \\
\hline 83.0 & 5000 & 5500 & 821 & 1814 & 2866 & 458065 & 161468 & 196959 & 99651 \\
\hline 83.3 & 5000 & 5447 & 818 & 1799 & 2831 & 459880 & 161741 & 197559 & 100595 \\
\hline 83.7 & 5000 & 5395 & 815 & 1784 & 2795 & 461678 & 162012 & 198154 & 101526 \\
\hline 84.0 & 5000 & 5343 & 812 & 1770 & 2760 & 463459 & 162283 & 198744 & 102446 \\
\hline 84.3 & 5000 & 5291 & 809 & 1756 & 2726 & 465223 & 162553 & 199329 & 103355 \\
\hline 84.7 & 5000 & 5241 & 806 & 1743 & 2691 & 466969 & 162821 & 199910 & 104252 \\
\hline 85.0 & 5000 & 5191 & 804 & 1729 & 2657 & 468699 & 163089 & 200487 & 105138 \\
\hline 85.3 & 5000 & 5141 & 801 & 1716 & 2624 & 470413 & 163356 & 201059 & 106013 \\
\hline 85.7 & 5000 & 5092 & 798 & 1704 & 2590 & 472110 & 163622 & 201627 & 106876 \\
\hline 86.0 & 5000 & 5044 & 796 & 1691 & 2557 & 473791 & 163888 & 202191 & 107728 \\
\hline 86.3 & 5000 & 4996 & 793 & 1679 & 2524 & 475456 & 164152 & 202750 & 108569 \\
\hline 86.7 & 5000 & 4949 & 791 & 1667 & 2491 & 477106 & 164416 & 203306 & 109400 \\
\hline 87.0 & 5000 & 4902 & 788 & 1655 & 2458 & 478740 & 164678 & 203858 & 110219 \\
\hline 87.3 & 5000 & 4856 & 786 & 1643 & 2426 & 480358 & 164940 & 204405 & 111028 \\
\hline 87.7 & 5000 & 4810 & 784 & 1632 & 2395 & 481961 & 165202 & 204949 & 111826 \\
\hline 88.0 & 5000 & 4765 & 781 & 1620 & 2364 & 483550 & 165462 & 205489 & 112614 \\
\hline 88.3 & 5000 & 4720 & 779 & 1609 & 2333 & 485123 & 165722 & 206026 & 113392 \\
\hline 88.7 & 5000 & 4677 & 777 & 1597 & 2302 & 486682 & 165981 & 206558 & 114159 \\
\hline 89.0 & 5000 & 4633 & 775 & 1586 & 2272 & 488226 & 166239 & 207087 & 114916 \\
\hline 89.3 & 5000 & 4590 & 773 & 1575 & 2243 & 489756 & 166496 & 207612 & 115664 \\
\hline 89.7 & 5000 & 4548 & 771 & 1564 & 2213 & 491272 & 166753 & 208133 & 116402 \\
\hline 90.0 & 5000 & 4506 & 769 & 1553 & 2185 & 492774 & 167009 & 208651 & 117130 \\
\hline 90.3 & 5000 & 4465 & 767 & 1543 & 2156 & 494262 & 167265 & 209165 & 117849 \\
\hline 90.7 & 5000 & 4425 & 765 & 1532 & 2128 & 495737 & 167520 & 209676 & 118558 \\
\hline 91.0 & 5000 & 4385 & 762 & 1522 & 2101 & 497199 & 167774 & 210183 & 119258 \\
\hline 91.3 & 5000 & 4346 & 760 & 1511 & 2074 & 498647 & 168027 & 210687 & 119950 \\
\hline 91.7 & 5000 & 4308 & 758 & 1501 & 2048 & 500083 & 168280 & 211187 & 120632 \\
\hline 92.0 & 5000 & 4270 & 756 & 1491 & 2022 & 501506 & 168532 & 211685 & 121307 \\
\hline 92.3 & 5000 & 4234 & 755 & 1482 & 1998 & 502917 & 168784 & 212178 & 121972 \\
\hline 92.7 & 5000 & 4198 & 753 & 1472 & 1973 & 504317 & 169035 & 212669 & 122630 \\
\hline 93.0 & 5000 & 4163 & 751 & 1462 & 1950 & 505704 & 169285 & 213157 & 123280 \\
\hline 93.3 & 5000 & 4129 & 749 & 1453 & 1927 & 507080 & 169535 & 213641 & 123923 \\
\hline 93.7 & 5000 & 4096 & 747 & 1444 & 1905 & 508446 & 169784 & 214122 & 124557 \\
\hline 94.0 & 5000 & 4063 & 745 & 1435 & 1883 & 509800 & 170032 & 214601 & 125185 \\
\hline 94.3 & 5000 & 4032 & 743 & 1426 & 1862 & 511144 & 170280 & 215076 & 125806 \\
\hline 94.7 & 5000 & 4001 & 742 & 1418 & 1842 & 512477 & 170527 & 215549 & 126420 \\
\hline 95.0 & 5000 & 3971 & 740 & 1409 & 1822 & 513801 & 170774 & 216019 & 127027 \\
\hline 95.3 & 5000 & 3942 & 738 & 1401 & 1803 & 515115 & 171020 & 216485 & 127628 \\
\hline 95.7 & 5000 & 3914 & 737 & 1392 & 1785 & 516419 & 171265 & 216950 & 128223 \\
\hline 96.0 & 5000 & 3886 & 735 & 1384 & 1767 & 517714 & 171510 & 217411 & 128812 \\
\hline 96.3 & 5000 & 3860 & 733 & 1377 & 1750 & 519001 & 171755 & 217870 & 129395 \\
\hline 96.7 & 5000 & 3834 & 732 & 1369 & 1733 & 520279 & 171999 & 218326 & 129973 \\
\hline 97.0 & 5000 & 3808 & 730 & 1361 & 1717 & 521548 & 172242 & 218780 & 130545 \\
\hline 97.3 & 5000 & 3783 & 729 & 1354 & 1701 & 522809 & 172485 & 219231 & 131112 \\
\hline 97.7 & 5000 & 3759 & 727 & 1346 & 1685 & 524062 & 172727 & 219680 & 131674 \\
\hline
\end{tabular}




\begin{tabular}{|c|c|c|c|c|c|c|c|c|c|}
\hline 98.0 & 5000 & 3734 & 726 & 1339 & 1669 & 525307 & 172969 & 220127 & 132230 \\
\hline 98.3 & 5000 & 3710 & 724 & 1332 & 1654 & 526544 & 173211 & 220571 & 132782 \\
\hline 98.7 & 5000 & 3686 & 723 & 1325 & 1639 & 527773 & 173452 & 221012 & 133328 \\
\hline 99.0 & 5000 & 3663 & 722 & 1318 & 1624 & 528994 & 173692 & 221451 & 133869 \\
\hline 99.3 & 5000 & 3640 & 720 & 1311 & 1609 & 530207 & 173932 & 221888 & 134405 \\
\hline 99.7 & 5000 & 3617 & 719 & 1304 & 1594 & 531413 & 174172 & 222323 & 134937 \\
\hline 100.0 & 5000 & 3595 & 718 & 1298 & 1580 & 532612 & 174411 & 222756 & 135463 \\
\hline 100.3 & 5000 & 3573 & 717 & 1291 & 1565 & 533803 & 174650 & 223186 & 135985 \\
\hline 100.7 & 5000 & 3552 & 715 & 1285 & 1551 & 534987 & 174889 & 223615 & 136502 \\
\hline 101.0 & 5000 & 3530 & 714 & 1279 & 1538 & 536164 & 175127 & 224041 & 137015 \\
\hline 101.3 & 5000 & 3509 & 713 & 1272 & 1524 & 537334 & 175365 & 224465 & 137523 \\
\hline 101.7 & 5000 & 3489 & 712 & 1266 & 1511 & 538497 & 175602 & 224887 & 138026 \\
\hline 102.0 & 5000 & 3469 & 711 & 1260 & 1497 & 539653 & 175839 & 225307 & 138526 \\
\hline 102.3 & 5000 & 3449 & 710 & 1255 & 1484 & 540803 & 176075 & 225726 & 139020 \\
\hline 102.7 & 5000 & 3429 & 709 & 1249 & 1472 & 541946 & 176312 & 226142 & 139511 \\
\hline 103.0 & 5000 & 3410 & 708 & 1243 & 1459 & 543083 & 176548 & 226556 & 139997 \\
\hline 103.3 & 5000 & 3391 & 707 & 1238 & 1447 & 544213 & 176783 & 226969 & 140480 \\
\hline 103.7 & 5000 & 3373 & 706 & 1233 & 1434 & 545338 & 177019 & 227380 & 140958 \\
\hline 104.0 & 5000 & 3355 & 705 & 1227 & 1423 & 546456 & 177254 & 227789 & 141432 \\
\hline 104.3 & 5000 & 3337 & 704 & 1222 & 1411 & 547568 & 177488 & 228196 & 141902 \\
\hline 104.7 & 5000 & 3320 & 703 & 1217 & 1399 & 548675 & 177723 & 228602 & 142369 \\
\hline 105.0 & 5000 & 3303 & 702 & 1212 & 1388 & 549776 & 177957 & 229006 & 142831 \\
\hline 105.3 & 5000 & 3286 & 702 & 1208 & 1377 & 550871 & 178191 & 229409 & 143290 \\
\hline 105.7 & 5000 & 3270 & 701 & 1203 & 1366 & 551961 & 178424 & 229810 & 143746 \\
\hline 106.0 & 5000 & 3254 & 700 & 1198 & 1355 & 553046 & 178658 & 230209 & 144197 \\
\hline 106.3 & 5000 & 3238 & 699 & 1194 & 1345 & 554125 & 178891 & 230607 & 144646 \\
\hline 106.7 & 5000 & 3223 & 699 & 1190 & 1334 & 555200 & 179124 & 231004 & 145090 \\
\hline 107.0 & 5000 & 3207 & 698 & 1185 & 1324 & 556269 & 179357 & 231399 & 145532 \\
\hline 107.3 & 5000 & 3193 & 698 & 1181 & 1314 & 557334 & 179589 & 231792 & 145970 \\
\hline 107.7 & 5000 & 3178 & 697 & 1177 & 1304 & 558393 & 179822 & 232185 & 146405 \\
\hline 108.0 & 5000 & 3163 & 696 & 1173 & 1294 & 559448 & 180054 & 232575 & 146836 \\
\hline 108.3 & 5000 & 3149 & 696 & 1169 & 1285 & 560498 & 180286 & 232965 & 147264 \\
\hline 108.7 & 5000 & 3135 & 695 & 1164 & 1275 & 561543 & 180517 & 233353 & 147689 \\
\hline 109.0 & 5000 & 3121 & 695 & 1160 & 1265 & 562584 & 180749 & 233740 & 148111 \\
\hline 109.3 & 5000 & 3107 & 694 & 1157 & 1256 & 563619 & 180981 & 234125 & 148530 \\
\hline 109.7 & 5000 & 3093 & 694 & 1153 & 1247 & 564651 & 181212 & 234510 & 148945 \\
\hline 110.0 & 5000 & 3080 & 694 & 1149 & 1237 & 565678 & 181443 & 234893 & 149358 \\
\hline 110.3 & 5000 & 3067 & 693 & 1145 & 1228 & 566700 & 181675 & 235274 & 149767 \\
\hline 110.7 & 5000 & 3054 & 693 & 1141 & 1219 & 567718 & 181906 & 235655 & 150174 \\
\hline 111.0 & 5000 & 3041 & 693 & 1138 & 1210 & 568732 & 182137 & 236034 & 150577 \\
\hline 111.3 & 5000 & 3028 & 692 & 1134 & 1202 & 569741 & 182367 & 236412 & 150978 \\
\hline 111.7 & 5000 & 3016 & 692 & 1131 & 1193 & 570746 & 182598 & 236789 & 151376 \\
\hline 112.0 & 5000 & 3003 & 692 & 1127 & 1185 & 571747 & 182829 & 237164 & 151770 \\
\hline 112.3 & 5000 & 2991 & 691 & 1124 & 1176 & 572744 & 183059 & 237539 & 152163 \\
\hline 112.7 & 5000 & 2979 & 691 & 1121 & 1168 & 573738 & 183289 & 237912 & 152552 \\
\hline 113.0 & 5000 & 2967 & 690 & 1117 & 1160 & 574727 & 183519 & 238285 & 152938 \\
\hline 113.3 & 5000 & 2956 & 690 & 1114 & 1151 & 575712 & 183750 & 238656 & 153322 \\
\hline 113.7 & 5000 & 2944 & 690 & 1111 & 1143 & 576693 & 183979 & 239027 & 153703 \\
\hline 114.0 & 5000 & 2933 & 689 & 1108 & 1136 & 577671 & 184209 & 239396 & 154082 \\
\hline 114.3 & 5000 & 2922 & 689 & 1105 & 1128 & 578645 & 184439 & 239765 & 154458 \\
\hline 114.7 & 5000 & 2911 & 689 & 1103 & 1120 & 579615 & 184669 & 240132 & 154831 \\
\hline 115.0 & 5000 & 2901 & 688 & 1100 & 1113 & 580582 & 184898 & 240499 & 155202 \\
\hline 115.3 & 5000 & 2890 & 688 & 1097 & 1105 & 581546 & 185127 & 240865 & 155571 \\
\hline 115.7 & 5000 & 2880 & 688 & 1095 & 1098 & 582506 & 185357 & 241230 & 155937 \\
\hline 116.0 & 5000 & 2870 & 687 & 1092 & 1091 & 583463 & 185586 & 241594 & 156300 \\
\hline 116.3 & 5000 & 2860 & 687 & 1090 & 1084 & 584416 & 185815 & 241957 & 156661 \\
\hline 116.7 & 5000 & 2850 & 686 & 1088 & 1077 & 585366 & 186043 & 242319 & 157020 \\
\hline 117.0 & 5000 & 2841 & 686 & 1085 & 1070 & 586313 & 186272 & 242681 & 157377 \\
\hline 117.3 & 5000 & 2831 & 686 & 1083 & 1063 & 587257 & 186501 & 243042 & 157731 \\
\hline
\end{tabular}




\begin{tabular}{|c|c|c|c|c|c|c|c|c|c|}
\hline \begin{tabular}{|l|}
117.7 \\
\end{tabular} & 5000 & 2822 & 685 & 1081 & 1056 & 588198 & 186729 & 243402 & 158083 \\
\hline 118.0 & 5000 & 2813 & 685 & 1078 & 1050 & 589136 & 186958 & 243762 & 158433 \\
\hline \begin{tabular}{|l|}
118.3 \\
\end{tabular} & 5000 & 2804 & 685 & 1076 & 1043 & 590071 & 187186 & 244121 & 158781 \\
\hline 118.7 & 5000 & 2795 & 684 & 1074 & 1037 & 591003 & 187414 & 244479 & 159127 \\
\hline 119.0 & 5000 & 2787 & 684 & 1072 & 1031 & 591932 & 187642 & 244836 & 159470 \\
\hline 119.3 & 5000 & 2778 & 683 & 1070 & 1025 & 592858 & 187870 & 245193 & 159812 \\
\hline 119.7 & 5000 & 2770 & 683 & 1068 & 1019 & 593781 & 188098 & 245549 & 160151 \\
\hline 120.0 & 5000 & 2761 & 683 & 1066 & 1013 & 594701 & 188325 & 245904 & 160489 \\
\hline 120.3 & 5000 & 2753 & 682 & 1064 & 1007 & 595619 & 188553 & 246259 & 160825 \\
\hline 120.7 & 5000 & 2745 & 682 & 1062 & 1001 & 596534 & 188780 & 246613 & 161158 \\
\hline 121.0 & 5000 & 2737 & 682 & 1060 & 996 & 597446 & 189007 & 246966 & 161490 \\
\hline 121.3 & 5000 & 2730 & 681 & 1058 & 990 & 598356 & 189234 & 247319 & 161821 \\
\hline 121.7 & 5000 & 2722 & 681 & 1056 & 985 & 599263 & 189461 & 247671 & 162149 \\
\hline 122.0 & 5000 & 2715 & 681 & 1054 & 980 & 600168 & 189688 & 248022 & 162476 \\
\hline 122.3 & 5000 & 2707 & 680 & 1052 & 975 & 601071 & 189915 & 248373 & 162801 \\
\hline 122.7 & 5000 & 2700 & 680 & 1051 & 970 & 601971 & 190142 & 248723 & 163124 \\
\hline \begin{tabular}{|l|}
123.0 \\
\end{tabular} & 5000 & 2693 & 679 & 1049 & 965 & 602868 & 190368 & 249073 & 163446 \\
\hline 123.3 & 5000 & 2687 & 679 & 1047 & 960 & 603764 & 190594 & 249422 & 163766 \\
\hline 123.7 & 5000 & 2680 & 679 & 1045 & 956 & 604657 & 190821 & 249770 & 164084 \\
\hline 124.0 & 5000 & 2673 & 678 & 1044 & 951 & 605548 & 191047 & 250118 & 164401 \\
\hline \begin{tabular}{|l|}
124.3 \\
\end{tabular} & 5000 & 2667 & 678 & 1042 & 947 & 606437 & 191273 & 250466 & 164717 \\
\hline 124.7 & 5000 & 2661 & 678 & 1041 & 943 & 607324 & 191499 & 250812 & 165031 \\
\hline \begin{tabular}{|l|}
125.0 \\
\end{tabular} & 5000 & 2654 & 677 & 1039 & 938 & 608208 & 191725 & 251159 & 165344 \\
\hline \begin{tabular}{|l|}
125.3 \\
\end{tabular} & 5000 & 2649 & 677 & 1037 & 934 & 609091 & 191950 & 251505 & 165655 \\
\hline \begin{tabular}{|l|}
125.7 \\
\end{tabular} & 5000 & 2643 & 677 & 1036 & 930 & 609972 & 192176 & 251850 & 165965 \\
\hline \begin{tabular}{|l|}
126.0 \\
\end{tabular} & 5000 & 2637 & 676 & 1034 & 927 & 610851 & 192401 & 252195 & 166274 \\
\hline \begin{tabular}{|l|}
126.3 \\
\end{tabular} & 5000 & 2631 & 676 & 1033 & 923 & 611728 & 192626 & 252539 & 166582 \\
\hline \begin{tabular}{|l|}
126.7 \\
\end{tabular} & 5000 & 2626 & 675 & 1031 & 919 & 612604 & 192852 & 252883 & 166888 \\
\hline \begin{tabular}{|l|}
127.0 \\
\end{tabular} & 5000 & 2621 & 675 & 1030 & 916 & 613477 & 193077 & 253226 & 167193 \\
\hline 127.3 & 5000 & 2615 & 675 & 1029 & 912 & 614349 & 193302 & 253569 & 167498 \\
\hline \begin{tabular}{|l|}
127.7 \\
\end{tabular} & 5000 & 2610 & 674 & 1027 & 909 & 615219 & 193526 & 253912 & 167800 \\
\hline 128.0 & 5000 & 2605 & 674 & 1026 & 905 & 616088 & 193751 & 254254 & 168102 \\
\hline \begin{tabular}{|l|}
128.3 \\
\end{tabular} & 5000 & 2600 & 674 & 1025 & 902 & 616954 & 193976 & 254595 & 168403 \\
\hline \begin{tabular}{|l|}
128.7 \\
\end{tabular} & 5000 & 2595 & 673 & 1023 & 899 & 617819 & 194200 & 254937 & 168702 \\
\hline \begin{tabular}{|l|}
129.0 \\
\end{tabular} & 5000 & 2590 & 673 & 1022 & 895 & 618683 & 194424 & 255277 & 169001 \\
\hline \begin{tabular}{|l|}
129.3 \\
\end{tabular} & 5000 & 2586 & 672 & 1021 & 892 & 619545 & 194648 & 255618 & 169298 \\
\hline \begin{tabular}{|l|}
129.7 \\
\end{tabular} & 5000 & 2581 & 672 & 1020 & 889 & 620405 & 194872 & 255958 & 169594 \\
\hline \begin{tabular}{|l|}
130.0 \\
\end{tabular} & 5000 & 2576 & 672 & 1019 & 886 & 621263 & 195096 & 256297 & 169890 \\
\hline \begin{tabular}{|l|}
130.3 \\
\end{tabular} & 5000 & 2572 & 671 & 1018 & 883 & 622121 & 195320 & 256637 & 170184 \\
\hline \begin{tabular}{|l|}
130.7 \\
\end{tabular} & 5000 & 2567 & 671 & 1017 & 880 & 622976 & 195544 & 256976 & 170477 \\
\hline \begin{tabular}{|l|}
131.0 \\
\end{tabular} & 5000 & 2563 & 671 & 1016 & 877 & 623830 & 195767 & 257314 & 170769 \\
\hline \begin{tabular}{|l|}
131.3 \\
\end{tabular} & 5000 & 2559 & 670 & 1015 & 874 & 624683 & 195991 & 257652 & 171061 \\
\hline \begin{tabular}{|l|}
131.7 \\
\end{tabular} & 5000 & 2554 & 670 & 1014 & 871 & 625534 & 196214 & 257990 & 171351 \\
\hline \begin{tabular}{|l|}
132.0 \\
\end{tabular} & 5000 & 2550 & 670 & 1013 & 868 & 626384 & 196437 & 258328 & 171640 \\
\hline 132.3 & 5000 & 2546 & 669 & 1012 & 865 & 627233 & 196660 & 258665 & 171929 \\
\hline 132.7 & 5000 & 2542 & 669 & 1011 & 862 & 628080 & 196883 & 259002 & 172216 \\
\hline \begin{tabular}{|l|}
133.0 \\
\end{tabular} & 5000 & 2538 & 668 & 1010 & 860 & 628926 & 197106 & 259339 & 172503 \\
\hline 133.3 & 5000 & 2534 & 668 & 1009 & 857 & 629770 & 197329 & 259675 & 172788 \\
\hline \begin{tabular}{|l|}
133.7 \\
\end{tabular} & 5000 & 2530 & 668 & 1008 & 854 & 630614 & 197551 & 260011 & 173073 \\
\hline 134.0 & 5000 & 2527 & 667 & 1008 & 852 & 631456 & 197774 & 260347 & 173357 \\
\hline 134.3 & 5000 & 2523 & 667 & 1007 & 849 & 632297 & 197996 & 260683 & 173640 \\
\hline 134.7 & 5000 & 2519 & 667 & 1006 & 847 & 633136 & 198218 & 261018 & 173922 \\
\hline \begin{tabular}{|l|}
135.0 \\
\end{tabular} & 5000 & 2516 & 666 & 1005 & 844 & 633975 & 198441 & 261353 & 174204 \\
\hline 135.3 & 5000 & 2513 & 666 & 1005 & 842 & 634813 & 198663 & 261688 & 174484 \\
\hline \begin{tabular}{|l|}
135.7 \\
\end{tabular} & 5000 & 2509 & 666 & 1004 & 840 & 635649 & 198884 & 262023 & 174764 \\
\hline 136.0 & 5000 & 2506 & 665 & 1003 & 837 & 636484 & 199106 & 262358 & 175043 \\
\hline \begin{tabular}{|l|}
136.3 \\
\end{tabular} & 5000 & 2503 & 665 & 1003 & 835 & 637319 & 199328 & 262692 & 175322 \\
\hline 136.7 & 5000 & 2500 & 664 & 1002 & 833 & 638152 & 199549 & 263026 & 175599 \\
\hline \begin{tabular}{|l|}
137.0 \\
\end{tabular} & 5000 & 2497 & 664 & 1002 & 831 & 638984 & 199771 & 263360 & 175876 \\
\hline
\end{tabular}




\begin{tabular}{|c|c|c|c|c|c|c|c|c|c|}
\hline 137.3 & 5000 & 2494 & 664 & 1001 & 829 & 639816 & 199992 & 263694 & 176152 \\
\hline 137.7 & 5000 & 2491 & 663 & 1001 & 826 & 640646 & 200213 & 264027 & 176428 \\
\hline 138.0 & 5000 & 2488 & 663 & 1000 & 824 & 641475 & 200434 & 264361 & 176703 \\
\hline 138.3 & 5000 & 2485 & 663 & 1000 & 822 & 642303 & 200655 & 264694 & 176977 \\
\hline 138.7 & 5000 & 2482 & 662 & 999 & 820 & 643130 & 200875 & 265027 & 177250 \\
\hline 139.0 & 5000 & 2479 & 662 & 999 & 818 & 643956 & 201096 & 265360 & 177523 \\
\hline 139.3 & 5000 & 2476 & 661 & 998 & 816 & 644782 & 201317 & 265693 & 177795 \\
\hline 139.7 & 5000 & 2473 & 661 & 998 & 814 & 645606 & 201537 & 266025 & 178067 \\
\hline 140.0 & 5000 & 2470 & 661 & 997 & 813 & 646429 & 201757 & 266357 & 178337 \\
\hline 140.3 & 5000 & 2468 & 660 & 997 & 811 & 647252 & 201977 & 266689 & 178608 \\
\hline 140.7 & 5000 & 2465 & 660 & 996 & 809 & 648073 & 202197 & 267021 & 178877 \\
\hline 141.0 & 5000 & 2462 & 660 & 995 & 807 & 648894 & 202417 & 267353 & 179146 \\
\hline 141.3 & 5000 & 2459 & 659 & 995 & 805 & 649714 & 202637 & 267685 & 179415 \\
\hline 141.7 & 5000 & 2457 & 659 & 994 & 804 & 650533 & 202857 & 268016 & 179683 \\
\hline 142.0 & 5000 & 2454 & 659 & 994 & 802 & 651351 & 203076 & 268347 & 179950 \\
\hline 142.3 & 5000 & 2452 & 658 & 993 & 800 & 652168 & 203295 & 268678 & 180216 \\
\hline 142.7 & 5000 & 2449 & 658 & 993 & 798 & 652984 & 203515 & 269009 & 180483 \\
\hline \begin{tabular}{|l|}
143.0 \\
\end{tabular} & 5000 & 2447 & 657 & 992 & 797 & 653800 & 203734 & 269340 & 180748 \\
\hline 143.3 & 5000 & 2444 & 657 & 992 & 795 & 654614 & 203953 & 269671 & 181013 \\
\hline \begin{tabular}{|l|}
143.7 \\
\end{tabular} & 5000 & 2442 & 657 & 991 & 794 & 655428 & 204172 & 270001 & 181278 \\
\hline \begin{tabular}{|l|}
144.0 \\
\end{tabular} & 5000 & 2439 & 656 & 991 & 792 & 656241 & 204391 & 270331 & 181542 \\
\hline 144.3 & 5000 & 2437 & 656 & 990 & 791 & 657053 & 204609 & 270661 & 181805 \\
\hline \begin{tabular}{|l|}
144.7 \\
\end{tabular} & 5000 & 2434 & 656 & 990 & 789 & 657865 & 204828 & 270991 & 182068 \\
\hline \begin{tabular}{|l|}
145.0 \\
\end{tabular} & 5000 & 2432 & 655 & 989 & 788 & 658676 & 205046 & 271321 & 182331 \\
\hline 145.3 & 5000 & 2430 & 655 & 989 & 786 & 659486 & 205264 & 271650 & 182593 \\
\hline \begin{tabular}{|l|}
145.7 \\
\end{tabular} & 5000 & 2427 & 655 & 988 & 785 & 660295 & 205483 & 271979 & 182855 \\
\hline 146.0 & 5000 & 2425 & 654 & 987 & 783 & 661103 & 205701 & 272308 & 183116 \\
\hline 146.3 & 5000 & 2423 & 654 & 987 & 782 & 661911 & 205918 & 272637 & 183377 \\
\hline \begin{tabular}{|l|}
146.7 \\
\end{tabular} & 5000 & 2421 & 653 & 986 & 781 & 662718 & 206136 & 272966 & 183637 \\
\hline 147.0 & 5000 & 2418 & 653 & 986 & 780 & 663524 & 206354 & 273295 & 183897 \\
\hline \begin{tabular}{|l|}
147.3 \\
\end{tabular} & 5000 & 2416 & 653 & 985 & 778 & 664330 & 206571 & 273623 & 184156 \\
\hline \begin{tabular}{|l|}
147.7 \\
\end{tabular} & 5000 & 2414 & 652 & 985 & 777 & 665134 & 206789 & 273951 & 184415 \\
\hline \begin{tabular}{|l|}
148.0 \\
\end{tabular} & 5000 & 2412 & 652 & 984 & 776 & 665938 & 207006 & 274279 & 184674 \\
\hline \begin{tabular}{|l|}
148.3 \\
\end{tabular} & 5000 & 2410 & 652 & 984 & 775 & 666742 & 207223 & 274607 & 184932 \\
\hline \begin{tabular}{|l|}
148.7 \\
\end{tabular} & 5000 & 2408 & 651 & 983 & 774 & 667544 & 207440 & 274935 & 185190 \\
\hline 149.0 & 5000 & 2406 & 651 & 983 & 773 & 668346 & 207657 & 275263 & 185448 \\
\hline \begin{tabular}{|l|}
149.3 \\
\end{tabular} & 5000 & 2404 & 650 & 982 & 772 & 669147 & 207874 & 275590 & 185705 \\
\hline \begin{tabular}{|l|}
149.7 \\
\end{tabular} & 5000 & 2402 & 650 & 982 & 770 & 669948 & 208091 & 275917 & 185962 \\
\hline 150.0 & 5000 & 2400 & 650 & 981 & 769 & 670748 & 208307 & 276244 & 186218 \\
\hline 150.3 & 5000 & 2398 & 649 & 981 & 769 & 671547 & 208524 & 276571 & 186475 \\
\hline \begin{tabular}{|l|}
150.7 \\
\end{tabular} & 5000 & 2397 & 649 & 980 & 768 & 672346 & 208740 & 276897 & 186731 \\
\hline \begin{tabular}{|l|}
151.0 \\
\end{tabular} & 5000 & 2395 & 649 & 979 & 767 & 673144 & 208956 & 277224 & 186986 \\
\hline \begin{tabular}{|l|}
151.3 \\
\end{tabular} & 5000 & 2393 & 648 & 979 & 766 & 673942 & 209172 & 277550 & 187241 \\
\hline \begin{tabular}{|l|}
151.7 \\
\end{tabular} & 5000 & 2391 & 648 & 978 & 765 & 674739 & 209388 & 277876 & 187496 \\
\hline 152.0 & 5000 & 2390 & 648 & 978 & 764 & 675535 & 209604 & 278202 & 187751 \\
\hline 152.3 & 5000 & 2388 & 647 & 977 & 763 & 676331 & 209820 & 278528 & 188006 \\
\hline \begin{tabular}{|l|}
152.7 \\
\end{tabular} & 5000 & 2386 & 647 & 977 & 763 & 677126 & 210036 & 278853 & 188260 \\
\hline 153.0 & 5000 & 2385 & 646 & 976 & 762 & 677921 & 210251 & 279179 & 188514 \\
\hline 153.3 & 5000 & 2383 & 646 & 976 & 761 & 678716 & 210466 & 279504 & 188768 \\
\hline \begin{tabular}{|l|}
153.7 \\
\end{tabular} & 5000 & 2381 & 646 & 975 & 760 & 679509 & 210682 & 279829 & 189021 \\
\hline 154.0 & 5000 & 2380 & 645 & 975 & 760 & 680303 & 210897 & 280154 & 189274 \\
\hline 154.3 & 5000 & 2378 & 645 & 974 & 759 & 681096 & 211112 & 280478 & 189528 \\
\hline \begin{tabular}{|l|}
154.7 \\
\end{tabular} & 5000 & 2377 & 645 & 974 & 759 & 681888 & 211326 & 280803 & 189781 \\
\hline 155.0 & 5000 & 2375 & 644 & 973 & 758 & 682680 & 211541 & 281127 & 190033 \\
\hline 155.3 & 5000 & 2374 & 644 & 973 & 758 & 683471 & 211756 & 281451 & 190286 \\
\hline 155.7 & 5000 & 2373 & 644 & 972 & 757 & 684262 & 211970 & 281775 & 190538 \\
\hline \begin{tabular}{|l|}
156.0 \\
\end{tabular} & 5000 & 2371 & 643 & 971 & 757 & 685053 & 212185 & 282099 & 190790 \\
\hline 156.3 & 5000 & 2370 & 643 & 971 & 756 & 685843 & 212399 & 282423 & 191043 \\
\hline \begin{tabular}{|l|}
156.7 \\
\end{tabular} & 5000 & 2369 & 642 & 970 & 756 & 686632 & 212613 & 282746 & 191295 \\
\hline
\end{tabular}




\begin{tabular}{|c|c|c|c|c|c|c|c|c|c|}
\hline \begin{tabular}{|l|}
157.0 \\
\end{tabular} & 5000 & 2367 & 642 & 970 & 755 & 687421 & 212827 & 283069 & 191546 \\
\hline \begin{tabular}{|l|}
157.3 \\
\end{tabular} & 5000 & 2366 & 642 & 969 & 755 & 688210 & 213041 & 283393 & 191798 \\
\hline \begin{tabular}{|l|}
157.7 \\
\end{tabular} & 5000 & 2365 & 641 & 969 & 755 & 688998 & 213254 & 283715 & 192050 \\
\hline 158.0 & 5000 & 2363 & 641 & 968 & 754 & 689786 & 213468 & 284038 & 192301 \\
\hline 158.3 & 5000 & 2362 & 641 & 968 & 754 & 690573 & 213682 & 284361 & 192552 \\
\hline \begin{tabular}{|l|}
158.7 \\
\end{tabular} & 5000 & 2361 & 640 & 967 & 753 & 691360 & 213895 & 284683 & 192804 \\
\hline 159.0 & 5000 & 2360 & 640 & 967 & 753 & 692147 & 214108 & 285005 & 193055 \\
\hline 159.3 & 5000 & 2358 & 639 & 966 & 753 & 692933 & 214321 & 285327 & 193306 \\
\hline \begin{tabular}{|l|}
159.7 \\
\end{tabular} & 5000 & 2357 & 639 & 966 & 752 & 693719 & 214534 & 285649 & 193556 \\
\hline 160.0 & 5000 & 2356 & 639 & 965 & 752 & 694504 & 214747 & 285971 & 193807 \\
\hline 160.3 & 5000 & 2354 & 638 & 965 & 751 & 695289 & 214960 & 286292 & 194058 \\
\hline 160.7 & 5000 & 2353 & 638 & 964 & 751 & 696073 & 215173 & 286614 & 194308 \\
\hline 161.0 & 5000 & 2352 & 638 & 963 & 751 & 696857 & 215385 & 286935 & 194558 \\
\hline 161.3 & 5000 & 2350 & 637 & 963 & 750 & 697640 & 215598 & 287256 & 194808 \\
\hline \begin{tabular}{|l|}
161.7 \\
\end{tabular} & 5000 & 2349 & 637 & 962 & 750 & 698423 & 215810 & 287577 & 195058 \\
\hline 162.0 & 5000 & 2348 & 637 & 962 & 749 & 699206 & 216022 & 287897 & 195308 \\
\hline 162.3 & 5000 & 2347 & 636 & 961 & 749 & 699988 & 216234 & 288218 & 195558 \\
\hline \begin{tabular}{|l|}
162.7 \\
\end{tabular} & 5000 & 2345 & 636 & 961 & 749 & 700770 & 216446 & 288538 & 195807 \\
\hline 163.0 & 5000 & 2344 & 635 & 960 & 748 & 701551 & 216658 & 288858 & 196057 \\
\hline 163.3 & 5000 & 2343 & 635 & 960 & 748 & 702332 & 216869 & 289178 & 196306 \\
\hline \begin{tabular}{|l|}
163.7 \\
\end{tabular} & 5000 & 2341 & 635 & 959 & 747 & 703112 & 217081 & 289498 & 196555 \\
\hline 164.0 & 5000 & 2340 & 634 & 959 & 747 & 703892 & 217292 & 289817 & 196804 \\
\hline \begin{tabular}{|l|}
164.3 \\
\end{tabular} & 5000 & 2339 & 634 & 958 & 747 & 704672 & 217503 & 290137 & 197053 \\
\hline \begin{tabular}{|l|}
164.7 \\
\end{tabular} & 5000 & 2337 & 634 & 958 & 746 & 705451 & 217715 & 290456 & 197302 \\
\hline 165.0 & 5000 & 2336 & 633 & 957 & 746 & 706230 & 217926 & 290775 & 197551 \\
\hline 165.3 & 5000 & 2335 & 633 & 957 & 745 & 707008 & 218137 & 291094 & 197799 \\
\hline \begin{tabular}{|l|}
165.7 \\
\end{tabular} & 5000 & 2334 & 633 & 956 & 745 & 707786 & 218347 & 291412 & 198048 \\
\hline 166.0 & 5000 & 2332 & 632 & 955 & 745 & 708563 & 218558 & 291731 & 198296 \\
\hline \begin{tabular}{|l|}
166.3 \\
\end{tabular} & 5000 & 2331 & 632 & 955 & 744 & 709340 & 218769 & 292049 & 198544 \\
\hline 166.7 & 5000 & 2330 & 631 & 954 & 744 & 710117 & 218979 & 292367 & 198792 \\
\hline \begin{tabular}{|l|}
167.0 \\
\end{tabular} & 5000 & 2328 & 631 & 954 & 743 & 710893 & 219189 & 292685 & 199040 \\
\hline 167.3 & 5000 & 2327 & 631 & 953 & 743 & 711669 & 219399 & 293003 & 199287 \\
\hline \begin{tabular}{|l|}
167.7 \\
\end{tabular} & 5000 & 2326 & 630 & 953 & 743 & 712444 & 219610 & 293321 & 199535 \\
\hline \begin{tabular}{|l|}
168.0 \\
\end{tabular} & 5000 & 2324 & 630 & 952 & 742 & 713219 & 219819 & 293638 & 199782 \\
\hline \begin{tabular}{|l|}
168.3 \\
\end{tabular} & 5000 & 2323 & 630 & 952 & 742 & 713993 & 220029 & 293955 & 200030 \\
\hline \begin{tabular}{|l|}
168.7 \\
\end{tabular} & 5000 & 2322 & 629 & 951 & 741 & 714767 & 220239 & 294273 & 200277 \\
\hline \begin{tabular}{|l|}
169.0 \\
\end{tabular} & 5000 & 2321 & 629 & 951 & 741 & 715540 & 220449 & 294589 & 200524 \\
\hline 169.3 & 5000 & 2319 & 628 & 950 & 741 & 716313 & 220658 & 294906 & 200771 \\
\hline \begin{tabular}{|l|}
169.7 \\
\end{tabular} & 5000 & 2318 & 628 & 950 & 740 & 717086 & 220867 & 295223 & 201018 \\
\hline 170.0 & 5000 & 2317 & 628 & 949 & 740 & 717858 & 221077 & 295539 & 201264 \\
\hline \begin{tabular}{|l|}
170.3 \\
\end{tabular} & 5000 & 2315 & 627 & 949 & 739 & 718630 & 221286 & 295855 & 201511 \\
\hline 170.7 & 5000 & 2314 & 627 & 948 & 739 & 719401 & 221495 & 296171 & 201757 \\
\hline \begin{tabular}{|l|}
171.0 \\
\end{tabular} & 5000 & 2313 & 627 & 947 & 739 & 720172 & 221703 & 296487 & 202003 \\
\hline 171.3 & 5000 & 2311 & 626 & 947 & 738 & 720943 & 221912 & 296803 & 202249 \\
\hline 171.7 & 5000 & 2310 & 626 & 946 & 738 & 721713 & 222121 & 297118 & 202495 \\
\hline 172.0 & 5000 & 2309 & 626 & 946 & 737 & 722482 & 222329 & 297434 & 202741 \\
\hline \begin{tabular}{|l|}
172.3 \\
\end{tabular} & 5000 & 2308 & 625 & 945 & 737 & 723251 & 222538 & 297749 & 202987 \\
\hline 172.7 & 5000 & 2306 & 625 & 945 & 737 & 724020 & 222746 & 298064 & 203232 \\
\hline \begin{tabular}{|l|}
173.0 \\
\end{tabular} & 5000 & 2305 & 624 & 944 & 736 & 724788 & 222954 & 298379 & 203478 \\
\hline \begin{tabular}{|l|}
173.3 \\
\end{tabular} & 5000 & 2304 & 624 & 944 & 736 & 725556 & 223162 & 298693 & 203723 \\
\hline 173.7 & 5000 & 2302 & 624 & 943 & 735 & 726324 & 223370 & 299008 & 203968 \\
\hline 174.0 & 5000 & 2301 & 623 & 943 & 735 & 727091 & 223578 & 299322 & 204213 \\
\hline \begin{tabular}{|l|}
174.3 \\
\end{tabular} & 5000 & 2300 & 623 & 942 & 735 & 727857 & 223785 & 299636 & 204458 \\
\hline 174.7 & 5000 & 2298 & 623 & 942 & 734 & 728624 & 223993 & 299950 & 204703 \\
\hline 175.0 & 5000 & 2297 & 622 & 941 & 734 & 729389 & 224200 & 300264 & 204948 \\
\hline 175.3 & 5000 & 2296 & 622 & 941 & 733 & 730155 & 224407 & 300577 & 205192 \\
\hline \begin{tabular}{|l|}
175.7 \\
\end{tabular} & 5000 & 2295 & 622 & 940 & 733 & 730919 & 224615 & 300891 & 205436 \\
\hline 176.0 & 5000 & 2293 & 621 & 939 & 733 & 731684 & 224822 & 301204 & 205681 \\
\hline \begin{tabular}{|l|}
176.3 \\
\end{tabular} & 5000 & 2292 & 621 & 939 & 732 & 732448 & 225028 & 301517 & 205925 \\
\hline
\end{tabular}




\begin{tabular}{|c|c|c|c|c|c|c|c|c|c|}
\hline \begin{tabular}{|l|}
176.7 \\
\end{tabular} & 5000 & 2291 & 620 & 938 & 732 & 733211 & 225235 & 301830 & 206169 \\
\hline \begin{tabular}{|l|}
177.0 \\
\end{tabular} & 5000 & 2289 & 620 & 938 & 731 & 733975 & 225442 & 302143 & 206412 \\
\hline \begin{tabular}{|l|}
177.3 \\
\end{tabular} & 5000 & 2288 & 620 & 937 & 731 & 734737 & 225648 & 302455 & 206656 \\
\hline 177.7 & 5000 & 2287 & 619 & 937 & 731 & 735500 & 225855 & 302767 & 206900 \\
\hline 178.0 & 5000 & 2285 & 619 & 936 & 730 & 736261 & 226061 & 303079 & 207143 \\
\hline 178.3 & 5000 & 2284 & 619 & 936 & 730 & 737023 & 226267 & 303391 & 207386 \\
\hline \begin{tabular}{|l|}
178.7 \\
\end{tabular} & 5000 & 2283 & 618 & 935 & 729 & 737784 & 226473 & 303703 & 207630 \\
\hline 179.0 & 5000 & 2282 & 618 & 935 & 729 & 738544 & 226679 & 304015 & 207873 \\
\hline \begin{tabular}{|l|}
179.3 \\
\end{tabular} & 5000 & 2280 & 617 & 934 & 729 & 739304 & 226885 & 304326 & 208115 \\
\hline 179.7 & 5000 & 2279 & 617 & 934 & 728 & 740064 & 227091 & 304637 & 208358 \\
\hline 180.0 & 5000 & 2278 & 617 & 933 & 728 & 740823 & 227297 & 304948 & 208601 \\
\hline \begin{tabular}{|l|}
180.3 \\
\end{tabular} & 5000 & 2276 & 616 & 933 & 727 & 741582 & 227502 & 305259 & 208843 \\
\hline 180.7 & 5000 & 2275 & 616 & 932 & 727 & 742340 & 227707 & 305570 & 209086 \\
\hline 181.0 & 5000 & 2274 & 616 & 931 & 727 & 743098 & 227913 & 305881 & 209328 \\
\hline \begin{tabular}{|l|}
181.3 \\
\end{tabular} & 5000 & 2272 & 615 & 931 & 726 & 743855 & 228118 & 306191 & 209570 \\
\hline 181.7 & 5000 & 2271 & 615 & 930 & 726 & 744612 & 228323 & 306501 & 209812 \\
\hline \begin{tabular}{|l|}
182.0 \\
\end{tabular} & 5000 & 2270 & 615 & 930 & 725 & 745369 & 228528 & 306811 & 210054 \\
\hline \begin{tabular}{|l|}
182.3 \\
\end{tabular} & 5000 & 2269 & 614 & 929 & 725 & 746125 & 228732 & 307121 & 210295 \\
\hline 182.7 & 5000 & 2267 & 614 & 929 & 725 & 746881 & 228937 & 307431 & 210537 \\
\hline \begin{tabular}{|l|}
183.0 \\
\end{tabular} & 5000 & 2266 & 613 & 928 & 724 & 747636 & 229141 & 307740 & 210778 \\
\hline \begin{tabular}{|l|}
183.3 \\
\end{tabular} & 5000 & 2265 & 613 & 928 & 724 & 748391 & 229346 & 308049 & 211020 \\
\hline 183.7 & 5000 & 2263 & 613 & 927 & 723 & 749146 & 229550 & 308358 & 211261 \\
\hline \begin{tabular}{|l|}
184.0 \\
\end{tabular} & 5000 & 2262 & 612 & 927 & 723 & 749900 & 229754 & 308667 & 211502 \\
\hline \begin{tabular}{|l|}
184.3 \\
\end{tabular} & 5000 & 2261 & 612 & 926 & 723 & 750653 & 229958 & 308976 & 211743 \\
\hline \begin{tabular}{|l|}
184.7 \\
\end{tabular} & 5000 & 2259 & 612 & 926 & 722 & 751407 & 230162 & 309285 & 211983 \\
\hline 185.0 & 5000 & 2258 & 611 & 925 & 722 & 752159 & 230366 & 309593 & 212224 \\
\hline \begin{tabular}{|l|}
185.3 \\
\end{tabular} & 5000 & 2257 & 611 & 925 & 721 & 752912 & 230570 & 309901 & 212464 \\
\hline \begin{tabular}{|l|}
185.7 \\
\end{tabular} & 5000 & 2256 & 611 & 924 & 721 & 753663 & 230773 & 310209 & 212705 \\
\hline \begin{tabular}{|l|}
186.0 \\
\end{tabular} & 5000 & 2254 & 610 & 923 & 721 & 754415 & 230977 & 310517 & 212945 \\
\hline 186.3 & 5000 & 2253 & 610 & 923 & 720 & 755166 & 231180 & 310825 & 213185 \\
\hline \begin{tabular}{|l|}
186.7 \\
\end{tabular} & 5000 & 2252 & 609 & 922 & 720 & 755916 & 231383 & 311133 & 213425 \\
\hline 187.0 & 5000 & 2250 & 609 & 922 & 719 & 756667 & 231586 & 311440 & 213665 \\
\hline \begin{tabular}{|l|}
187.3 \\
\end{tabular} & 5000 & 2249 & 609 & 921 & 719 & 757416 & 231789 & 311747 & 213904 \\
\hline \begin{tabular}{|l|}
187.7 \\
\end{tabular} & 5000 & 2248 & 608 & 921 & 719 & 758166 & 231992 & 312054 & 214144 \\
\hline \begin{tabular}{|l|}
188.0 \\
\end{tabular} & 5000 & 2246 & 608 & 920 & 718 & 758914 & 232194 & 312361 & 214383 \\
\hline 188.3 & 5000 & 2245 & 608 & 920 & 718 & 759663 & 232397 & 312667 & 214623 \\
\hline \begin{tabular}{|l|}
188.7 \\
\end{tabular} & 5000 & 2244 & 607 & 919 & 717 & 760411 & 232599 & 312974 & 214862 \\
\hline 189.0 & 5000 & 2243 & 607 & 919 & 717 & 761158 & 232802 & 313280 & 215101 \\
\hline \begin{tabular}{|l|}
189.3 \\
\end{tabular} & 5000 & 2241 & 606 & 918 & 717 & 761905 & 233004 & 313586 & 215340 \\
\hline 189.7 & 5000 & 2240 & 606 & 918 & 716 & 762652 & 233206 & 313892 & 215578 \\
\hline \begin{tabular}{|l|}
190.0 \\
\end{tabular} & 5000 & 2239 & 606 & 917 & 716 & 763398 & 233408 & 314198 & 215817 \\
\hline 190.3 & 5000 & 2237 & 605 & 917 & 715 & 764144 & 233610 & 314503 & 216055 \\
\hline \begin{tabular}{|l|}
190.7 \\
\end{tabular} & 5000 & 2236 & 605 & 916 & 715 & 764889 & 233812 & 314809 & 216294 \\
\hline 191.0 & 5000 & 2235 & 605 & 915 & 715 & 765634 & 234013 & 315114 & 216532 \\
\hline \begin{tabular}{|l|}
191.3 \\
\end{tabular} & 5000 & 2233 & 604 & 915 & 714 & 766378 & 234215 & 315419 & 216770 \\
\hline 191.7 & 5000 & 2232 & 604 & 914 & 714 & 767122 & 234416 & 315724 & 217008 \\
\hline \begin{tabular}{|l|}
192.0 \\
\end{tabular} & 5000 & 2231 & 604 & 914 & 713 & 767866 & 234617 & 316028 & 217246 \\
\hline 192.3 & 5000 & 2230 & 603 & 913 & 713 & 768609 & 234818 & 316333 & 217483 \\
\hline \begin{tabular}{|l|}
192.7 \\
\end{tabular} & 5000 & 2228 & 603 & 913 & 713 & 769352 & 235019 & 316637 & 217721 \\
\hline 193.0 & 5000 & 2227 & 602 & 912 & 712 & 770094 & 235220 & 316941 & 217958 \\
\hline 193.3 & 5000 & 2226 & 602 & 912 & 712 & 770836 & 235421 & 317245 & 218195 \\
\hline \begin{tabular}{|l|}
193.7 \\
\end{tabular} & 5000 & 2224 & 602 & 911 & 711 & 771578 & 235621 & 317549 & 218433 \\
\hline \begin{tabular}{|l|}
194.0 \\
\end{tabular} & 5000 & 2223 & 601 & 911 & 711 & 772319 & 235822 & 317852 & 218670 \\
\hline 194.3 & 5000 & 2222 & 601 & 910 & 711 & 773060 & 236022 & 318156 & 218906 \\
\hline \begin{tabular}{|l|}
194.7 \\
\end{tabular} & 5000 & 2220 & 601 & 910 & 710 & 773800 & 236223 & 318459 & 219143 \\
\hline 195.0 & 5000 & 2219 & 600 & 909 & 710 & 774540 & 236423 & 318762 & 219380 \\
\hline \begin{tabular}{|l|}
195.3 \\
\end{tabular} & 5000 & 2218 & 600 & 909 & 709 & 775279 & 236623 & 319065 & 219616 \\
\hline 195.7 & 5000 & 2217 & 600 & 908 & 709 & 776018 & 236822 & 319368 & 219852 \\
\hline \begin{tabular}{|l|}
196.0 \\
\end{tabular} & 5000 & 2215 & 599 & 907 & 709 & 776756 & 237022 & 319670 & 220089 \\
\hline
\end{tabular}




\begin{tabular}{|c|c|c|c|c|c|c|c|c|c|}
\hline \begin{tabular}{|l|}
196.3 \\
\end{tabular} & 5000 & 2214 & 599 & 907 & 708 & 777494 & 237222 & 319972 & 220325 \\
\hline \begin{tabular}{|l|}
196.7 \\
\end{tabular} & 5000 & 2213 & 598 & 906 & 708 & 778232 & 237421 & 320274 & 220561 \\
\hline \begin{tabular}{|l|}
197.0 \\
\end{tabular} & 5000 & 2211 & 598 & 906 & 707 & 778969 & 237621 & 320576 & 220796 \\
\hline \begin{tabular}{|l|}
197.3 \\
\end{tabular} & 5000 & 2210 & 598 & 905 & 707 & 779706 & 237820 & 320878 & 221032 \\
\hline 197.7 & 5000 & 2209 & 597 & 905 & 707 & 780442 & 238019 & 321180 & 221268 \\
\hline 198.0 & 5000 & 2207 & 597 & 904 & 706 & 781178 & 238218 & 321481 & 221503 \\
\hline \begin{tabular}{|l|}
198.3 \\
\end{tabular} & 5000 & 2206 & 597 & 904 & 706 & 781913 & 238417 & 321782 & 221738 \\
\hline 198.7 & 5000 & 2205 & 596 & 903 & 705 & 782648 & 238616 & 322083 & 221973 \\
\hline \begin{tabular}{|l|}
199.0 \\
\end{tabular} & 5000 & 2204 & 596 & 903 & 705 & 783382 & 238814 & 322384 & 222208 \\
\hline 199.3 & 5000 & 2202 & 595 & 902 & 705 & 784116 & 239013 & 322685 & 222443 \\
\hline 199.7 & 5000 & 2201 & 595 & 902 & 704 & 784850 & 239211 & 322986 & 222678 \\
\hline 200.0 & 5000 & 2200 & 595 & 901 & 704 & 785583 & 239410 & 323286 & 222912 \\
\hline 200.3 & 5000 & 2198 & 594 & 901 & 703 & 786316 & 239608 & 323586 & 223147 \\
\hline 200.7 & 5000 & 2197 & 594 & 900 & 703 & 787048 & 239806 & 323886 & 223381 \\
\hline 201.0 & 5000 & 2196 & 594 & 899 & 703 & 787780 & 240004 & 324186 & 223615 \\
\hline 201.3 & 5000 & 2194 & 593 & 899 & 702 & 788512 & 240201 & 324486 & 223849 \\
\hline 201.7 & 5000 & 2193 & 593 & 898 & 702 & 789243 & 240399 & 324785 & 224083 \\
\hline 202.0 & 5000 & 2192 & 593 & 898 & 701 & 789973 & 240597 & 325084 & 224317 \\
\hline 202.3 & 5000 & 2191 & 592 & 897 & 701 & 790704 & 240794 & 325383 & 224551 \\
\hline 202.7 & 5000 & 2189 & 592 & 897 & 701 & 791433 & 240991 & 325682 & 224784 \\
\hline 203.0 & 5000 & 2188 & 591 & 896 & 700 & 792163 & 241188 & 325981 & 225018 \\
\hline 203.3 & 5000 & 2187 & 591 & 896 & 700 & 792891 & 241386 & 326280 & 225251 \\
\hline \begin{tabular}{|l|}
203.7 \\
\end{tabular} & 5000 & 2185 & 591 & 895 & 699 & 793620 & 241582 & 326578 & 225484 \\
\hline 204.0 & 5000 & 2184 & 590 & 895 & 699 & 794348 & 241779 & 326876 & 225717 \\
\hline 204.3 & 5000 & 2183 & 590 & 894 & 699 & 795075 & 241976 & 327174 & 225950 \\
\hline 204.7 & 5000 & 2181 & 590 & 894 & 698 & 795803 & 242172 & 327472 & 226182 \\
\hline 205.0 & 5000 & 2180 & 589 & 893 & 698 & 796529 & 242369 & 327770 & 226415 \\
\hline 205.3 & 5000 & 2179 & 589 & 893 & 697 & 797256 & 242565 & 328068 & 226647 \\
\hline 205.7 & 5000 & 2178 & 589 & 892 & 697 & 797981 & 242761 & 328365 & 226880 \\
\hline 206.0 & 5000 & 2176 & 588 & 891 & 697 & 798707 & 242957 & 328662 & 227112 \\
\hline 206.3 & 5000 & 2175 & 588 & 891 & 696 & 799432 & 243153 & 328959 & 227344 \\
\hline 206.7 & 5000 & 2174 & 587 & 890 & 696 & 800156 & 243349 & 329256 & 227576 \\
\hline \begin{tabular}{|l|}
207.0 \\
\end{tabular} & 5000 & 2172 & 587 & 890 & 695 & 800880 & 243545 & 329552 & 227808 \\
\hline 207.3 & 5000 & 2171 & 587 & 889 & 695 & 801604 & 243740 & 329849 & 228039 \\
\hline \begin{tabular}{|l|}
207.7 \\
\end{tabular} & 5000 & 2170 & 586 & 889 & 695 & 802327 & 243936 & 330145 & 228271 \\
\hline 208.0 & 5000 & 2168 & 586 & 888 & 694 & 803050 & 244131 & 330441 & 228502 \\
\hline 208.3 & 5000 & 2167 & 586 & 888 & 694 & 803772 & 244326 & 330737 & 228733 \\
\hline 208.7 & 5000 & 2166 & 585 & 887 & 693 & 804494 & 244521 & 331033 & 228964 \\
\hline 209.0 & 5000 & 2165 & 585 & 887 & 693 & 805215 & 244716 & 331328 & 229195 \\
\hline 209.3 & 5000 & 2163 & 584 & 886 & 693 & 805936 & 244911 & 331624 & 229426 \\
\hline \begin{tabular}{|l|}
209.7 \\
\end{tabular} & 5000 & 2162 & 584 & 886 & 692 & 806657 & 245106 & 331919 & 229657 \\
\hline 210.0 & 5000 & 2161 & 584 & 885 & 692 & 807377 & 245301 & 332214 & 229887 \\
\hline 210.3 & 5000 & 2159 & 583 & 885 & 691 & 808097 & 245495 & 332509 & 230118 \\
\hline 210.7 & 5000 & 2158 & 583 & 884 & 691 & 808816 & 245689 & 332803 & 230348 \\
\hline 211.0 & 5000 & 2157 & 583 & 883 & 691 & 809535 & 245884 & 333098 & 230578 \\
\hline 211.3 & 5000 & 2155 & 582 & 883 & 690 & 810253 & 246078 & 333392 & 230808 \\
\hline 211.7 & 5000 & 2154 & 582 & 882 & 690 & 810971 & 246272 & 333686 & 231038 \\
\hline 212.0 & 5000 & 2153 & 582 & 882 & 689 & 811689 & 246466 & 333980 & 231268 \\
\hline 212.3 & 5000 & 2151 & 581 & 881 & 689 & 812406 & 246659 & 334274 & 231498 \\
\hline \begin{tabular}{|l|}
212.7 \\
\end{tabular} & 5000 & 2150 & 581 & 881 & 689 & 813123 & 246853 & 334567 & 231727 \\
\hline 213.0 & 5000 & 2149 & 580 & 880 & 688 & 813839 & 247046 & 334861 & 231956 \\
\hline 213.3 & 5000 & 2148 & 580 & 880 & 688 & 814555 & 247240 & 335154 & 232186 \\
\hline 213.7 & 5000 & 2146 & 580 & 879 & 687 & 815271 & 247433 & 335447 & 232415 \\
\hline 214.0 & 5000 & 2145 & 579 & 879 & 687 & 815986 & 247626 & 335740 & 232644 \\
\hline 214.3 & 5000 & 2144 & 579 & 878 & 687 & 816700 & 247819 & 336033 & 232872 \\
\hline 214.7 & 5000 & 2142 & 579 & 878 & 686 & 817414 & 248012 & 336325 & 233101 \\
\hline 215.0 & 5000 & 2141 & 578 & 877 & 686 & 818128 & 248205 & 336617 & 233330 \\
\hline 215.3 & 5000 & 2140 & 578 & 877 & 685 & 818841 & 248397 & 336909 & 233558 \\
\hline \begin{tabular}{|l|}
215.7 \\
\end{tabular} & 5000 & 2139 & 578 & 876 & 685 & 819554 & 248590 & 337201 & 233786 \\
\hline
\end{tabular}




\begin{tabular}{|c|c|c|c|c|c|c|c|c|c|}
\hline \begin{tabular}{|l|}
216.0 \\
\end{tabular} & 5000 & 2137 & 577 & 875 & 685 & 820266 & 248782 & 337493 & 234015 \\
\hline 216.3 & 5000 & 2136 & 577 & 875 & 684 & 820978 & 248974 & 337785 & 234243 \\
\hline \begin{tabular}{|l|}
216.7 \\
\end{tabular} & 5000 & 2135 & 576 & 874 & 684 & 821690 & 249167 & 338076 & 234470 \\
\hline 217.0 & 5000 & 2133 & 576 & 874 & 683 & 822401 & 249359 & 338367 & 234698 \\
\hline 217.3 & 5000 & 2132 & 576 & 873 & 683 & 823112 & 249550 & 338658 & 234926 \\
\hline 217.7 & 5000 & 2131 & 575 & 873 & 683 & 823822 & 249742 & 338949 & 235153 \\
\hline 218.0 & 5000 & 2129 & 575 & 872 & 682 & 824532 & 249934 & 339240 & 235381 \\
\hline 218.3 & 5000 & 2128 & 575 & 872 & 682 & 825241 & 250125 & 339531 & 235608 \\
\hline 218.7 & 5000 & 2127 & 574 & 871 & 681 & 825950 & 250317 & 339821 & 235835 \\
\hline 219.0 & 5000 & 2126 & 574 & 871 & 681 & 826658 & 250508 & 340111 & 236062 \\
\hline 219.3 & 5000 & 2124 & 573 & 870 & 681 & 827366 & 250699 & 340401 & 236289 \\
\hline 219.7 & 5000 & 2123 & 573 & 870 & 680 & 828074 & 250890 & 340691 & 236516 \\
\hline 220.0 & 5000 & 2122 & 573 & 869 & 680 & 828781 & 251081 & 340981 & 236742 \\
\hline 220.3 & 5000 & 2120 & 572 & 869 & 679 & 829488 & 251272 & 341270 & 236969 \\
\hline 220.7 & 5000 & 2119 & 572 & 868 & 679 & 830194 & 251463 & 341559 & 237195 \\
\hline 221.0 & 5000 & 2118 & 572 & 867 & 679 & 830900 & 251653 & 341848 & 237421 \\
\hline 221.3 & 5000 & 2116 & 571 & 867 & 678 & 831605 & 251843 & 342137 & 237647 \\
\hline 221.7 & 5000 & 2115 & 571 & 866 & 678 & 832310 & 252034 & 342426 & 237873 \\
\hline 222.0 & 5000 & 2114 & 571 & 866 & 677 & 833015 & 252224 & 342715 & 238099 \\
\hline 222.3 & 5000 & 2113 & 570 & 865 & 677 & 833719 & 252414 & 343003 & 238325 \\
\hline 222.7 & 5000 & 2111 & 570 & 865 & 677 & 834423 & 252604 & 343291 & 238550 \\
\hline 223.0 & 5000 & 2110 & 569 & 864 & 676 & 835126 & 252794 & 343579 & 238776 \\
\hline 223.3 & 5000 & 2109 & 569 & 864 & 676 & 835829 & 252983 & 343867 & 239001 \\
\hline 223.7 & 5000 & 2107 & 569 & 863 & 675 & 836532 & 253173 & 344155 & 239226 \\
\hline 224.0 & 5000 & 2106 & 568 & 863 & 675 & 837234 & 253362 & 344443 & 239451 \\
\hline 224.3 & 5000 & 2105 & 568 & 862 & 675 & 837935 & 253552 & 344730 & 239676 \\
\hline 224.7 & 5000 & 2103 & 568 & 862 & 674 & 838636 & 253741 & 345017 & 239901 \\
\hline 225.0 & 5000 & 2102 & 567 & 861 & 674 & 839337 & 253930 & 345304 & 240125 \\
\hline 225.3 & 5000 & 2101 & 567 & 861 & 673 & 840037 & 254119 & 345591 & 240350 \\
\hline 225.7 & 5000 & 2100 & 567 & 860 & 673 & 840737 & 254308 & 345877 & 240574 \\
\hline 226.0 & 5000 & 2098 & 566 & 859 & 673 & 841436 & 254496 & 346164 & 240798 \\
\hline 226.3 & 5000 & 2097 & 566 & 859 & 672 & 842135 & 254685 & 346450 & 241022 \\
\hline 226.7 & 5000 & 2096 & 565 & 858 & 672 & 842834 & 254873 & 346736 & 241246 \\
\hline 227.0 & 5000 & 2094 & 565 & 858 & 671 & 843532 & 255062 & 347022 & 241470 \\
\hline 227.3 & 5000 & 2093 & 565 & 857 & 671 & 844230 & 255250 & 347308 & 241694 \\
\hline 227.7 & 5000 & 2092 & 564 & 857 & 671 & 844927 & 255438 & 347593 & 241917 \\
\hline 228.0 & 5000 & 2090 & 564 & 856 & 670 & 845624 & 255626 & 347879 & 242141 \\
\hline 228.3 & 5000 & 2089 & 564 & 856 & 670 & 846320 & 255814 & 348164 & 242364 \\
\hline 228.7 & 5000 & 2088 & 563 & 855 & 669 & 847016 & 256002 & 348449 & 242587 \\
\hline 229.0 & 5000 & 2087 & 563 & 855 & 669 & 847711 & 256189 & 348734 & 242810 \\
\hline 229.3 & 5000 & 2085 & 562 & 854 & 669 & 848406 & 256377 & 349018 & 243033 \\
\hline 229.7 & 5000 & 2084 & 562 & 854 & 668 & 849101 & 256564 & 349303 & 243256 \\
\hline 230.0 & 5000 & 2083 & 562 & 853 & 668 & 849795 & 256751 & 349587 & 243478 \\
\hline 230.3 & 5000 & 2081 & 561 & 853 & 667 & 850489 & 256938 & 349871 & 243701 \\
\hline 230.7 & 5000 & 2080 & 561 & 852 & 667 & 851182 & 257125 & 350155 & 243923 \\
\hline 231.0 & 5000 & 2079 & 561 & 851 & 667 & 851875 & 257312 & 350439 & 244145 \\
\hline 231.3 & 5000 & 2077 & 560 & 851 & 666 & 852568 & 257499 & 350723 & 244368 \\
\hline 231.7 & 5000 & 2076 & 560 & 850 & 666 & 853260 & 257685 & 351006 & 244590 \\
\hline 232.0 & 5000 & 2075 & 560 & 850 & 665 & 853951 & 257872 & 351289 & 244811 \\
\hline 232.3 & 5000 & 2074 & 559 & 849 & 665 & 854643 & 258058 & 351573 & 245033 \\
\hline 232.7 & 5000 & 2072 & 559 & 849 & 665 & 855333 & 258244 & 351855 & 245255 \\
\hline 233.0 & 5000 & 2071 & 558 & 848 & 664 & 856024 & 258431 & 352138 & 245476 \\
\hline 233.3 & 5000 & 2070 & 558 & 848 & 664 & 856713 & 258617 & 352421 & 245697 \\
\hline 233.7 & 5000 & 2068 & 558 & 847 & 663 & 857403 & 258802 & 352703 & 245919 \\
\hline 234.0 & 5000 & 2067 & 557 & 847 & 663 & 858092 & 258988 & 352985 & 246140 \\
\hline 234.3 & 5000 & 2066 & 557 & 846 & 663 & 858780 & 259174 & 353267 & 246361 \\
\hline 234.7 & 5000 & 2064 & 557 & 846 & 662 & 859469 & 259359 & 353549 & 246581 \\
\hline 235.0 & 5000 & 2063 & 556 & 845 & 662 & 860156 & 259545 & 353831 & 246802 \\
\hline 235.3 & 5000 & 2062 & 556 & 845 & 661 & 860844 & 259730 & 354112 & 247023 \\
\hline
\end{tabular}




\begin{tabular}{|c|c|c|c|c|c|c|c|c|c|}
\hline \begin{tabular}{|l|}
235.7 \\
\end{tabular} & 5000 & 2061 & 556 & 844 & 661 & 861530 & 259915 & 354394 & 247243 \\
\hline 236.0 & 5000 & 2059 & 555 & 843 & 661 & 862217 & 260100 & 354675 & 247463 \\
\hline 236.3 & 5000 & 2058 & 555 & 843 & 660 & 862903 & 260285 & 354956 & 247683 \\
\hline 236.7 & 5000 & 2057 & 554 & 842 & 660 & 863588 & 260470 & 355237 & 247903 \\
\hline 237.0 & 5000 & 2055 & 554 & 842 & 659 & 864273 & 260654 & 355517 & 248123 \\
\hline 237.3 & 5000 & 2054 & 554 & 841 & 659 & 864958 & 260839 & 355798 & 248343 \\
\hline 237.7 & 5000 & 2053 & 553 & 841 & 659 & 865642 & 261023 & 356078 & 248562 \\
\hline 238.0 & 5000 & 2051 & 553 & 840 & 658 & 866326 & 261208 & 356358 & 248782 \\
\hline 238.3 & 5000 & 2050 & 553 & 840 & 658 & 867009 & 261392 & 356638 & 249001 \\
\hline 238.7 & 5000 & 2049 & 552 & 839 & 657 & 867692 & 261576 & 356918 & 249220 \\
\hline 239.0 & 5000 & 2048 & 552 & 839 & 657 & 868374 & 261760 & 357197 & 249439 \\
\hline 239.3 & 5000 & 2046 & 551 & 838 & 657 & 869057 & 261943 & 357477 & 249658 \\
\hline 239.7 & 5000 & 2045 & 551 & 838 & 656 & 869738 & 262127 & 357756 & 249877 \\
\hline 240.0 & 5000 & 2044 & 551 & 837 & 656 & 870420 & 262311 & 358035 & 250096 \\
\hline 240.3 & 5000 & 2042 & 550 & 837 & 655 & 871100 & 262494 & 358314 & 250314 \\
\hline 240.7 & 5000 & 2041 & 550 & 836 & 655 & 871781 & 262678 & 358592 & 250533 \\
\hline 241.0 & 5000 & 2040 & 550 & 835 & 655 & 872461 & 262861 & 358871 & 250751 \\
\hline 241.3 & 5000 & 2038 & 549 & 835 & 654 & 873140 & 263044 & 359149 & 250969 \\
\hline 241.7 & 5000 & 2037 & 549 & 834 & 654 & 873819 & 263227 & 359427 & 251187 \\
\hline 242.0 & 5000 & 2036 & 549 & 834 & 653 & 874498 & 263410 & 359705 & 251405 \\
\hline 242.3 & 5000 & 2035 & 548 & 833 & 653 & 875176 & 263592 & 359983 & 251622 \\
\hline 242.7 & 5000 & 2033 & 548 & 833 & 653 & 875854 & 263775 & 360261 & 251840 \\
\hline 243.0 & 5000 & 2032 & 547 & 832 & 652 & 876531 & 263958 & 360538 & 252057 \\
\hline 243.3 & 5000 & 2031 & 547 & 832 & 652 & 877208 & 264140 & 360815 & 252275 \\
\hline 243.7 & 5000 & 2029 & 547 & 831 & 651 & 877884 & 264322 & 361093 & 252492 \\
\hline 244.0 & 5000 & 2028 & 546 & 831 & 651 & 878560 & 264504 & 361369 & 252709 \\
\hline 244.3 & 5000 & 2027 & 546 & 830 & 651 & 879236 & 264686 & 361646 & 252926 \\
\hline 244.7 & 5000 & 2025 & 546 & 830 & 650 & 879911 & 264868 & 361923 & 253143 \\
\hline 245.0 & 5000 & 2024 & 545 & 829 & 650 & 880586 & 265050 & 362199 & 253359 \\
\hline 245.3 & 5000 & 2023 & 545 & 829 & 649 & 881260 & 265232 & 362475 & 253576 \\
\hline 245.7 & 5000 & 2022 & 545 & 828 & 649 & 881934 & 265413 & 362751 & 253792 \\
\hline 246.0 & 5000 & 2020 & 544 & 827 & 649 & 882607 & 265594 & 363027 & 254008 \\
\hline 246.3 & 5000 & 2019 & 544 & 827 & 648 & 883280 & 265776 & 363303 & 254224 \\
\hline \begin{tabular}{|l|}
246.7 \\
\end{tabular} & 5000 & 2018 & 543 & 826 & 648 & 883953 & 265957 & 363578 & 254440 \\
\hline 247.0 & 5000 & 2016 & 543 & 826 & 647 & 884625 & 266138 & 363854 & 254656 \\
\hline 247.3 & 5000 & 2015 & 543 & 825 & 647 & 885296 & 266319 & 364129 & 254872 \\
\hline 247.7 & 5000 & 2014 & 542 & 825 & 647 & 885968 & 266500 & 364404 & 255087 \\
\hline 248.0 & 5000 & 2012 & 542 & 824 & 646 & 886638 & 266680 & 364679 & 255303 \\
\hline 248.3 & 5000 & 2011 & 542 & 824 & 646 & 887309 & 266861 & 364953 & 255518 \\
\hline 248.7 & 5000 & 2010 & 541 & 823 & 645 & 887979 & 267041 & 365228 & 255733 \\
\hline 249.0 & 5000 & 2009 & 541 & 823 & 645 & 888648 & 267222 & 365502 & 255948 \\
\hline 249.3 & 5000 & 2007 & 540 & 822 & 645 & 889317 & 267402 & 365776 & 256163 \\
\hline 249.7 & 5000 & 2006 & 540 & 822 & 644 & 889986 & 267582 & 366050 & 256378 \\
\hline 250.0 & 5000 & 2005 & 540 & 821 & 644 & 890654 & 267762 & 366324 & 256593 \\
\hline 250.3 & 5000 & 2003 & 539 & 821 & 643 & 891322 & 267941 & 366597 & 256807 \\
\hline 250.7 & 5000 & 2002 & 539 & 820 & 643 & 891989 & 268121 & 366871 & 257021 \\
\hline 251.0 & 5000 & 2001 & 539 & 819 & 643 & 892656 & 268301 & 367144 & 257236 \\
\hline 251.3 & 5000 & 1999 & 538 & 819 & 642 & 893323 & 268480 & 367417 & 257450 \\
\hline 251.7 & 5000 & 1998 & 538 & 818 & 642 & 893989 & 268659 & 367690 & 257664 \\
\hline 252.0 & 5000 & 1997 & 538 & 818 & 641 & 894655 & 268839 & 367963 & 257877 \\
\hline 252.3 & 5000 & 1996 & 537 & 817 & 641 & 895320 & 269018 & 368235 & 258091 \\
\hline 252.7 & 5000 & 1994 & 537 & 817 & 641 & 895985 & 269197 & 368507 & 258305 \\
\hline 253.0 & 5000 & 1993 & 536 & 816 & 640 & 896649 & 269375 & 368779 & 258518 \\
\hline 253.3 & 5000 & 1992 & 536 & 816 & 640 & 897313 & 269554 & 369051 & 258731 \\
\hline 253.7 & 5000 & 1990 & 536 & 815 & 639 & 897976 & 269733 & 369323 & 258945 \\
\hline 254.0 & 5000 & 1989 & 535 & 815 & 639 & 898639 & 269911 & 369595 & 259158 \\
\hline 254.3 & 5000 & 1988 & 535 & 814 & 639 & 899302 & 270089 & 369866 & 259370 \\
\hline 254.7 & 5000 & 1987 & 535 & 814 & 638 & 899964 & 270268 & 370137 & 259583 \\
\hline 255.0 & 5000 & 1985 & 534 & 813 & 638 & 900626 & 270446 & 370408 & 259796 \\
\hline
\end{tabular}




\begin{tabular}{|c|c|c|c|c|c|c|c|c|c|}
\hline \begin{tabular}{|l|}
255.3 \\
\end{tabular} & 5000 & 1984 & 534 & 813 & 637 & 901287 & 270624 & 370679 & 260008 \\
\hline 255.7 & 5000 & 1983 & 534 & 812 & 637 & 901948 & 270801 & 370950 & 260221 \\
\hline 256.0 & 5000 & 1982 & 534 & 811 & 637 & 902608 & 270979 & 371221 & 260433 \\
\hline 256.3 & 5000 & 1980 & 533 & 811 & 636 & 903268 & 271157 & 371491 & 260645 \\
\hline 256.7 & 5000 & 1979 & 533 & 810 & 636 & 903927 & 271334 & 371761 & 260857 \\
\hline 257.0 & 5000 & 1978 & 533 & 810 & 635 & 904586 & 271512 & 372031 & 261069 \\
\hline \begin{tabular}{|l|}
257.3 \\
\end{tabular} & 5000 & 1977 & 532 & 809 & 635 & 905245 & 271689 & 372301 & 261280 \\
\hline 257.7 & 5000 & 1975 & 532 & 809 & 635 & 905903 & 271866 & 372571 & 261492 \\
\hline 258.0 & 5000 & 1974 & 532 & 808 & 634 & 906561 & 272044 & 372840 & 261703 \\
\hline 258.3 & 5000 & 1973 & 532 & 808 & 634 & 907219 & 272221 & 373109 & 261915 \\
\hline 258.7 & 5000 & 1972 & 531 & 807 & 633 & 907876 & 272398 & 373378 & 262126 \\
\hline 259.0 & 5000 & 1971 & 531 & 807 & 633 & 908533 & 272575 & 373647 & 262337 \\
\hline 259.3 & 5000 & 1969 & 531 & 806 & 633 & 909189 & 272751 & 373916 & 262547 \\
\hline 259.7 & 5000 & 1968 & 531 & 806 & 632 & 909845 & 272928 & 374185 & 262758 \\
\hline 260.0 & 5000 & 1967 & 530 & 805 & 632 & 910501 & 273105 & 374453 & 262969 \\
\hline 260.3 & 5000 & 1966 & 530 & 805 & 631 & 911156 & 273281 & 374721 & 263179 \\
\hline 260.7 & 5000 & 1965 & 530 & 804 & 631 & 911811 & 273458 & 374989 & 263389 \\
\hline 261.0 & 5000 & 1964 & 530 & 803 & 631 & 912465 & 273634 & 375257 & 263600 \\
\hline 261.3 & 5000 & 1962 & 529 & 803 & 630 & 913119 & 273811 & 375525 & 263810 \\
\hline \begin{tabular}{|l|}
261.7 \\
\end{tabular} & 5000 & 1961 & 529 & 802 & 630 & 913773 & 273987 & 375793 & 264020 \\
\hline 262.0 & 5000 & 1960 & 529 & 802 & 629 & 914426 & 274163 & 376060 & 264229 \\
\hline 262.3 & 5000 & 1959 & 529 & 801 & 629 & 915079 & 274339 & 376327 & 264439 \\
\hline \begin{tabular}{|l|}
262.7 \\
\end{tabular} & 5000 & 1958 & 528 & 801 & 629 & 915732 & 274516 & 376594 & 264649 \\
\hline 263.0 & 5000 & 1957 & 528 & 800 & 628 & 916384 & 274692 & 376861 & 264858 \\
\hline 263.3 & 5000 & 1956 & 528 & 800 & 628 & 917036 & 274868 & 377127 & 265067 \\
\hline 263.7 & 5000 & 1954 & 528 & 799 & 627 & 917688 & 275044 & 377394 & 265277 \\
\hline 264.0 & 5000 & 1953 & 528 & 799 & 627 & 918339 & 275219 & 377660 & 265486 \\
\hline 264.3 & 5000 & 1952 & 527 & 798 & 627 & 918990 & 275395 & 377926 & 265694 \\
\hline 264.7 & 5000 & 1951 & 527 & 798 & 626 & 919640 & 275571 & 378192 & 265903 \\
\hline 265.0 & 5000 & 1950 & 527 & 797 & 626 & 920290 & 275747 & 378458 & 266112 \\
\hline 265.3 & 5000 & 1949 & 527 & 797 & 625 & 920940 & 275922 & 378723 & 266320 \\
\hline 265.7 & 5000 & 1948 & 527 & 796 & 625 & 921589 & 276098 & 378989 & 266529 \\
\hline 266.0 & 5000 & 1947 & 527 & 795 & 625 & 922238 & 276274 & 379254 & 266737 \\
\hline 266.3 & 5000 & 1946 & 526 & 795 & 624 & 922886 & 276449 & 379519 & 266945 \\
\hline \begin{tabular}{|l|}
266.7 \\
\end{tabular} & 5000 & 1944 & 526 & 794 & 624 & 923534 & 276625 & 379784 & 267153 \\
\hline 267.0 & 5000 & 1943 & 526 & 794 & 623 & 924182 & 276800 & 380048 & 267361 \\
\hline 267.3 & 5000 & 1942 & 526 & 793 & 623 & 924830 & 276975 & 380313 & 267568 \\
\hline 267.7 & 5000 & 1941 & 526 & 793 & 623 & 925477 & 277151 & 380577 & 267776 \\
\hline 268.0 & 5000 & 1940 & 526 & 792 & 622 & 926124 & 277326 & 380841 & 267983 \\
\hline 268.3 & 5000 & 1939 & 526 & 792 & 622 & 926770 & 277501 & 381105 & 268191 \\
\hline 268.7 & 5000 & 1938 & 525 & 791 & 621 & 927417 & 277676 & 381369 & 268398 \\
\hline 269.0 & 5000 & 1937 & 525 & 791 & 621 & 928062 & 277851 & 381632 & 268605 \\
\hline 269.3 & 5000 & 1936 & 525 & 790 & 621 & 928708 & 278026 & 381896 & 268812 \\
\hline 269.7 & 5000 & 1935 & 525 & 790 & 620 & 929353 & 278201 & 382159 & 269019 \\
\hline 270.0 & 5000 & 1934 & 525 & 789 & 620 & 929998 & 278376 & 382422 & 269225 \\
\hline 270.3 & 5000 & 1933 & 525 & 789 & 619 & 930643 & 278551 & 382685 & 269432 \\
\hline 270.7 & 5000 & 1932 & 525 & 788 & 619 & 931287 & 278726 & 382948 & 269638 \\
\hline 271.0 & 5000 & 1931 & 525 & 787 & 619 & 931932 & 278901 & 383210 & 269844 \\
\hline 271.3 & 5000 & 1930 & 524 & 787 & 618 & 932575 & 279075 & 383472 & 270050 \\
\hline \begin{tabular}{|l|}
271.7 \\
\end{tabular} & 5000 & 1929 & 524 & 786 & 618 & 933219 & 279250 & 383734 & 270256 \\
\hline 272.0 & 5000 & 1928 & 524 & 786 & 617 & 933862 & 279425 & 383996 & 270462 \\
\hline 272.3 & 5000 & 1927 & 524 & 785 & 617 & 934505 & 279599 & 384258 & 270668 \\
\hline 272.7 & 5000 & 1926 & 524 & 785 & 617 & 935147 & 279774 & 384520 & 270874 \\
\hline 273.0 & 5000 & 1925 & 524 & 784 & 616 & 935789 & 279949 & 384781 & 271079 \\
\hline 273.3 & 5000 & 1924 & 524 & 784 & 616 & 936431 & 280123 & 385042 & 271284 \\
\hline 273.7 & 5000 & 1923 & 524 & 784 & 615 & 937073 & 280298 & 385303 & 271490 \\
\hline 274.0 & 5000 & 1922 & 524 & 783 & 615 & 937714 & 280472 & 385564 & 271695 \\
\hline 274.3 & 5000 & 1921 & 523 & 783 & 615 & 938355 & 280647 & 385825 & 271900 \\
\hline \begin{tabular}{|l|}
274.7 \\
\end{tabular} & 5000 & 1920 & 523 & 782 & 614 & 938995 & 280821 & 386086 & 272104 \\
\hline
\end{tabular}




\begin{tabular}{|c|c|c|c|c|c|c|c|c|c|}
\hline \begin{tabular}{|l|}
275.0 \\
\end{tabular} & 5000 & 1919 & 523 & 782 & 614 & 939635 & 280996 & 386346 & 272309 \\
\hline 275.3 & 5000 & 1918 & 523 & 781 & 613 & 940275 & 281170 & 386607 & 272513 \\
\hline \begin{tabular}{|l|}
275.7 \\
\end{tabular} & 5000 & 1917 & 523 & 781 & 613 & 940914 & 281345 & 386867 & 272718 \\
\hline 276.0 & 5000 & 1916 & 523 & 780 & 613 & 941553 & 281519 & 387127 & 272922 \\
\hline 276.3 & 5000 & 1915 & 523 & 780 & 612 & 942191 & 281693 & 387387 & 273126 \\
\hline 276.7 & 5000 & 1914 & 523 & 779 & 612 & 942829 & 281868 & 387646 & 273330 \\
\hline 277.0 & 5000 & 1913 & 523 & 779 & 611 & 943467 & 282042 & 387906 & 273534 \\
\hline 277.3 & 5000 & 1912 & 523 & 779 & 611 & 944105 & 282216 & 388165 & 273738 \\
\hline 277.7 & 5000 & 1911 & 522 & 778 & 611 & 944742 & 282390 & 388424 & 273941 \\
\hline 278.0 & 5000 & 1910 & 522 & 778 & 610 & 945379 & 282564 & 388684 & 274145 \\
\hline 278.3 & 5000 & 1909 & 522 & 777 & 610 & 946016 & 282739 & 388943 & 274348 \\
\hline 278.7 & 5000 & 1908 & 522 & 777 & 609 & 946652 & 282913 & 389201 & 274551 \\
\hline 279.0 & 5000 & 1907 & 522 & 776 & 609 & 947288 & 283087 & 389460 & 274754 \\
\hline 279.3 & 5000 & 1906 & 522 & 776 & 609 & 947924 & 283261 & 389719 & 274957 \\
\hline 279.7 & 5000 & 1906 & 522 & 776 & 608 & 948559 & 283435 & 389977 & 275160 \\
\hline 280.0 & 5000 & 1905 & 522 & 775 & 608 & 949194 & 283609 & 390236 & 275362 \\
\hline 280.3 & 5000 & 1904 & 522 & 775 & 607 & 949829 & 283783 & 390494 & 275565 \\
\hline 280.7 & 5000 & 1903 & 521 & 774 & 607 & 950463 & 283957 & 390752 & 275767 \\
\hline 281.0 & 5000 & 1902 & 521 & 774 & 607 & 951097 & 284130 & 391010 & 275970 \\
\hline 281.3 & 5000 & 1901 & 521 & 774 & 606 & 951731 & 284304 & 391268 & 276172 \\
\hline 281.7 & 5000 & 1900 & 521 & 773 & 606 & 952365 & 284478 & 391526 & 276374 \\
\hline 282.0 & 5000 & 1899 & 521 & 773 & 605 & 952998 & 284652 & 391783 & 276576 \\
\hline 282.3 & 5000 & 1898 & 521 & 773 & 605 & 953631 & 284825 & 392041 & 276777 \\
\hline 282.7 & 5000 & 1898 & 521 & 772 & 605 & 954263 & 284999 & 392298 & 276979 \\
\hline 283.0 & 5000 & 1897 & 521 & 772 & 604 & 954896 & 285173 & 392556 & 277180 \\
\hline 283.3 & 5000 & 1896 & 521 & 772 & 604 & 955528 & 285346 & 392813 & 277382 \\
\hline 283.7 & 5000 & 1895 & 520 & 771 & 603 & 956159 & 285519 & 393070 & 277583 \\
\hline 284.0 & 5000 & 1894 & 520 & 771 & 603 & 956790 & 285693 & 393327 & 277784 \\
\hline 284.3 & 5000 & 1893 & 520 & 771 & 603 & 957421 & 285866 & 393584 & 277985 \\
\hline 284.7 & 5000 & 1893 & 520 & 770 & 602 & 958052 & 286039 & 393841 & 278185 \\
\hline 285.0 & 5000 & 1892 & 520 & 770 & 602 & 958683 & 286213 & 394098 & 278386 \\
\hline 285.3 & 5000 & 1891 & 520 & 770 & 601 & 959313 & 286386 & 394354 & 278586 \\
\hline 285.7 & 5000 & 1890 & 520 & 769 & 601 & 959942 & 286559 & 394611 & 278787 \\
\hline \begin{tabular}{|l|}
286.0 \\
\end{tabular} & 5000 & 1889 & 520 & 769 & 601 & 960572 & 286732 & 394867 & 278987 \\
\hline 286.3 & 5000 & 1888 & 520 & 769 & 600 & 961201 & 286905 & 395123 & 279187 \\
\hline 286.7 & 5000 & 1888 & 519 & 768 & 600 & 961830 & 287078 & 395379 & 279387 \\
\hline 287.0 & 5000 & 1887 & 519 & 768 & 599 & 962459 & 287251 & 395635 & 279587 \\
\hline 287.3 & 5000 & 1886 & 519 & 768 & 599 & 963087 & 287424 & 395891 & 279787 \\
\hline 287.7 & 5000 & 1885 & 519 & 767 & 599 & 963716 & 287597 & 396147 & 279986 \\
\hline 288.0 & 5000 & 1884 & 519 & 767 & 598 & 964344 & 287770 & 396402 & 280186 \\
\hline 288.3 & 5000 & 1884 & 519 & 767 & 598 & 964971 & 287943 & 396658 & 280385 \\
\hline 288.7 & 5000 & 1883 & 519 & 767 & 597 & 965599 & 288116 & 396913 & 280584 \\
\hline 289.0 & 5000 & 1882 & 519 & 766 & 597 & 966226 & 288289 & 397169 & 280783 \\
\hline 289.3 & 5000 & 1881 & 519 & 766 & 597 & 966853 & 288462 & 397424 & 280982 \\
\hline 289.7 & 5000 & 1880 & 518 & 766 & 596 & 967480 & 288635 & 397679 & 281181 \\
\hline 290.0 & 5000 & 1880 & 518 & 766 & 596 & 968106 & 288808 & 397935 & 281379 \\
\hline 290.3 & 5000 & 1879 & 518 & 765 & 595 & 968733 & 288980 & 398190 & 281578 \\
\hline 290.7 & 5000 & 1878 & 518 & 765 & 595 & 969359 & 289153 & 398445 & 281776 \\
\hline \begin{tabular}{|l|}
291.0 \\
\end{tabular} & 5000 & 1877 & 518 & 765 & 595 & 969984 & 289326 & 398699 & 281974 \\
\hline \begin{tabular}{|l|}
291.3 \\
\end{tabular} & 5000 & 1877 & 518 & 765 & 594 & 970610 & 289498 & 398954 & 282172 \\
\hline 291.7 & 5000 & 1876 & 518 & 764 & 594 & 971235 & 289671 & 399209 & 282370 \\
\hline 292.0 & 5000 & 1875 & 518 & 764 & 593 & 971860 & 289844 & 399463 & 282568 \\
\hline 292.3 & 5000 & 1875 & 518 & 764 & 593 & 972485 & 290016 & 399718 & 282766 \\
\hline 292.7 & 5000 & 1874 & 517 & 764 & 593 & 973109 & 290189 & 399972 & 282963 \\
\hline 293.0 & 5000 & 1873 & 517 & 764 & 592 & 973734 & 290361 & 400227 & 283161 \\
\hline 293.3 & 5000 & 1872 & 517 & 763 & 592 & 974358 & 290534 & 400481 & 283358 \\
\hline 293.7 & 5000 & 1872 & 517 & 763 & 591 & 974981 & 290706 & 400736 & 283555 \\
\hline 294.0 & 5000 & 1871 & 517 & 763 & 591 & 975605 & 290879 & 400990 & 283752 \\
\hline 294.3 & 5000 & 1870 & 517 & 763 & 591 & 976228 & 291051 & 401244 & 283949 \\
\hline
\end{tabular}




\begin{tabular}{|c|c|c|c|c|c|c|c|c|c|}
\hline \begin{tabular}{|l|}
294.7 \\
\end{tabular} & 5000 & 1870 & 517 & 763 & 590 & 976851 & 291223 & 401498 & 284146 \\
\hline 295.0 & 5000 & 1869 & 517 & 762 & 590 & 977474 & 291396 & 401752 & 284342 \\
\hline 295.3 & 5000 & 1868 & 517 & 762 & 589 & 978096 & 291568 & 402006 & 284539 \\
\hline 295.7 & 5000 & 1867 & 516 & 762 & 589 & 978719 & 291740 & 402260 & 284735 \\
\hline 296.0 & 5000 & 1867 & 516 & 762 & 589 & 979341 & 291912 & 402514 & 284932 \\
\hline 296.3 & 5000 & 1866 & 516 & 762 & 588 & 979963 & 292084 & 402768 & 285128 \\
\hline 296.7 & 5000 & 1865 & 516 & 762 & 588 & 980585 & 292257 & 403022 & 285324 \\
\hline 297.0 & 5000 & 1865 & 516 & 761 & 587 & 981206 & 292429 & 403275 & 285519 \\
\hline 297.3 & 5000 & 1864 & 516 & 761 & 587 & 981828 & 292601 & 403529 & 285715 \\
\hline 297.7 & 5000 & 1863 & 516 & 761 & 587 & 982449 & 292773 & 403783 & 285910 \\
\hline 298.0 & 5000 & 1863 & 516 & 761 & 586 & 983070 & 292945 & 404037 & 286106 \\
\hline 298.3 & 5000 & 1862 & 516 & 761 & 586 & 983691 & 293116 & 404290 & 286301 \\
\hline 298.7 & 5000 & 1862 & 515 & 761 & 585 & 984312 & 293288 & 404544 & 286496 \\
\hline 299.0 & 5000 & 1861 & 515 & 760 & 585 & 984932 & 293460 & 404798 & 286691 \\
\hline 299.3 & 5000 & 1860 & 515 & 760 & 585 & 985553 & 293632 & 405051 & 286886 \\
\hline 299.7 & 5000 & 1860 & 515 & 760 & 584 & 986173 & 293803 & 405305 & 287081 \\
\hline 300.0 & 5000 & 1859 & 515 & 760 & 584 & 986793 & 293975 & 405558 & 287275 \\
\hline 300.3 & 5000 & 1858 & 515 & 760 & 584 & 987412 & 294146 & 405811 & 287470 \\
\hline 300.7 & 5000 & 1858 & 515 & 760 & 583 & 988032 & 294318 & 406065 & 287664 \\
\hline 301.0 & 5000 & 1857 & 515 & 759 & 583 & 988651 & 294489 & 406318 & 287859 \\
\hline 301.3 & 5000 & 1857 & 515 & 759 & 583 & 989270 & 294661 & 406571 & 288053 \\
\hline 301.7 & 5000 & 1856 & 514 & 759 & 582 & 989889 & 294832 & 406824 & 288247 \\
\hline 302.0 & 5000 & 1855 & 514 & 759 & 582 & 990508 & 295004 & 407078 & 288441 \\
\hline 302.3 & 5000 & 1855 & 514 & 759 & 582 & 991127 & 295175 & 407331 & 288634 \\
\hline 302.7 & 5000 & 1854 & 514 & 759 & 581 & 991745 & 295346 & 407584 & 288828 \\
\hline 303.0 & 5000 & 1854 & 514 & 758 & 581 & 992364 & 295517 & 407836 & 289022 \\
\hline 303.3 & 5000 & 1853 & 514 & 758 & 581 & 992982 & 295689 & 408089 & 289215 \\
\hline 303.7 & 5000 & 1852 & 514 & 758 & 580 & 993600 & 295860 & 408342 & 289409 \\
\hline 304.0 & 5000 & 1852 & 514 & 758 & 580 & 994217 & 296031 & 408595 & 289602 \\
\hline 304.3 & 5000 & 1851 & 514 & 758 & 580 & 994835 & 296202 & 408847 & 289795 \\
\hline 304.7 & 5000 & 1851 & 513 & 758 & 580 & 995452 & 296373 & 409100 & 289988 \\
\hline 305.0 & 5000 & 1850 & 513 & 758 & 579 & 996069 & 296544 & 409353 & 290181 \\
\hline 305.3 & 5000 & 1850 & 513 & 757 & 579 & 996686 & 296716 & 409605 & 290374 \\
\hline 305.7 & 5000 & 1849 & 513 & 757 & 579 & 997303 & 296887 & 409857 & 290567 \\
\hline 306.0 & 5000 & 1849 & 513 & 757 & 578 & 997920 & 297058 & 410110 & 290760 \\
\hline 306.3 & 5000 & 1848 & 513 & 757 & 578 & 998536 & 297229 & 410362 & 290952 \\
\hline 306.7 & 5000 & 1848 & 513 & 757 & 578 & 999152 & 297399 & 410614 & 291145 \\
\hline 307.0 & 5000 & 1847 & 513 & 757 & 578 & 999768 & 297570 & 410866 & 291337 \\
\hline 307.3 & 5000 & 1846 & 513 & 756 & 577 & 1000384 & 297741 & 411119 & 291530 \\
\hline 307.7 & 5000 & 1846 & 512 & 756 & 577 & 1001000 & 297912 & 411371 & 291722 \\
\hline 308.0 & 5000 & 1845 & 512 & 756 & 577 & 1001616 & 298083 & 411623 & 291915 \\
\hline 308.3 & 5000 & 1845 & 512 & 756 & 577 & 1002231 & 298254 & 411874 & 292107 \\
\hline 308.7 & 5000 & 1844 & 512 & 756 & 577 & 1002846 & 298424 & 412126 & 292299 \\
\hline 309.0 & 5000 & 1844 & 512 & 756 & 576 & 1003461 & 298595 & 412378 & 292491 \\
\hline 309.3 & 5000 & 1843 & 512 & 755 & 576 & 1004076 & 298766 & 412630 & 292683 \\
\hline 309.7 & 5000 & 1843 & 512 & 755 & 576 & 1004690 & 298937 & 412881 & 292875 \\
\hline 310.0 & 5000 & 1842 & 512 & 755 & 576 & 1005305 & 299107 & 413133 & 293067 \\
\hline 310.3 & 5000 & 1842 & 512 & 755 & 575 & 1005919 & 299278 & 413385 & 293259 \\
\hline 310.7 & 5000 & 1842 & 512 & 755 & 575 & 1006533 & 299448 & 413636 & 293451 \\
\hline 311.0 & 5000 & 1841 & 511 & 755 & 575 & 1007147 & 299619 & 413888 & 293643 \\
\hline 311.3 & 5000 & 1841 & 511 & 754 & 575 & 1007760 & 299789 & 414139 & 293834 \\
\hline 311.7 & 5000 & 1840 & 511 & 754 & 575 & 1008374 & 299960 & 414390 & 294026 \\
\hline 312.0 & 5000 & 1840 & 511 & 754 & 574 & 1008987 & 300130 & 414642 & 294217 \\
\hline 312.3 & 5000 & 1839 & 511 & 754 & 574 & 1009600 & 300301 & 414893 & 294409 \\
\hline 312.7 & 5000 & 1839 & 511 & 754 & 574 & 1010213 & 300471 & 415144 & 294600 \\
\hline 313.0 & 5000 & 1838 & 511 & 754 & 574 & 1010826 & 300641 & 415395 & 294791 \\
\hline 313.3 & 5000 & 1838 & 511 & 754 & 574 & 1011438 & 300811 & 415647 & 294983 \\
\hline 313.7 & 5000 & 1837 & 511 & 753 & 574 & 1012050 & 300982 & 415898 & 295174 \\
\hline 314.0 & 5000 & 1837 & 510 & 753 & 573 & 1012663 & 301152 & 416149 & 295365 \\
\hline
\end{tabular}




\begin{tabular}{|c|c|c|c|c|c|c|c|c|c|}
\hline 314.3 & 5000 & 1837 & 510 & 753 & 573 & 1013275 & 301322 & 416400 & 295556 \\
\hline 314.7 & 5000 & 1836 & 510 & 753 & 573 & 1013887 & 301492 & 416651 & 295747 \\
\hline 315.0 & 5000 & 1836 & 510 & 753 & 573 & 1014498 & 301662 & 416902 & 295938 \\
\hline 315.3 & 5000 & 1835 & 510 & 753 & 573 & 1015110 & 301832 & 417153 & 296129 \\
\hline 315.7 & 5000 & 1835 & 510 & 752 & 573 & 1015722 & 302001 & 417404 & 296320 \\
\hline 316.0 & 5000 & 1835 & 510 & 752 & 573 & 1016333 & 302171 & 417655 & 296510 \\
\hline 316.3 & 5000 & 1834 & 510 & 752 & 572 & 1016944 & 302341 & 417906 & 296701 \\
\hline 316.7 & 5000 & 1834 & 510 & 752 & 572 & 1017556 & 302511 & 418157 & 296892 \\
\hline 317.0 & 5000 & 1833 & 509 & 752 & 572 & 1018167 & 302680 & 418407 & 297082 \\
\hline 317.3 & 5000 & 1833 & 509 & 752 & 572 & 1018778 & 302850 & 418658 & 297273 \\
\hline 317.7 & 5000 & 1833 & 509 & 751 & 572 & 1019388 & 303020 & 418909 & 297464 \\
\hline 318.0 & 5000 & 1832 & 509 & 751 & 572 & 1019999 & 303189 & 419159 & 297654 \\
\hline 318.3 & 5000 & 1832 & 509 & 751 & 572 & 1020610 & 303359 & 419410 & 297845 \\
\hline 318.7 & 5000 & 1831 & 509 & 751 & 572 & 1021220 & 303529 & 419660 & 298035 \\
\hline 319.0 & 5000 & 1831 & 509 & 751 & 572 & 1021830 & 303698 & 419910 & 298226 \\
\hline 319.3 & 5000 & 1831 & 509 & 751 & 571 & 1022441 & 303868 & 420160 & 298416 \\
\hline 319.7 & 5000 & 1830 & 509 & 750 & 571 & 1023051 & 304037 & 420411 & 298607 \\
\hline 320.0 & 5000 & 1830 & 508 & 750 & 571 & 1023661 & 304206 & 420661 & 298797 \\
\hline 320.3 & 5000 & 1829 & 508 & 750 & 571 & 1024270 & 304376 & 420911 & 298987 \\
\hline 320.7 & 5000 & 1829 & 508 & 750 & 571 & 1024880 & 304545 & 421161 & 299178 \\
\hline 321.0 & 5000 & 1829 & 508 & 750 & 571 & 1025490 & 304715 & 421411 & 299368 \\
\hline 321.3 & 5000 & 1828 & 508 & 750 & 571 & 1026099 & 304884 & 421661 & 299558 \\
\hline \begin{tabular}{|l|}
321.7 \\
\end{tabular} & 5000 & 1828 & 508 & 750 & 571 & 1026708 & 305053 & 421910 & 299748 \\
\hline 322.0 & 5000 & 1828 & 508 & 749 & 570 & 1027318 & 305222 & 422160 & 299939 \\
\hline 322.3 & 5000 & 1827 & 508 & 749 & 570 & 1027927 & 305392 & 422410 & 300129 \\
\hline 322.7 & 5000 & 1827 & 508 & 749 & 570 & 1028536 & 305561 & 422660 & 300319 \\
\hline 323.0 & 5000 & 1826 & 507 & 749 & 570 & 1029144 & 305730 & 422909 & 300509 \\
\hline 323.3 & 5000 & 1826 & 507 & 749 & 570 & 1029753 & 305899 & 423159 & 300699 \\
\hline 323.7 & 5000 & 1826 & 507 & 749 & 570 & 1030362 & 306068 & 423408 & 300889 \\
\hline 324.0 & 5000 & 1825 & 507 & 748 & 570 & 1030970 & 306237 & 423657 & 301079 \\
\hline 324.3 & 5000 & 1825 & 507 & 748 & 570 & 1031578 & 306406 & 423907 & 301269 \\
\hline 324.7 & 5000 & 1824 & 507 & 748 & 569 & 1032187 & 306575 & 424156 & 301459 \\
\hline 325.0 & 5000 & 1824 & 507 & 748 & 569 & 1032795 & 306744 & 424405 & 301649 \\
\hline 325.3 & 5000 & 1824 & 507 & 748 & 569 & 1033403 & 306913 & 424654 & 301839 \\
\hline 325.7 & 5000 & 1823 & 507 & 748 & 569 & 1034010 & 307082 & 424903 & 302029 \\
\hline 326.0 & 5000 & 1823 & 506 & 747 & 569 & 1034618 & 307251 & 425152 & 302218 \\
\hline 326.3 & 5000 & 1822 & 506 & 747 & 569 & 1035226 & 307420 & 425401 & 302408 \\
\hline 326.7 & 5000 & 1822 & 506 & 747 & 569 & 1035833 & 307589 & 425650 & 302598 \\
\hline 327.0 & 5000 & 1822 & 506 & 747 & 569 & 1036440 & 307757 & 425899 & 302788 \\
\hline 327.3 & 5000 & 1821 & 506 & 747 & 569 & 1037048 & 307926 & 426148 & 302977 \\
\hline \begin{tabular}{|l|}
327.7 \\
\end{tabular} & 5000 & 1821 & 506 & 747 & 568 & 1037655 & 308095 & 426397 & 303167 \\
\hline 328.0 & 5000 & 1821 & 506 & 746 & 568 & 1038262 & 308264 & 426645 & 303356 \\
\hline 328.3 & 5000 & 1820 & 506 & 746 & 568 & 1038868 & 308432 & 426894 & 303546 \\
\hline 328.7 & 5000 & 1820 & 506 & 746 & 568 & 1039475 & 308601 & 427143 & 303735 \\
\hline 329.0 & 5000 & 1819 & 505 & 746 & 568 & 1040082 & 308769 & 427392 & 303924 \\
\hline 329.3 & 5000 & 1819 & 505 & 746 & 568 & 1040688 & 308938 & 427640 & 304113 \\
\hline \begin{tabular}{|l|}
329.7 \\
\end{tabular} & 5000 & 1819 & 505 & 746 & 568 & 1041294 & 309106 & 427889 & 304303 \\
\hline 330.0 & 5000 & 1818 & 505 & 746 & 568 & 1041901 & 309274 & 428138 & 304492 \\
\hline 330.3 & 5000 & 1818 & 505 & 745 & 567 & 1042507 & 309443 & 428386 & 304681 \\
\hline 330.7 & 5000 & 1817 & 505 & 745 & 567 & 1043113 & 309611 & 428635 & 304870 \\
\hline 331.0 & 5000 & 1817 & 505 & 745 & 567 & 1043718 & 309779 & 428883 & 305059 \\
\hline 331.3 & 5000 & 1817 & 505 & 745 & 567 & 1044324 & 309947 & 429131 & 305247 \\
\hline 331.7 & 5000 & 1816 & 505 & 745 & 567 & 1044930 & 310115 & 429380 & 305436 \\
\hline 332.0 & 5000 & 1816 & 504 & 745 & 567 & 1045535 & 310283 & 429628 & 305625 \\
\hline 332.3 & 5000 & 1815 & 504 & 744 & 567 & 1046140 & 310451 & 429876 & 305814 \\
\hline 332.7 & 5000 & 1815 & 504 & 744 & 567 & 1046746 & 310619 & 430124 & 306003 \\
\hline 333.0 & 5000 & 1815 & 504 & 744 & 566 & 1047351 & 310787 & 430373 & 306192 \\
\hline 333.3 & 5000 & 1814 & 504 & 744 & 566 & 1047956 & 310955 & 430621 & 306380 \\
\hline 333.7 & 5000 & 1814 & 504 & 744 & 566 & 1048560 & 311123 & 430869 & 306569 \\
\hline
\end{tabular}




\begin{tabular}{|c|c|c|c|c|c|c|c|c|c|}
\hline 334.0 & 5000 & 1813 & 504 & 744 & 566 & 1049165 & 311291 & 431116 & 306758 \\
\hline 334.3 & 5000 & 1813 & 504 & 743 & 566 & 1049769 & 311459 & 431364 & 306946 \\
\hline 334.7 & 5000 & 1813 & 504 & 743 & 566 & 1050373 & 311627 & 431612 & 307135 \\
\hline 335.0 & 5000 & 1812 & 503 & 743 & 566 & 1050977 & 311794 & 431860 & 307323 \\
\hline 335.3 & 5000 & 1812 & 503 & 743 & 566 & 1051581 & 311962 & 432107 & 307512 \\
\hline 335.7 & 5000 & 1812 & 503 & 743 & 566 & 1052184 & 312130 & 432355 & 307700 \\
\hline 336.0 & 5000 & 1811 & 503 & 743 & 565 & 1052788 & 312298 & 432603 & 307889 \\
\hline 336.3 & 5000 & 1811 & 503 & 742 & 565 & 1053391 & 312465 & 432850 & 308077 \\
\hline 336.7 & 5000 & 1810 & 503 & 742 & 565 & 1053994 & 312633 & 433097 & 308266 \\
\hline 337.0 & 5000 & 1810 & 503 & 742 & 565 & 1054598 & 312800 & 433345 & 308454 \\
\hline 337.3 & 5000 & 1810 & 503 & 742 & 565 & 1055201 & 312968 & 433592 & 308642 \\
\hline 337.7 & 5000 & 1809 & 503 & 742 & 565 & 1055803 & 313136 & 433839 & 308831 \\
\hline 338.0 & 5000 & 1809 & 502 & 742 & 565 & 1056406 & 313303 & 434086 & 309019 \\
\hline 338.3 & 5000 & 1808 & 502 & 742 & 565 & 1057009 & 313471 & 434334 & 309207 \\
\hline 338.7 & 5000 & 1808 & 502 & 741 & 564 & 1057611 & 313638 & 434581 & 309395 \\
\hline 339.0 & 5000 & 1808 & 502 & 741 & 564 & 1058214 & 313805 & 434828 & 309584 \\
\hline 339.3 & 5000 & 1807 & 502 & 741 & 564 & 1058816 & 313973 & 435074 & 309772 \\
\hline \begin{tabular}{|l|}
339.7 \\
\end{tabular} & 5000 & 1807 & 502 & 741 & 564 & 1059418 & 314140 & 435321 & 309960 \\
\hline 340.0 & 5000 & 1806 & 502 & 741 & 564 & 1060020 & 314307 & 435568 & 310148 \\
\hline 340.3 & 5000 & 1806 & 502 & 741 & 564 & 1060622 & 314475 & 435815 & 310336 \\
\hline 340.7 & 5000 & 1806 & 502 & 740 & 564 & 1061224 & 314642 & 436061 & 310524 \\
\hline 341.0 & 5000 & 1805 & 501 & 740 & 564 & 1061825 & 314809 & 436308 & 310712 \\
\hline \begin{tabular}{|l|}
341.3 \\
\end{tabular} & 5000 & 1805 & 501 & 740 & 563 & 1062427 & 314976 & 436555 & 310900 \\
\hline 341.7 & 5000 & 1805 & 501 & 740 & 563 & 1063028 & 315144 & 436801 & 311088 \\
\hline 342.0 & 5000 & 1804 & 501 & 740 & 563 & 1063629 & 315311 & 437048 & 311276 \\
\hline 342.3 & 5000 & 1804 & 501 & 740 & 563 & 1064231 & 315478 & 437294 & 311464 \\
\hline 342.7 & 5000 & 1803 & 501 & 739 & 563 & 1064832 & 315645 & 437540 & 311651 \\
\hline 343.0 & 5000 & 1803 & 501 & 739 & 563 & 1065432 & 315812 & 437787 & 311839 \\
\hline 343.3 & 5000 & 1803 & 501 & 739 & 563 & 1066033 & 315979 & 438033 & 312027 \\
\hline 343.7 & 5000 & 1802 & 501 & 739 & 563 & 1066634 & 316146 & 438279 & 312214 \\
\hline 344.0 & 5000 & 1802 & 501 & 739 & 563 & 1067234 & 316313 & 438525 & 312402 \\
\hline 344.3 & 5000 & 1801 & 500 & 739 & 562 & 1067835 & 316480 & 438772 & 312589 \\
\hline 344.7 & 5000 & 1801 & 500 & 738 & 562 & 1068435 & 316646 & 439018 & 312777 \\
\hline 345.0 & 5000 & 1801 & 500 & 738 & 562 & 1069035 & 316813 & 439264 & 312964 \\
\hline 345.3 & 5000 & 1800 & 500 & 738 & 562 & 1069635 & 316980 & 439510 & 313151 \\
\hline 345.7 & 5000 & 1800 & 500 & 738 & 562 & 1070235 & 317146 & 439756 & 313338 \\
\hline 346.0 & 5000 & 1799 & 500 & 738 & 562 & 1070835 & 317313 & 440002 & 313526 \\
\hline 346.3 & 5000 & 1799 & 500 & 738 & 562 & 1071434 & 317479 & 440248 & 313713 \\
\hline 346.7 & 5000 & 1799 & 500 & 738 & 562 & 1072034 & 317646 & 440494 & 313900 \\
\hline 347.0 & 5000 & 1798 & 500 & 737 & 561 & 1072633 & 317812 & 440740 & 314087 \\
\hline \begin{tabular}{|l|}
347.3 \\
\end{tabular} & 5000 & 1798 & 499 & 737 & 561 & 1073232 & 317979 & 440986 & 314274 \\
\hline 347.7 & 5000 & 1798 & 499 & 737 & 561 & 1073832 & 318145 & 441232 & 314461 \\
\hline 348.0 & 5000 & 1797 & 499 & 737 & 561 & 1074431 & 318311 & 441478 & 314647 \\
\hline 348.3 & 5000 & 1797 & 499 & 737 & 561 & 1075029 & 318477 & 441723 & 314834 \\
\hline 348.7 & 5000 & 1796 & 499 & 737 & 561 & 1075628 & 318644 & 441969 & 315021 \\
\hline 349.0 & 5000 & 1796 & 499 & 736 & 561 & 1076227 & 318810 & 442214 & 315208 \\
\hline 349.3 & 5000 & 1796 & 499 & 736 & 561 & 1076825 & 318976 & 442460 & 315395 \\
\hline 349.7 & 5000 & 1795 & 499 & 736 & 560 & 1077424 & 319142 & 442705 & 315582 \\
\hline 350.0 & 5000 & 1795 & 499 & 736 & 560 & 1078022 & 319308 & 442951 & 315768 \\
\hline 350.3 & 5000 & 1794 & 498 & 736 & 560 & 1078620 & 319474 & 443196 & 315955 \\
\hline 350.7 & 5000 & 1794 & 498 & 736 & 560 & 1079218 & 319641 & 443441 & 316142 \\
\hline 351.0 & 5000 & 1794 & 498 & 735 & 560 & 1079816 & 319807 & 443686 & 316328 \\
\hline 351.3 & 5000 & 1793 & 498 & 735 & 560 & 1080414 & 319973 & 443931 & 316515 \\
\hline 351.7 & 5000 & 1793 & 498 & 735 & 560 & 1081011 & 320139 & 444176 & 316701 \\
\hline 352.0 & 5000 & 1792 & 498 & 735 & 560 & 1081609 & 320304 & 444421 & 316888 \\
\hline 352.3 & 5000 & 1792 & 498 & 735 & 560 & 1082206 & 320470 & 444666 & 317074 \\
\hline 352.7 & 5000 & 1792 & 498 & 735 & 559 & 1082803 & 320636 & 444911 & 317261 \\
\hline 353.0 & 5000 & 1791 & 498 & 734 & 559 & 1083401 & 320802 & 445156 & 317447 \\
\hline 353.3 & 5000 & 1791 & 497 & 734 & 559 & 1083998 & 320968 & 445401 & 317634 \\
\hline
\end{tabular}




\begin{tabular}{|c|c|c|c|c|c|c|c|c|c|}
\hline 353.7 & 5000 & 1791 & 497 & 734 & 559 & 1084594 & 321134 & 445645 & 317820 \\
\hline 354.0 & 5000 & 1790 & 497 & 734 & 559 & 1085191 & 321299 & 445890 & 318006 \\
\hline 354.3 & 5000 & 1790 & 497 & 734 & 559 & 1085788 & 321465 & 446134 & 318193 \\
\hline 354.7 & 5000 & 1789 & 497 & 734 & 559 & 1086384 & 321631 & 446379 & 318379 \\
\hline 355.0 & 5000 & 1789 & 497 & 734 & 559 & 1086981 & 321797 & 446623 & 318565 \\
\hline 355.3 & 5000 & 1789 & 497 & 733 & 558 & 1087577 & 321962 & 446868 & 318751 \\
\hline 355.7 & 5000 & 1788 & 497 & 733 & 558 & 1088173 & 322128 & 447112 & 318938 \\
\hline 356.0 & 5000 & 1788 & 497 & 733 & 558 & 1088769 & 322293 & 447356 & 319124 \\
\hline 356.3 & 5000 & 1788 & 497 & 733 & 558 & 1089365 & 322459 & 447600 & 319310 \\
\hline 356.7 & 5000 & 1787 & 497 & 733 & 558 & 1089961 & 322624 & 447844 & 319496 \\
\hline 357.0 & 5000 & 1787 & 496 & 733 & 558 & 1090556 & 322790 & 448088 & 319682 \\
\hline 357.3 & 5000 & 1786 & 496 & 732 & 558 & 1091152 & 322955 & 448332 & 319868 \\
\hline 357.7 & 5000 & 1786 & 496 & 732 & 558 & 1091747 & 323121 & 448576 & 320054 \\
\hline 358.0 & 5000 & 1786 & 496 & 732 & 557 & 1092342 & 323286 & 448820 & 320240 \\
\hline 358.3 & 5000 & 1785 & 496 & 732 & 557 & 1092938 & 323451 & 449064 & 320426 \\
\hline 358.7 & 5000 & 1785 & 496 & 732 & 557 & 1093533 & 323617 & 449308 & 320612 \\
\hline 359.0 & 5000 & 1785 & 496 & 732 & 557 & 1094127 & 323782 & 449552 & 320797 \\
\hline 359.3 & 5000 & 1784 & 496 & 731 & 557 & 1094722 & 323947 & 449795 & 320983 \\
\hline 359.7 & 5000 & 1784 & 496 & 731 & 557 & 1095317 & 324112 & 450039 & 321169 \\
\hline 360.0 & 5000 & 1784 & 496 & 731 & 557 & 1095911 & 324278 & 450283 & 321354 \\
\hline 360.3 & 5000 & 1783 & 496 & 731 & 557 & 1096506 & 324443 & 450527 & 321540 \\
\hline 360.7 & 5000 & 1783 & 496 & 731 & 557 & 1097100 & 324608 & 450770 & 321725 \\
\hline 361.0 & 5000 & 1783 & 496 & 731 & 556 & 1097694 & 324773 & 451014 & 321910 \\
\hline 361.3 & 5000 & 1782 & 496 & 730 & 556 & 1098288 & 324938 & 451258 & 322096 \\
\hline 361.7 & 5000 & 1782 & 495 & 730 & 556 & 1098882 & 325103 & 451501 & 322281 \\
\hline 362.0 & 5000 & 1782 & 495 & 730 & 556 & 1099476 & 325268 & 451745 & 322466 \\
\hline 362.3 & 5000 & 1781 & 495 & 730 & 556 & 1100069 & 325433 & 451988 & 322651 \\
\hline 362.7 & 5000 & 1781 & 495 & 730 & 556 & 1100663 & 325598 & 452231 & 322836 \\
\hline 363.0 & 5000 & 1781 & 495 & 730 & 556 & 1101256 & 325763 & 452475 & 323021 \\
\hline 363.3 & 5000 & 1780 & 495 & 730 & 556 & 1101849 & 325928 & 452718 & 323206 \\
\hline 363.7 & 5000 & 1780 & 495 & 729 & 555 & 1102443 & 326093 & 452961 & 323392 \\
\hline 364.0 & 5000 & 1780 & 495 & 729 & 555 & 1103036 & 326258 & 453204 & 323577 \\
\hline 364.3 & 5000 & 1779 & 495 & 729 & 555 & 1103628 & 326423 & 453448 & 323761 \\
\hline 364.7 & 5000 & 1779 & 495 & 729 & 555 & 1104221 & 326588 & 453691 & 323946 \\
\hline 365.0 & 5000 & 1779 & 495 & 729 & 555 & 1104814 & 326753 & 453934 & 324131 \\
\hline
\end{tabular}




\section{Curriculum Vitae}

Born in P. R. China, Qinghua Jin has devoted himself on Mining Engineering technology research and development. He received his BS degree in Mineral Processing Engineering, Northeastern University, Shenyang, China (1990). From 1990 to 2000, he served as an engineer in Anshan Engineering \& Research Incorporation of Metallurgical Industry (AERIMI) under the Ministry of Metallurgical Industry of P. R. China.

He went to the United States in 2000 for further graduate study. Currently he is a candidate for Master of Science degree in Mining Engineering Department, West Virginia University. 